University of Louisville

ThinkIR: The University of Louisville's Institutional Repository

Electronic Theses and Dissertations

8-2014

\title{
MiRNA-21 has anti-inflammatory effects in the macrophage response to peritonitis.
}

\author{
Rebecca Elise Barnett \\ University of Louisville
}

Follow this and additional works at: https://ir.library.louisville.edu/etd

Part of the Biophysics Commons, and the Physiology Commons

\section{Recommended Citation}

Barnett, Rebecca Elise, "MiRNA-21 has anti-inflammatory effects in the macrophage response to peritonitis." (2014). Electronic Theses and Dissertations. Paper 75.

https://doi.org/10.18297/etd/75

This Doctoral Dissertation is brought to you for free and open access by ThinkIR: The University of Louisville's Institutional Repository. It has been accepted for inclusion in Electronic Theses and Dissertations by an authorized administrator of ThinkIR: The University of Louisville's Institutional Repository. This title appears here courtesy of the author, who has retained all other copyrights. For more information, please contact thinkir@louisville.edu. 


\title{
MIRNA-21 HAS ANTI-INFLAMMATORY EFFECTS IN THE MACROPHAGE RESPONSE TO PERITONITIS
}

\author{
By \\ Rebecca Elise Barnett \\ BSc - Imperial College, London, 2004 \\ MBBS - Imperial College, London, 2006 \\ MRCS - Royal College of Surgeons of England, 2010
}

\author{
A Dissertation \\ Submitted to the Faculty of the \\ School of Medicine of the University of Louisville \\ in Partial Fulfillment of the Requirements \\ for the Degree of \\ Doctor of Philosophy \\ Department of Physiology and Biophysics \\ University of Louisville \\ Louisville, Kentucky
}

August 2014 
Copyright 2014 by Rebecca Elise Barnett

All rights reserved 

MIRNA-21 HAS ANTI-INFLAMMATORY EFFECTS IN THE MACROPHAGE RESPONSE TO PERITONITIS

By

\author{
Rebecca Elise Barnett \\ BSc - Imperial College, London, 2004 \\ MBBS - Imperial College, London, 2006 \\ MRCS - Royal College of Surgeons of England, 2010 \\ A Dissertation Approved on
}

July 21,2014

By the following Dissertation Committee:

Dr. William G. Cheadle, Dissertation Director

Dr. Aruni Bhatnagar

Dr. Stanley D'Souza

Dr. Claudio Maldonado

Dr. Hiram C. Polk Jr.

Dr. William B. Wead 


\section{ACKNOWLEDGEMENTS}

This thesis is dedicated to my parents, Fiona and Andrew, who raised me to try everything, and believe that anything was achievable if you are willing to work for

it. Their love and encouragement has made me the person I am today and I have achieved more than I ever expected.

I was very fortunate to have been introduced to Dr. William G. Cheadle, who believed in me, and allowed me to pursue my interest in surgical peritonitis. His mentorship in both basic science and clinical research has kept me eminently busy. This has been a tremendous experience, and I am happy to have had the wisdom to embrace this opportunity.

Dr. Susan Galandiuk and Dr. Hiram C. Polk Jr. have honed my presentation skills over the course of the last three years, and taught me more than I ever could have imagined. I can only hope to inspire and lead the next generation of surgeons with a fraction of the success that they have achieved.

Many thanks to my PhD committee; Dr. Aruni Bhatnagar, Dr. Stanley D'Souza, Dr. Claudio Maldonado, Dr. Hiram C. Polk Jr and Dr. William B. Wead, from the Department of Physiology and Biophysics for their wise words and encouragement. 
A special thanks to Dr. Aruni Bhatnagar for incorporating me into miRNA-21 research group, and introducing me to Dr. Sanjay Srivastava whose generosity has elevated my work with the use miRNA-21 knockout mice, and the derived macrophage cell lines. I am also grateful to Dr. Dan Conklin for his input and assistance with animal experiments.

I have to recognize Sarah Gardner for her outstanding technical work, maintaining my sanity and always encouraging me and Rob Eichenberger for his leadership and management insights. A special thanks to my trio of lab assistants Bobby Keskey, Mike Rao and Ernesto Sepulveda, who along with a handful of summer students have helped me to achieve my goals.

Last, but by no means least I would like to acknowledge Adrian Billeter for all his guidance, support and friendship, without him this would not have been possible. 


\begin{abstract}
MIRNA-21 HAS ANTI-INFLAMMATORY EFFECTS IN THE MACROPHAGE RESPONSE TO PERITONITIS

Rebecca Elise Barnett
\end{abstract}

July 21, 2014

This project investigated the role of miRNA-21 in the macrophage response to peritonitis; with the goal of understanding whether the associated mechanism has potential benefits in the clinical treatment of peritonitis. A novel therapeutic intervention in the treatment of peritonitis could modulate the host immune response to decrease an exaggerated pro-inflammatory innate response and then prevent or ameliorate the development of sepsis and organ failure. We found the following:

1. MiRNA-21 expression increases in peritoneal macrophages after lipopolysaccharide (LPS) stimulation.

2. Over expression of miRNA-21 decreases TNF- $\alpha$ secretion from macrophages after LPS stimulation. Suppression of miRNA-21 expression results in increased TNF- $\alpha$ and IL-6, together with decreased IL-10 after LPS stimulation. 
3. Protein targets of miRNA-21 after LPS stimulation were not significantly different following suppression of miRNA-21.

4. NF-KB and ERK signaling was unaffected by suppression of miRNA-21.

5. MiRNA-21 is beneficial in survival following induction of peritonitis with LPS.

6. MiRNA-21 does not affect survival following induction of peritonitis with cecal ligation and puncture.

These findings demonstrate that although miRNA-21 is beneficial in modulating the macrophage response to LPS, the effect is buried in the multiple pathways activated after the clinically more relevant model of cecal ligation and puncture. The improved understanding of the anti-inflammatory effects of miRNA-21 in the macrophage response to peritonitis may result in a targeted therapy to intervene in clinical peritonitis. 
TABLE OF CONTENTS

Page

Acknowledgements ..................................................... ii

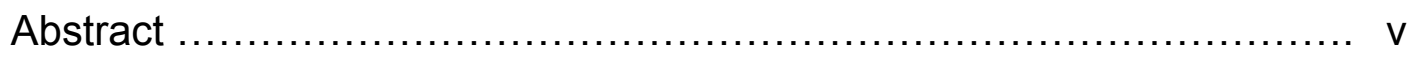

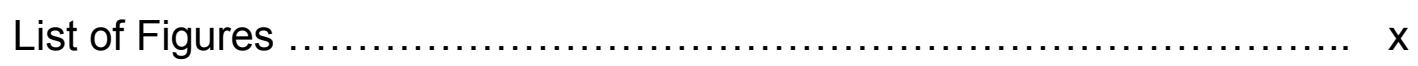

\section{Chapter}

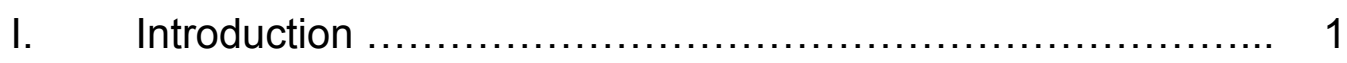

II. General Overview ......................................... 3

A. Clinical Importance of Peritonitis ............................. 3

B. Immune Response Overview ............................ 5

C. Macrophages …............................................. 7

D. MicroRNAs .................................................... 10

E. Models of Peritonitis ....................................... 16

III. Hypothesis and Experimental Plan .......................... 20

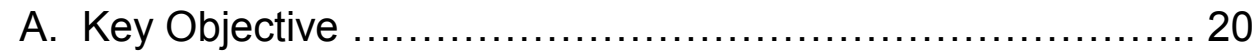

B. Hypothesis ................................................ 20

C. Specific Aims ................................................... 21

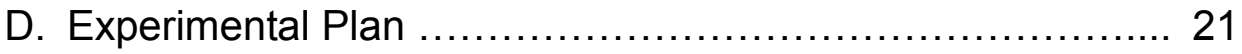




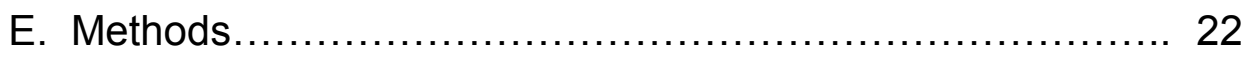

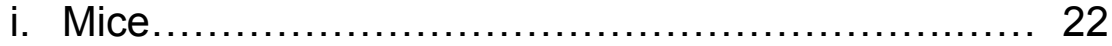

ii. Harvest of Peritoneal Cells........................... 24

iii. Macrophage Isolation................................... 24

iv. Lipopolysaccharide

Stimulation................................................... 27

v. RNA

Isolation............................................. 28

vi. MiRNA and MessengerRNA Expression.............. 28

vii. Cytokine Assays ...................................... 29

viii. Protein Isolation...................................... 29

ix. Western Blot......................................... 30

x. MiRNA Transfection.................................. 31

xi. Phosflow Pathway Analysis.......................... 32

xii. Peritonitis Models..................................... 33

xiii. Statistical Analysis................................... 35

IV. MiRNA-21 Expression in Peritoneal Macrophages............... 36

A. Introduction ................................................. 36

B. Results.................................................... 36

C. Discussion................................................. 44

V. MiRNA-21 has Anti-Inflammatory Effects in Peritoneal Macrophages................................................. 46

A. Introduction............................................... 46

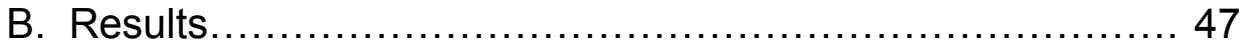

C. Discussion................................................... 51

VI. MiRNA-21 has Anti-Inflammatory Effects in BMM Macrophages 53

A. Introduction ................................................ 53

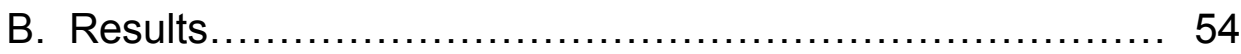

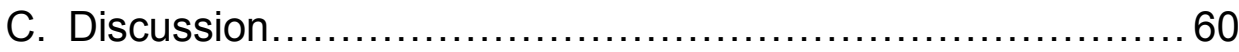

VII. MiRNA-21 affects NF-KB and ERK signaling .................. 64 
A. Introduction ................................................. 64

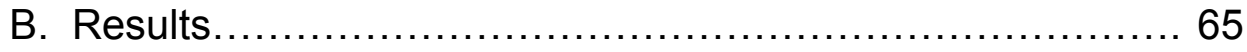

C. Discussion................................................... 68

VIII. Influence of miRNA-21 on Survival in LPS Peritonitis............ 70

A. Introduction.................................................. 70

B. Results.................................................. 71

C. Discussion................................................ 71

IX. Influence of miRNA-21 on Survival in Cecal Ligation and Puncture Peritonitis ........................................................ 78

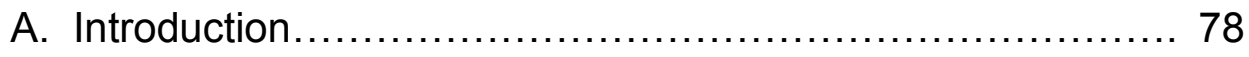

B. Results...................................................... 79

C. Discussion................................................... 79

X. MiRNA-21 Expression in Peritoneal Macrophages following Cecal Ligation and Puncture .......................................... 88

A. Introduction ................................................ 88

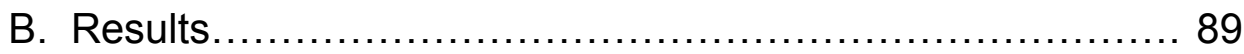

C. Discussion.................................................. 96

XI. Conclusions and Overview................................... 98

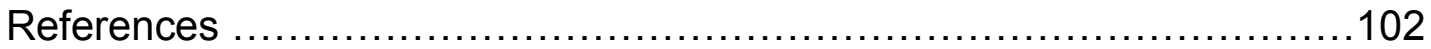

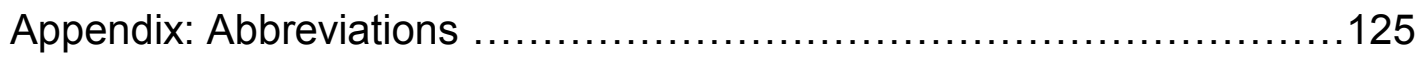

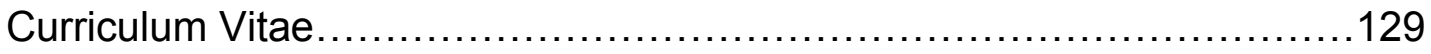




\section{LIST OF FIGURES}

Figure

Page

1. Toll-like Receptor-4 signaling...................................... 9

2. Outline of Study .................................................... 23

3. CD11b isolation of Peritoneal Macrophages....................... 26

4. Lipopolysaccharide Peritonitis Survival Curves..................... 34

5. Peritoneal Macrophage MiRNA-21 Expression after

Lipopolysaccharide ............................................ 37

6. Peritoneal Macrophage Pro-inflammatory cytokines after Lipopolysaccharide ............................................. 39

7. Peritoneal Macrophage Anti-inflammatory cytokine after Lipopolysaccharide .............................................. 40

8. Peritoneal Macrophage PDCD4 messengerRNA expression after Lipopolysaccharide.

9. Peritoneal Macrophage Peli1 messengerRNA expression after Lipopolysaccharide

10. Peritoneal Macrophage SPRY messengerRNA expression after Lipopolysaccharide. 
11. MiRNA-21 Expression after transfection.......................... 48

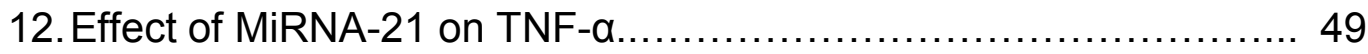

13. Effect of MiRNA-21 on IL-10 ................................... 50

14. TNF- $\alpha$ in Bone Marrow derived Macrophages....................... 55

15. IL-6 in Bone Marrow derived Macrophages........................ 56

16. IL-10 in Bone Marrow derived Macrophages....................... 57

17.PDCD4 in Bone Marrow derived Macrophages.................... 58

18. Peli1 in Bone Marrow derived Macrophages......................... 59

19. SPRY 1 and 2 in Bone Marrow derived Macrophages.............. 61

20. NF-KB Activation after Lipopolysaccharide in Bone Marrow derived

Macrophages..................................................... 66

21. ERK Activation after Lipopolysaccharide in Bone Marrow derived

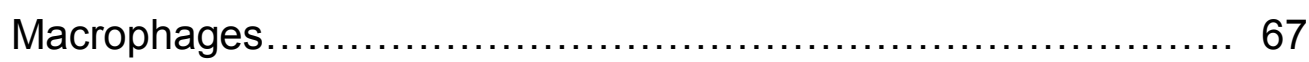

22. Mouse Surface Temperatures after Lipopolysaccharide Peritonitis 72

23. Mouse Weight after Lipopolysaccharide Peritonitis ................. 73

24. Survival after Lipopolysaccharide Peritonitis....................... 74

25. Surface Temperature and Weight in mice after Cecal Ligation and Puncture ............................................................ 80

26. Survival after 20G Cecal Ligation and Puncture................... 81

27. Peritoneal Macrophage MiRNA-21 Expression after Cecal Ligation and

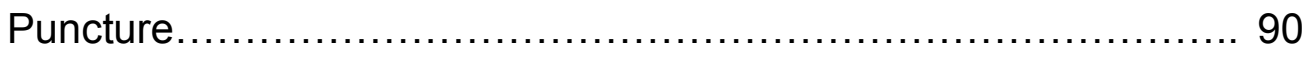

28. Peritoneal Exudate Cell counts after Cecal Ligation and Puncture... 91 
29. Peritoneal Macrophages after Cecal Ligation and Puncture........ 92

30. Peritoneal TNF- $\alpha$ after Cecal Ligation and Puncture................ 93

31. Peritoneal IL-6 after Cecal Ligation and Puncture.................. 94

32. Peritoneal IL-10 after Cecal Ligation and Puncture .................... 95 


\section{CHAPTER I}

\section{INTRODUCTION}

Peritonitis is regularly seen as part of clinical surgical practice. It can have multiple causes, resulting in bacterial infection within the peritoneal cavity of the abdomen. These include appendicitis, diverticulitis with perforation, and perforated bowel from a variety of other causes. Patients with peritonitis can have a variable disease course, from a mild, self-contained infection, through a whole body septic response potentially leading to multi-organ failure and potential fatality. It is a frequent cause for admission to the hospital and the surgical intensive care unit ${ }^{1}$. Although improvements in critical care have led to more patients surviving, there has been little change in the treatment of peritonitis in the last 50 years ${ }^{2}$. The mainstay remains 1 ) source control by removal, debridement, and/or drainage of infected and necrotic tissue; 2) antibiotics directed at Gram negative pathogens including anaerobes; and 3) supportive treatment of homeostatic functions in various organs such as the lungs, liver, kidneys, heart and gut.

Mortality is directly associated with an exaggerated pro-inflammatory innate response with development of sepsis and organ failure ${ }^{3}$. Several immune modulators have undergone clinical trials in recent years with the aim of manipulating the immune response to the benefit of the patient, but none have 
successfully been able to change patient outcomes. The purpose of this work is to investigate specific mechanisms by which the response of peritoneal macrophages to endotoxin and bacterial infection are regulated and identify potential routes for therapeutic intervention. 
CHAPTER ॥

\section{GENERAL OVERVIEW}

\section{A. Clinical Importance of Peritonitis}

Peritonitis is inflammation of the lining of the peritoneal cavity that occurs in response to local irritation or infection. It can be categorized into primary, secondary and tertiary 4,5. Primary or spontaneous bacterial peritonitis is relatively rare and occurs in ascites and liver failure. Secondary bacterial peritonitis is usually caused by a perforation, when enteric bacteria from the bowel are released into the peritoneal cavity and is our primary focus for these studies. Tertiary peritonitis is the persistence of bacteria despite adequate therapy, consisting of source control, drainage of any abscess and use of appropriate antibiotics ${ }^{4,6}$. Chemical peritonitis is less common, and occurs when blood, acid, bile, pancreatic juice, or other bodily fluids are released into the peritoneal cavity in the absence of infection. This usually occurs in the setting of surgical complications and trauma ${ }^{7}$.

Secondary bacterial peritonitis is a common cause of surgical sepsis and has multiple etiologies, stemming from ischemia or perforation of the bowel that leads to enteric bacteria within the peritoneal cavity ${ }^{2}$. The most common causes are inflammatory processes such as diverticulitis and appendicitis, but can also 
include traumatic injuries and colon cancers eroding through the bowel wall. Peritonitis can be a spectrum of disorders, ranging from a contained local irritation, such as that associated with a benign appendicitis to pancreatic necrosis and intestinal ischemia that are often associated with substantial morbidity and mortality ${ }^{5,8}$. Several scoring systems such as the Mannheim Peritonitis Index and the Acute Physiology and Chronic Health Evaluation (APACHE) II score have evolved to try to predict those with a risk of increased morbidity and more complicated disease course ${ }^{4,9-13}$.

The treatment of peritonitis has remained unchanged for the last 50 years; antibiotics directed at the offending gram negative aerobic and anaerobic bacteria and source control of the infection by open or laparoscopic resection, debridement, and drainage or percutaneous drainage. A recent Cochrane review concluded that no specific recommendations could be made about the first line antibiotics, as all included in the studies were equivalent, and included antibiotics active against gram negative aerobes and anaerobes ${ }^{14}$. Despite treatment, peritonitis may progress to sepsis, a systemic inflammatory response to a source of infection, consisting of fever, tachycardia, tachypnea, and leukocytosis and multi-organ dysfunction. The Dutch registry for intensive care shows approximately $2.5 \%$ of all intensive care admissions are due to intra-abdominal infection combined with sepsis ${ }^{15}$. 
Despite clinically proven treatment and the ability to predict those with a higher risk of morbidity and mortality, it remains unknown why some patients are unable to contain and eliminate such an infection, resulting in a persistence of bacteria in the peritoneum. Some have theorized that this is because of a failure of the host immune response to clear the infection, and that augmentation or modulation of the immune response may serve to enhance the clearance of bacteria in these patients. Some patients go onto a persistent inflammatory state and develop organ failure, despite adequate source control, which is also a source of significant morbidity and mortality. Several immune-modulators have undergone clinical trials following success in a lab environment, however none have been successful in a clinical setting ${ }^{16,17}$.

\section{B. Immune Response Overview}

The immune response occurs in 3 phases: 1$)$ The immediate innate (0-4 hours) response, which is recognition of the invading pathogen or tissue injury by preformed, non-specific and broadly specific effectors. 2) The early innate (4-96 hours) which deals with the recognition of microbial-associated molecular patterns and in the inflammation, recruitment and activation of effector cells; and 3) the adaptive (>96 hours) which consists of recognition by B and T cells and

clonal expansion and differentiation into effector cells ${ }^{18,19}$. All these process act 
synergistically to remove the infectious agent. This thesis will deal primarily with the early innate immune response in the first 96 hours of an infection.

The innate immune system has evolved to be the first line of response to pathogens. It consists of the mechanical barriers to infection such as that seen in the skin epithelium and the mucosa of the bowel wall. The activation of complement and coagulation cascades impairs pathogen function, as well as activating the cellular component of the innate immune system ${ }^{19}$. Pathogen associated molecular proteins (PAMPs) and damage associated molecular proteins (DAMPs) are released in response to pathogen invasion and are recognized by Pattern Recognition Receptors (PRRs) on the surface of immune cells ${ }^{20}$. This combination of bacterial proteins and those released by damaged cells binds to PRR receptors such as Toll-like receptors (TLR), NOD-like receptors and Mannose-Binding Lectin that can be either cell associated in the membrane or cytosol or secreted to stimulate the immune system ${ }^{19,21}$.

The major cells of the innate immune system are the macrophage and neutrophil both of which play an important role in the phagocytosis of bacteria, but the macrophage is the key orchestrator of the local reaction ${ }^{19,22}$. Macrophages reside in the tissues and release mediators such as, cytokines and chemokines to induce inflammation as well as directly attacking microbes via release of free radicals, proteolytic enzymes and phagocytose invading pathogens ${ }^{23,24}$. This release stimulates the influx of neutrophils and subsequently monocytes and 
macrophages from the peripheral circulation to assist in fighting the infection. The third main function of macrophages is antigen processing after phagocytosis and presentation to other immune cells which initiates the adaptive immune response with eventual specific antibody production ${ }^{19}$.

This pro-inflammatory response is followed by a regulated anti-inflammatory response which dampens down any excessive inflammation, to reduce the damage to surrounding normal tissue ${ }^{19}$. Often there is a dysfunctional early innate immune response that does not respond appropriately to the infection, which can lead to an imbalance in the pro and anti- inflammatory responses, which is detrimental to the health of the organism ${ }^{25}$.

\section{Macrophages}

Resident peritoneal cells include the mesothelial lining, mast cells and leucocytes. The human peritoneal resident leucocyte population comprises 45$90 \%$ macrophages, $10-47 \%$ lymphocytes and the rest NK cells, dendritic cells and neutrophils ${ }^{26}$. The mesothelial lining and macrophages are the main source of chemokines and cytokines that attract neutrophils and circulating monocytes to the peritoneum ${ }^{18}$. Cytokines bind to cell surface receptors on target cells, inducing intracellular signaling cascades to induce, or inhibit cytokine-regulated genes in the nucleus, thus manipulating cell activity. IL-10 produced by macrophages inhibits neutrophil recruitment and chemokine generation, which in 
turn inhibits pro-inflammatory cytokine release ${ }^{27}$. Diffusion of inflammatory mediators TNF- $\alpha$ and IL-1 $\beta$ from the circulation plays an important role in the pulmonary activation of resident macrophages which results in the associated lung disease and neutrophil infiltration seen in animal models ${ }^{28,29}$.

\section{Toll-like Receptor signaling}

Host immune cells recognize foreign microbial pathogens by pattern recognition receptors located on their surface. The most studied of these are the toll-like receptors of which there are 12 in mice, and 10 in humans; most are located within the cell membrane, though TLR-3, $-7,-8,-9,-11$ and -13 are within the cell cytosol ${ }^{19}$. TLR-4 is found on the cell membrane and responds to bacterial products such as lipopolysaccharide (LPS), derived from the outer membrane of gram-negative bacteria ${ }^{30}$. Ligand binding to TLR-4 results in the activation of intracellular signaling and release of cytokines (Figure 1). In the unstimulated cell, the transcription factor, nuclear factor kappa $\mathrm{B}(\mathrm{NF}-\mathrm{KB})$ is sequestered in the cytoplasm by inhibitory IKB proteins ${ }^{31}$. When LPS binds to TLR-4, myeloid differentiation primary response gene 88 (MyD88) is activated to initiate intracellular signaling pathways. This leads to the phosphorylation of IKB by IKB kinases (IKKs), its subsequent degradation and allows the dissociation of NF-KB from the inhibitory complex and its nuclear translocation to stimulate gene expression ${ }^{32}$. This stimulates the transcription of the pro-inflammatory cytokines notably Tumor Necrosis Factor- $\alpha$ (TNF- $\alpha$ ) and Interleukin-6 (IL-6) ${ }^{33,34}$. TLR-4 
Figure 1: Toll-like Receptor-4 signaling

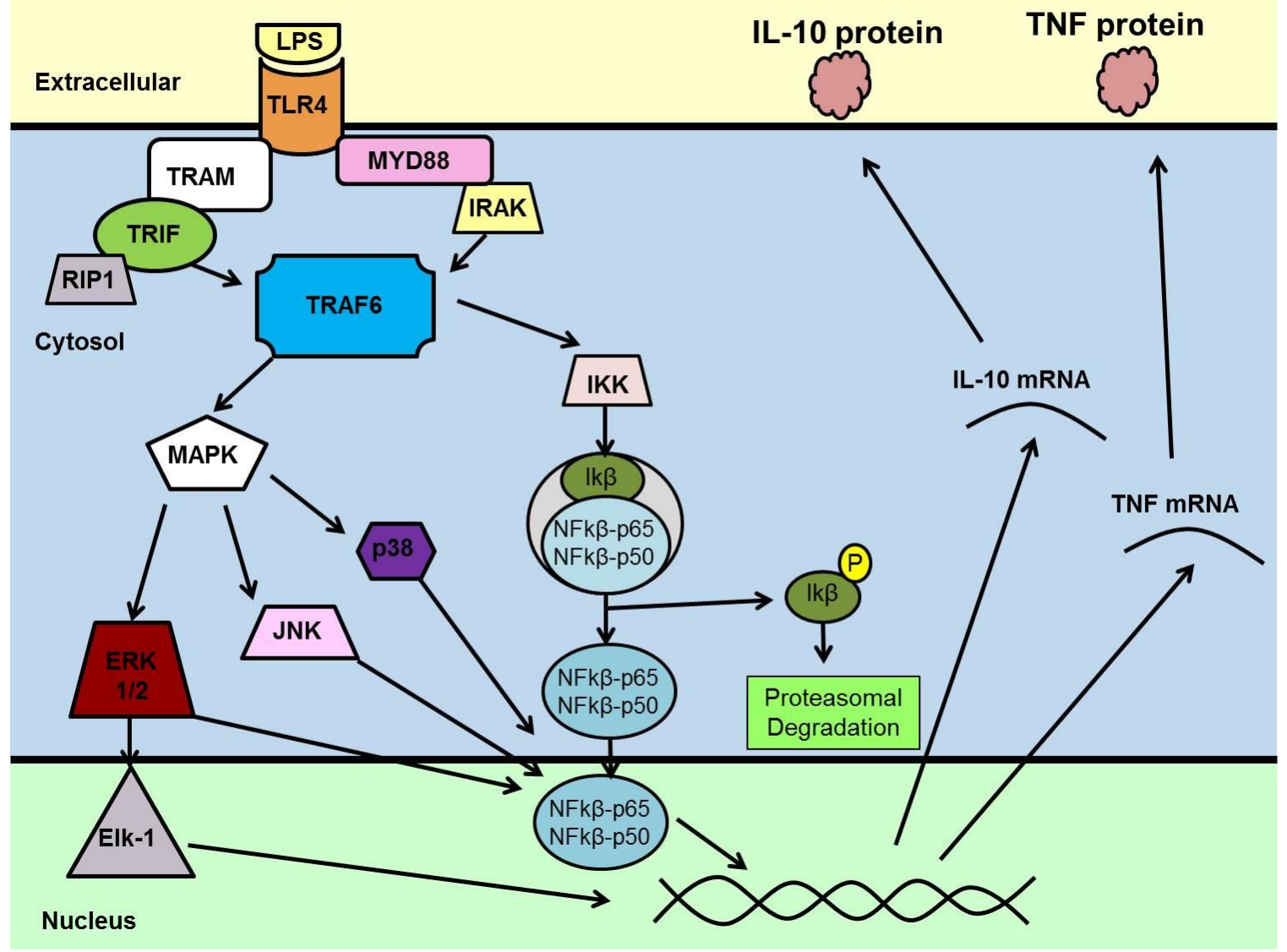

Overview of the Toll-Like Receptor 4 (TLR-4) signaling through MyD88 dependent and independent pathways. Lipopolysaccharide (LPS),TRIF-related adapter molecule (TRAM), TIR-domain-containing adaptor-inducing interferon $\beta$ (TRIF), Myeloid Differentiation Primary Response Gene 88 (MyD88), IL-1 Receptor Associated Kinase (IRAK), TNF-Receptor Associated Factor 6 (TRAF6), Mitogen Activated Protein Kinases pathway (MAPK), Extracellular Signal Related Kinase (ERK), c-Jun N-terminal Kinase (JNK), Inhibitory Kappa

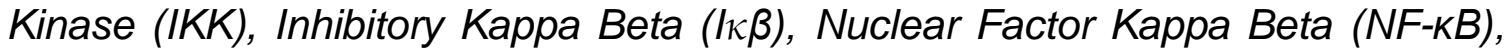
Interleukin-10 (IL-10) and Tumor Necrosis Factor- $\alpha$. 
also activates a MyD88-independent, TIR-domain-containing adaptor-inducing interferon $\beta$ (TRIF) dependent pathway ${ }^{32}$. MyD88-mediated signaling involves the activation of IL-1-Receptor associated kinases (IRAKs) ${ }^{35}$. IRAKs activate TRAF6 (TNF-Receptor Associated Factor; central signaling protein of TLR-4 pathway), which catalyses lysine 63 (K63) -linked ubiquitin chains. This TRAF6 mediated ubiquitination is important in amplifying TLR-4 signaling by stimulating multiple downstream pathways, through IKK, NF-KB and the MAPKs, extracellular signal-related kinase (ERK), JNK and p38 to induce the genes coding for inflammatory cytokines ${ }^{36,37}$.

\section{MicroRNAs}

MicroRNAs (miRNAs) are short non-coding RNAs, 22-25 nucleotides long, which act to inhibit protein production ${ }^{38}$. MiRNA are formed in the nucleus as primiRNA, cleaved into the hairpin shaped pre-miRNA by Drosha and exported from the nucleus into the cytoplasm by Exportin- ${ }^{39}$. In the cytoplasm the miRNA are further cleaved by Dicer and incorporated into the RNA-induced silencing complex (RISC). The RISC then binds to the 3' untranslated region (UTR) of messenger RNA (mRNA) to inhibit translation of proteins ${ }^{40}$. If the sequences are $100 \%$ complementary, then the mRNA is degraded, if the sequence is only $80 \%$ complementary, the mRNA remains intact, but unable to be translated into protein. MiRNA act as post-transcriptional modulators of protein translation ${ }^{41}$. 
There are $>1000$ miRNAs documented, each with hundreds of potential targets based on mRNA sequences, often experimentally unverified. There are multiple miRNAs known to target the TLR-4 signaling pathway ${ }^{42}$.

There has been a substantial increase in miRNA studies since the early discoveries made by Fire and Mellow ${ }^{43}$. The essential role that miRNAs play in cell function and their possibilities as stable biomarkers mean that there is much still to learn about the influence of miRNAs. For example miRNA and transcription factors both regulate inflammation, and now there are examples of transcription factors regulating miRNA expression directly ${ }^{40,44}$. As promoter regions of miRNAs are identified, a more focused understanding of their transcriptional regulation will emerge ${ }^{45}$.

\section{MicroRNA-21}

MiRNA-21 has been the object of multiple studies due to its high abundance and significant role in cardiovascular injury, cancer progression and metastasis ${ }^{46}$. The targets of miRNA-21 have roles in apoptosis, cell proliferation, cell migration, and invasion, and it has been shown to be up-regulated in multiple cancer types including but not limited to breast, lung, colorectal, hepatocellular, pancreatic and diffuse large B-cell lymphoma ${ }^{46-49}$. MiRNA-21 has also been found in the plasma of patients with colorectal cancer ${ }^{50}$. MiRNA-21 is located on chromosome 17 in the 10th intron of the protein coding gene TMEM49 whose function is currently 
unknown. It has its own promoter and expression is not affected by the TMEM49 promoter ${ }^{45}$. Transcription is stimulated by NF-KB and knockdown of NF-kB by siRNA and inhibitors has shown to reduce expression of miRNA-21 in a nicotineinduced cell proliferation model of gastric cancer ${ }^{44,51}$. LPS induces miRNA-21 via TLR-4, MyD88 and NF $\kappa$ B, which has a binding site in the miRNA-21 promoter region ${ }^{52}$. The role of miRNA-21 in the immune system is still under active investigation, though it is believed to be involved in the transition between the pro and anti-inflammatory phases of the early innate immune response. The miRNA21 targets that may contribute to this are Programmed cell death protein 4 (PDCD4), Pelino 1 (Peli1), and Sprouty (SPRY) proteins 1,2 and $4{ }^{53}$.

\section{Programmed Cell Death Protein 4}

PDCD4 has been validated as a target of miRNA-21 by independent groups ${ }^{51,54-}$ 56. There is a single highly conserved miRNA-21 target site within the 3'UTR region, and it's regulation by miRNA-21 has been reported in both human and murine cancer models ${ }^{52}$. Sheedy et al, show PDCD4 is a key step in the negative regulation of the inflammatory response to LPS ${ }^{51}$. PDCD4 ${ }^{-/-}$mice have been shown to have a lower mortality to LPS than PDCD4 ${ }^{+/+}$mice, associated with lower IL-6 and higher IL-10 levels ${ }^{51}$. 


\section{Pelino 1}

There are 3 mammalian homologs of the Pelino (Peli) proteins ${ }^{57}$ but only Peli1 has so far been described as a likely target of miRNA-21 ${ }^{53}$. The Peli proteins, like TRAF6, function as E3 ubiquitin ligases and interact with the IRAKs, inducing ubiquitination of IRAK1, and thus have been linked to the regulation of TLR-4 MyD88-dependent signaling ${ }^{57,58}$ as well as T cell activation ${ }^{59,60}$. Peli has also been demonstrated to be critical in TLR-3 activation of IKK and NF-KB, through interactions in the TRIF pathway ${ }^{36}$. Peli interacts with TRIF-signaling adaptor kinase RIP1 and mediates RIP1 ubiquitination, a key step in the TRIF-dependent IKK-signaling pathway, and is critical in TRIF-dependent TLR signaling, though non-essential for MyD88-dependent TLRs ${ }^{36}$. Peli1 has shown to be important in TLR-4-mediated gene induction, though only partially required for LPS stimulated activation of IKK and NF-KB (Figure 1). Peli1 is a proven target of miRNA-21 in liver regeneration, where Peli1 mRNA was inversely correlated with miRNA-21 levels ${ }^{61}$. Peli1 mRNA and protein expression is increased in macrophages that are stimulated by the TLR-4 ligand LPS, via a TRIF-dependent pathway, and independent of the MyD88-dependent pathway ${ }^{62}$. The IKK-related kinases or IRAK1 activate Peli1 on macrophage stimulation through the TLR MyD88 pathway and via TNF- $\alpha^{63}$. 


\section{Sprouty}

The Sprouty proteins were first described in 1998 as an inhibitor of fibroblast growth factor in Drosophilia ${ }^{64}$. There are four 4 isoforms in mammals, and all are postulated targets of miRNA-21. Sprouty proteins inhibit signaling by receptor tyrosine kinases affecting the activation of MAPK. Srpy1, $2 \& 4$ block the activation of ERK (extracellular signal related kinase) in cells stimulated by growth factors, different points in the signaling cascade depending on the biological context ${ }^{65-67}$. In mouse fibroblasts SPRY1 and 2 inhibit ERK/MAPK signaling at the level of Ras activation, in human epithelial cells, SPRY2 acts on RAF1 as does mammalian SPRY4 ${ }^{68-70}$. All sprouty isoforms inhibit the ERK pathway by themselves, but heterodimers and homodimers have enhanced inhibition ${ }^{71,72}$. In cardiac fibroblasts increased miRNA-21 is associated with decreased expression of SPRY1 and up-regulation of the ERK cascade ${ }^{73}$.

\section{Signaling molecules NF-KB and ERK}

There are five members of the mammalian NF-kB family, REIA, RelB, c-Rel, p50 and $\mathrm{p52}$, which combine to form multiple dimeric complexes and activate target genes by binding to the enhancer element $\mathrm{KB}^{74}$. As mentioned above, these proteins are sequestered in the cytoplasm by IKB proteins until the IKB proteins are phosphorylated and degraded by the proteasome allowing the NF-KB proteins to translocate to the nucleus to effect gene expression ${ }^{75,76}$. MiRNA-21 
overexpression was associated with a $\sim 40 \%$ decrease in NF-KB activity in HEK293 cells ${ }^{61}$.

ERK is one arm of the MAPK signaling pathway, triggered in response to TLR signaling ${ }^{77,78}$. The relationship between ERK activation and IL-10 production is not a simple one. Higher levels of ERK activation have been linked to higher IL10 production $^{79}$.

\section{Cytokines}

\section{Tumor Necrosis Factor $-\alpha$}

TNF- $\alpha$ is an important pro-inflammatory cytokine, the first one to be discovered as such with a plethora of effects when injected into animals including humans including fever, hypotension, metabolic acidosis and capillary leak ${ }^{80-82}$. TNF- $\alpha$ plays a regulatory role in promoting local and systemic bacterial clearance ${ }^{83}$.

IL-6

Interleukin-6 (IL-6) is released from macrophages in response to pathogens. It acts both locally to activate lymphocytes and increase antibody production, as well as systemically to induce fever, the production of acute phase proteins from the liver and neutrophil mobilization and migration to the focus of infection ${ }^{19,83}$. IL-6 correlates with mortality and IL-6 levels 6 hours from injury in a CLP model 
predicts mortality ${ }^{84}$ and has been shown to be the best biomarker of mortality in clinical sepsis ${ }^{85}$. IL-6 is induced by NF $\kappa$ B and augmented by PDCD $4{ }^{51}$. IL-10

Interleukin-10 (IL- 10), previously named cytokine synthesis inhibitory factor (CSIF), IL-10 suppresses both macrophage and dendritic cell function, including the ability to present antigens and the production of pro-inflammatory cytokines (IL-1 $\beta$, TNF- $\alpha$, and IL-12) ${ }^{79}$. IL-10, as an important part of an antiinflammatory response, limits the immune and inflammatory responses to pathogens, which might otherwise result in collateral damage to the host organism ${ }^{86,87}$. IL-10 is constitutively transcribed in many cells, though posttranscription regulations make the protein levels tightly regulated ${ }^{88}$. Loh et al, show that PDCD4 inhibits translation by blocking the binding of translation initiation factor elF4Gc to elF4A in an inactive conformation ${ }^{89}$. This is thought to be part of the mechanism by which IL-10 is suppressed by PDCD4, as PDCD4 inhibits the cap-dependent translation of mRNAs with complex 5' untranslated regions (UTRs), which include IL-10.

\section{E. Peritonitis Models}

The clinical infection of peritonitis that we see in our human surgical patients has been modeled using various several different methods. Each experimental model 
has its value, depending on the hypothesis of the experiment. The use of animal models, which while not exactly the same physiologically as human, allows in vivo investigation into the mammalian physiology of normal or pathologic processes, and well as to investigate mechanisms of disease. These models may also serve to test the ability of an intervention to interrupt normal or pathologic processes and aid in the preclinical testing of potential therapeutic agents ${ }^{16}$.

The most common models of experimental peritonitis are cecal ligation and puncture (CLP) and endotoxin (LPS) ${ }^{16}$. These are frequently performed in small animals due to cost considerations and the numbers required for experimentation. The defined characteristics of different strains and availability of genetic variants such as gene knockouts also make mice a useful model for peritonitis experiments.

\section{Lipopolysaccharide}

Lipopolysaccharide (LPS) or endotoxin is a common model of inflammation, especially in the mouse and has been a laboratory workhorse for decades. LPS is considered to be an important inducer of the septic response and intraperitoneal LPS is more likely to induce a hyperdynamic cardiovascular response than intravenous (IV) administration and is thus a better model for the human condition ${ }^{16}$. Induction of LPS peritonitis is simple, requiring only an intraperitoneal injection of the desired concentration of LPS in a standard carrier 
volume, and can be performed readily with minimal practice. While this model gives a bolus of bacterial protein, and it has less clinical relevance because patients have a septic focus that slowly seeds bacteria into the body ${ }^{90}$.

\section{Cecal Ligation and Puncture}

Cecal Ligation and puncture (CLP) is a well-established murine model of peritonitis that more closely models human peritonitis, as it combines the entry of enteric bacteria into the peritoneum, together with a foreign body reaction and an ischemic focus ${ }^{16}$. A small incision is made in the abdomen, and the cecum externalized. The distal segment is ligated, $\sim 1 \mathrm{~cm}$ from the cecal pole and a puncture made in the ligated segment. The cecum in the mouse is a blind-ended tube, so no obstruction is caused by ligation of the bowel, when properly performed. The bowel is then returned to the abdomen and the peritoneum and skin closed in layers. The severity of the model can be varied with the length of bowel ligated and the size and number of punctures in the cecum ${ }^{91}$. Cecal Ligation and puncture, in contrast to the LPS model, is a more time consuming cause of peritonitis, requiring superior surgical skills, and a more precise technique in order to consistently perform the same operation multiple times within the inherent variability in mouse anatomy. These animals develop an initial hyperdynamic cardiovascular response, similar to that seen in patients with

increased cardiac output and decreased systemic vascular resistance ${ }^{90}$. This develops into systemic bacteraemic infection and sepsis, which progressively 
undergoes cardiovascular collapse due to septic shock and death days after the initial insult, similar to the condition seen in peritonitis patients who die from multiple organ failure days after the onset of infection.

We propose to use both established models of peritonitis to examine the effect of miRNA-21 on both mechanistic and clinically relevant patterns of intra-abdominal infection. Existing data show that miRNA-21 acts on the TLR-4 pathway in response to LPS. If we are able to modify the balance of pro- and antiinflammatory immune response through manipulating the cytokines released in response to infectious stimuli, we may be able to affect survival and initiate the beginning of a new potential therapy for patients with peritonitis. 
CHAPTER III

HYPOTHESIS, SPECIFIC AIMS AND EXPERIMENTAL PLAN

\section{A. Key Objective}

To investigate the role of miRNA-21 in the macrophage response to peritonitis, and identify whether the associated regulatory mechanisms have potential benefits in the clinical treatment of peritonitis.

\section{B. Hypothesis}

We hypothesize that the outcome of peritonitis can be modulated by miRNA-21 through down regulation of NF-KB signaling that will affect macrophage cytokine release, to diminish local inflammation. 


\section{Specific Aims}

1: To establish a time course of miRNA-21 expression in peritoneal macrophages following an infectious insult, either lipopolysaccharide or cecal Ligation and Puncture.

2: To examine the mechanisms by which miRNA-21 regulates the inflammatory response.

3: To investigate the effects of miRNA-21 on macrophage cytokine production

4: To ascertain the effect of miRNA-21 knockout on survival in in vivo models of peritonitis - lipopolysaccharide or cecal ligation and puncture.

\section{Experimental Plan}

The overall goal of this project is to investigate the role of miRNA-21 in the macrophage response to peritonitis. We will establish the pattern of miRNA-21 expression and cytokine secretion from primary peritoneal macrophages. We will examine how modulation of miRNA-21 expression changes cytokine secretion. If we see a difference, we will investigate which targets of miRNA-21 that act on the TLR-4 signaling pathway are different between bone marrow derived macrophage cell lines from miRNA- $21^{+/+}$and miRNA-2 $21^{-/-}$mice. Finally we will investigate the clinical potential for the use of miRNA-21 as a novel agent in peritonitis by comparing the survival of miRNA- $21^{+/+}$and miRNA-21/- mice in LPS and 
cecal ligation and puncture models of peritonitis. An outline is shown in Figure 2.

\section{E. Methods}

\section{i. Mice}

Approvals for the study protocols were obtained from the Robley Rex Veteran Affairs Medical Center and University of Louisville Institutional Animal Care and Use Committees (VA: che37, UofL: 11064).

Wild-type Mice for Peritoneal Macrophage Experiments

Male 6 week old C57BL/6 mice obtained from Jackson Laboratories (Bar Harbor, ME) were housed with food and water ad libitum according to IACUC guidelines.

MiRNA-21 Knockout Mice and Wild Type Controls

The gene targeting of miRNA-21 in mice was performed by inGenious Targeting Laboratory (iTL), Inc (Ronkonkoma, NY) as previously described ${ }^{92}$. Briefly a targeting vector was constructed and transfected into hybrid embryonic stem cells by electroporation. Positive recombinant clones were identified by polymerase chain reaction (PCR). Targeted iTL BA1 hybrid embryonic stem cells were microinjected into C57BL/6 blastocysts. Resulting chimeras were mated to wild-type C57BL/6 mice to generate F1 heterozygous offspring with germline transmission. Mice were bred within our breeding facility. Genotype was confirmed by PCR prior to experimentation. 
Figure 2: Outline of Study

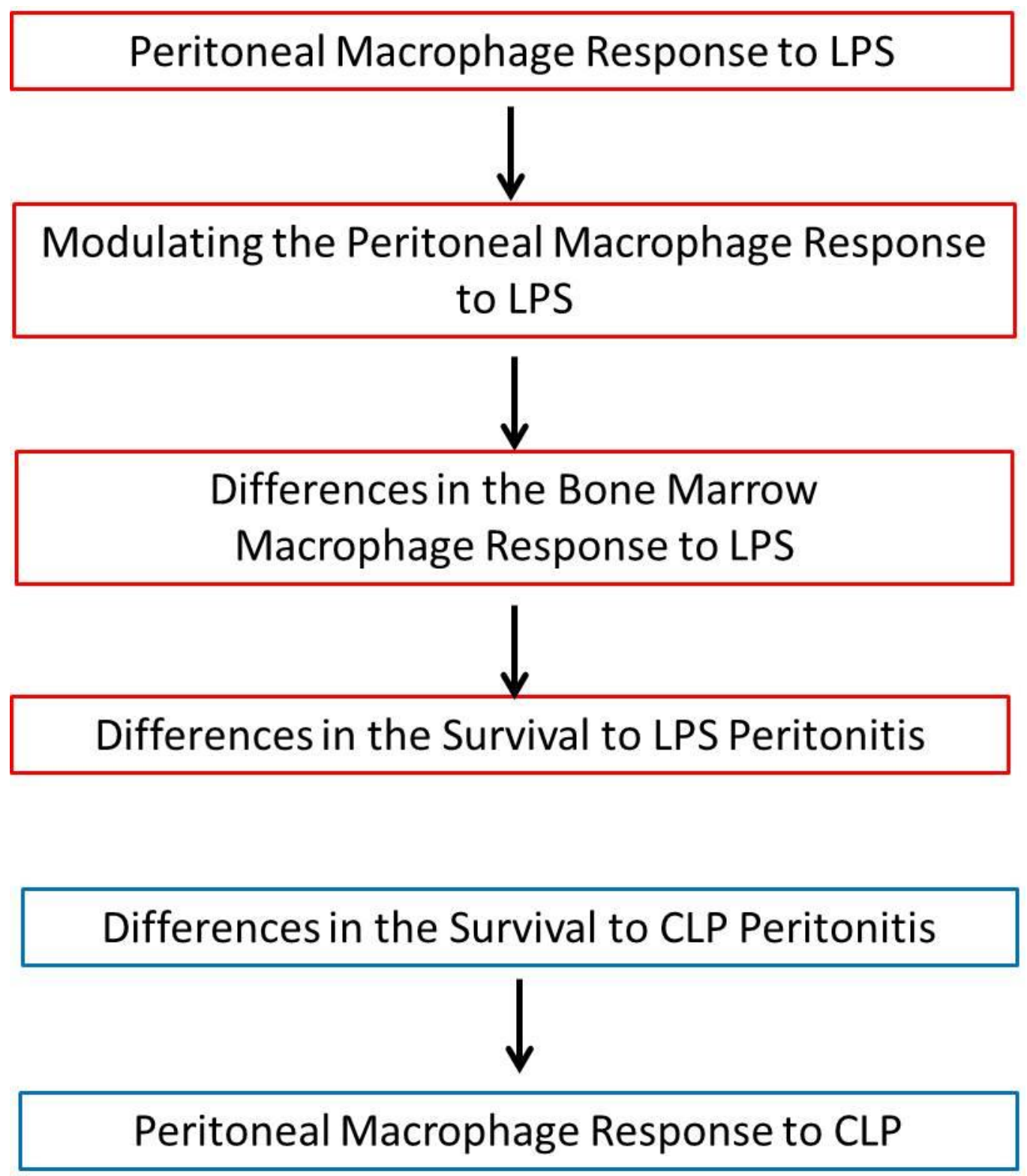

The study begins with the peritoneal macrophage response, and then utilizes

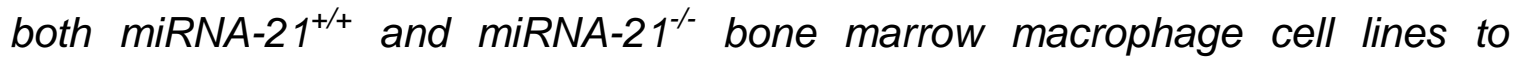
delineate the impact of miRNA-21 on the cellular response to lipopolysaccharide. In vivo models of peritonitis are then used to assess the effect of miRNA-21 in a whole body situation. 
Bone Marrow Macrophage Cell Lines

Immortalized macrophage cell lines (BMM) were established by infecting the bone marrow of miRNA- $21^{+/+}$and miRNA- $21^{-/-}$mice with the murine recombinant $\mathrm{J} 2$ retrovirus containing the $\mathrm{v}$-myc and v-ref oncogenes as previously described ${ }^{33,93,94}$. Cells were cultured in RPMI-1640 medium with $5 \%$ Fetal Bovine Serum, 1\% L-glutamine, 1\% HEPES and 0.1\% gentamicin (all Sigma Aldrich) at $37^{\circ} \mathrm{C}$ in a humidified incubator with $5 \%$ $\mathrm{CO}_{2}$

\section{ii. Harvest of Peritoneal Cells}

Naïve mice were anaesthetized with $2-3 \%$ isoflurane (Butler Schein, Dublin, $\mathrm{OH}$ ) and the abdomen lavaged with $3 \mathrm{~mL}$ of heparinized phosphate buffered saline (PBS) with no calcium or magnesium (Sigma Aldrich, St. Louis, MO). Lavage fluid was centrifuged to pellet peritoneal exudate cells (PECs) for macrophage isolation.

\section{iii. Macrophage Isolation}

Naive Mice - CD11b

Magnetic bead isolation products were purchased from Miltenyi Biotec (San Diego, CA). PECs from each mouse were resuspended at $10^{7}$ cells in $80 \mu \mathrm{L}$ autoMACS ${ }^{\mathrm{TM}}$ running buffer, and incubated at room temperature for $15 \mathrm{~min}$ with $\mathrm{CD} 11 \mathrm{~b}$ beads. After washing, the cells were resuspended in $500 \mu \mathrm{L}$ Running Buffer and passed through MS columns in a 
MiniMACS ${ }^{\mathrm{TM}}$ Separator magnet. After isolation the columns were washed three times and eluted with $1 \mathrm{~mL}$ running buffer and the isolated macrophages counted. This macrophage enriched population was manually quantified by hemocytometer with trypan blue exclusion method to determine total macrophage numbers and cell viability.

$\mathrm{CD} 11 \mathrm{~b}$ beads were used to isolate the peritoneal macrophages from naive mice, as CD11b forms part of the C3 complement receptor with CD18. In mice it is strongly expressed on monocytes, macrophages and microglia. There are lower levels of expression on granulocytes including neutrophils, NK cells, $\mathrm{CD}^{+} \mathrm{B}$ cells and subsets of dendritic cells. F4/80 is present on all mouse macrophages; however there is not a F4/80 bead available. Preliminary experiments confirmed that $>82 \%$ of $C D 11 b^{+}$cells isolated from the peritoneum of naïve wild type mice were $\mathrm{F} 4 / 80^{+}$(Figure $3)$.

After Cecal Ligation and Puncture - F4/80

PECs were resuspended at $10^{7}$ cells in $80 \mu \mathrm{L}$ PBS and incubated at $4^{\circ} \mathrm{C}$ for 25min with F4/80 R-Phycoerythrin (PE) antibodies (eBiosciences). After washing, the cells were resuspended in autoMACS ${ }^{\mathrm{TM}}$ running buffer and incubated with anti-PE beads (Militenyi Biotec) for a further 25 min at $4^{\circ} \mathrm{C}$. After a further wash, the cells were resuspended in $500 \mu \mathrm{L}$ running buffer and passed through MS columns (Militenyi Biotec) in a MiniMACS ${ }^{\mathrm{TM}}$ 
Figure 3: CD11b isolation of Peritoneal Macrophages
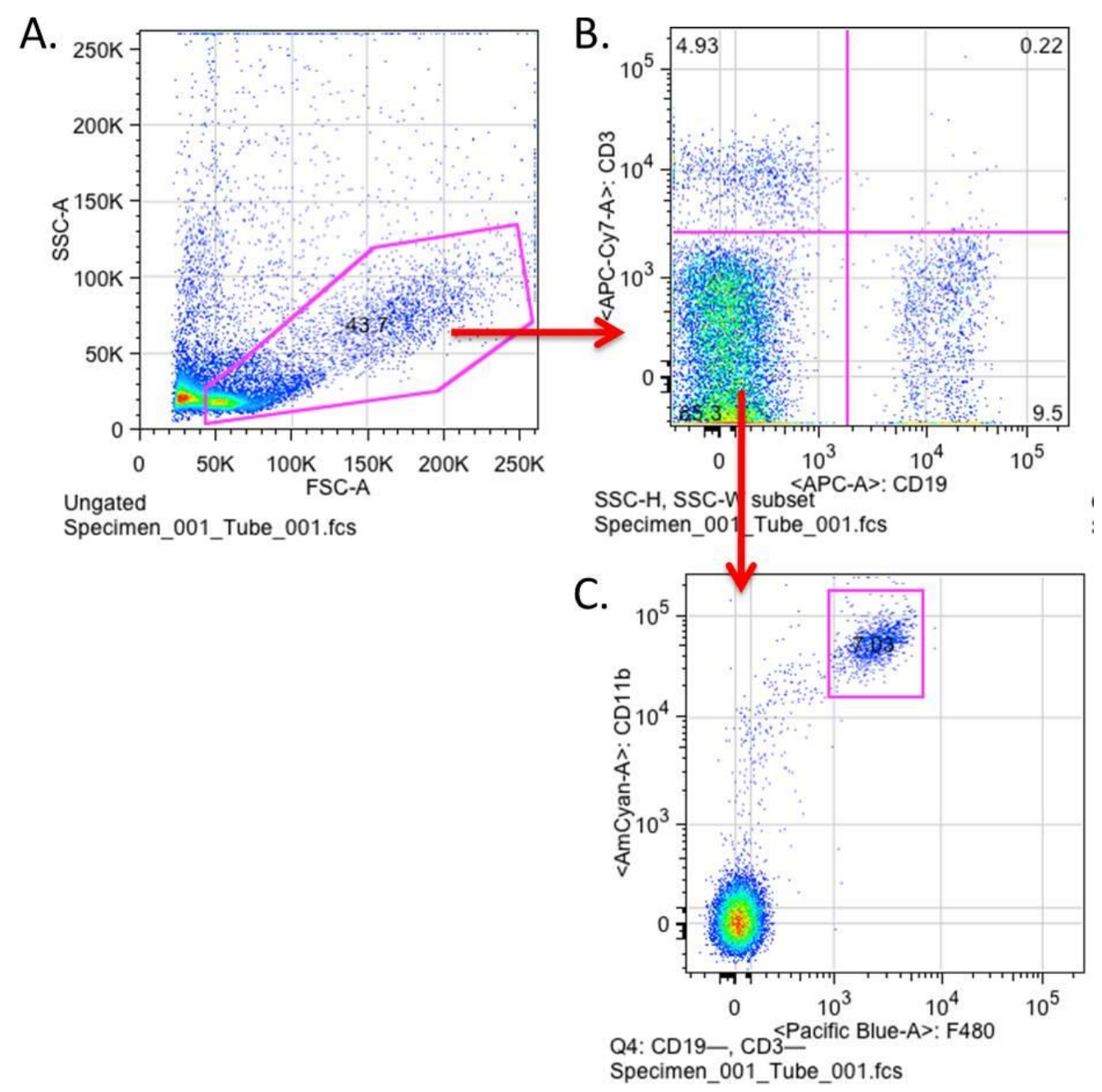

A) The cell population from the peritoneum of naïve wild type mice was gated the according to size (forward scatter - FSC) and granularity (side scatter - SSC). B) Cells were stained to ascertain distinct populations $\left(C D 3^{+}-T\right.$ cells, $C D 19^{+}-B$

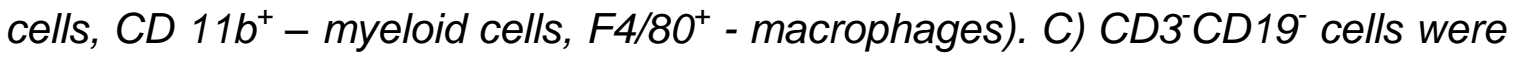
further gated to calculate the percentage of $F 4 / 80^{+}$from all $C D 11 b^{+}$cells. 
Separator (Militenyi Biotec) magnet. After isolation the columns were washed three times and eluted with $1 \mathrm{~mL}$ running buffer and the macrophages counted. This macrophage enriched population was manually quantified by hemocytometer with trypan blue exclusion method to determine total macrophage numbers and cell viability.

Following CLP there is an influx of neutrophils and circulating monocytes/macrophages into the peritoneum. These neutrophils are $\mathrm{CD} 11 \mathrm{~b}^{+}$; therefore to prevent a significant population of neutrophils within our macrophage samples, we performed the two-step isolation procedure. The purity of the isolated macrophages was $>80 \%$ as determined by flow cytometry.

\section{iv. Lipopolysaccharide Stimulation}

For most experiments the macrophages were suspended at $0.5 \times 10^{6} / \mathrm{mL}$ in RPMI-1640 medium with $10 \%$ fetal bovine serum, $1 \%$ L-glutamine and $1 \%$ antibiotic/antimycotic all from Sigma Aldrich (St. Louis, MO) and plated in a 24 well plate at $0.5 \times 10^{6} / 1 \mathrm{~mL}$ per well. Cells were rested overnight at $37^{\circ} \mathrm{C}$ in a humidified incubator with $5 \% \mathrm{CO}_{2}$ prior to stimulation. Samples were stimulated with lipopolysaccharide (LPS) 100ng/mL (E.Coli 011:B4; Sigma Aldrich). After stimulation cells were incubated for the indicated time periods. The culture media was removed and stored at $-80^{\circ} \mathrm{C}$ for cytokine quantification. Macrophages were allocated to either RNA 
isolation or lysed in $100 \mu \mathrm{L}$ of RIPA buffer (Sigma Aldrich) for protein quantification and western blot.

The macrophages were rested overnight following isolation and prior to stimulation. We have previously observed activation of monocytes/macrophages by centrifugation, changing cytokine profile. In order to see the response to a single LPS challenge, and avoid any tolerance effects we allowed the cells to rest prior to LPS stimulation.

\section{v. RNA Isolation}

Total RNA was isolated from the macrophages using mirVana miRNA isolation kits (Ambion, Life technologies) following manufacturer's protocol. RNA concentrations were determined and RNA purity was assessed using the NanoDrop 2000 (Thermo Scientific, Hudson, NH). All sample fulfilled the quality criteria (A260/280 ratio between 1.8 and 2.1).

\section{vi. MiRNA and MessengerRNA Expression}

MiRNA-21 expression was measured using Taqman ${ }^{\circledR}$ single miRNA assays and Taqman MiRNA Reverse Transcription Kit for miRNA (Applied Biosystems $®$, Life Technologies). U6 was used as a house keeping gene miRNA for normalization.

For mRNA expression RNA was transcribed into complementary DNA (cDNA) using High Capacity cDNA Reverse Transcription Kit for mRNA 
(Applied Biosystems ${ }^{\circledR}$ ). Taqman single gene assays for PDCD4, Peli1, SPRY1, SPRY2, and SPRY4. 18s was used as an internal control.

The StepOne Plus (Applied Biosystems $®$ ) was used to run the real time Polymerase Chain Reaction (PCR) using Fast Advanced Master Mix and the fast protocol (all products Life Technologies). StepOne Plus software v2.1 (Applied Biosystems ${ }^{\circledR}$ ) generated Cycle Threshold $(\mathrm{CT})$ values which were used to calculate fold changes using the $\Delta \Delta C T$-method ${ }^{95}$.

\section{vii. Cytokine Assays}

TNF- $\alpha$, IL-6 and IL-10 levels were measured in lavage media and culture media supernatants using enzyme-linked immunosorbent assays (ELISAs). Murine Ready-Set-Go kits were purchased for all ELISAs from e-Biosciences (San Diego, CA, USA) and then performed in 96-well plates according to the manufacturer's instructions. All samples were analyzed in

duplicate. Where necessary, samples were diluted in assay diluent to achieve cytokine concentrations within the range of the standard curve.

\section{viii. Protein isolation}

Protease and phosphatase inhibitors (Thermo Scientific) were added to proteins in RIPA buffer and sonicated using a Sonifier 250 (Branson Ultrasonics Danbury, CT). Protein quantification was determined by BCA Assay (Thermo Scientific, Rockford, IL) against a standard curve on Dynatech MR4000 using BioLinx 2.0 software. 


\section{ix. Western Blot}

All products for Western Blots were purchased from Life Technologies (Carlsbad, CA) unless otherwise specified and run according to manufacturer's protocols. $40 \mu \mathrm{g}$ of protein per sample was loaded into wells of a Bolt $4-12 \%$ Bis-Tris Plus mini gel with $4 x$ Bolt $^{\mathrm{TM}}$ LDS Sample Buffer with 1:100 2-mercaptoethanol, and run in Bolt MES SDS Running Buffer in a Bolt Mini Gel Tank on a Bio-Rad Power Pac 1000 (Hercules, CA) at $165 \mathrm{mV}$ for $35-60$ min with SeeBlue ${ }^{\circledR}$ Plus2 Prestained Standard. Proteins were transferred onto Nitrocellulose membrane using iBlot ${ }^{\circledR} \mathrm{Gel}$ Transfer stacks and an iBlot ${ }^{\mathrm{TM}}$ transfer device.

Non-specific binding was blocked with $7 \%$ non-fat milk in TBS-T $(9.68 \mathrm{~g}$

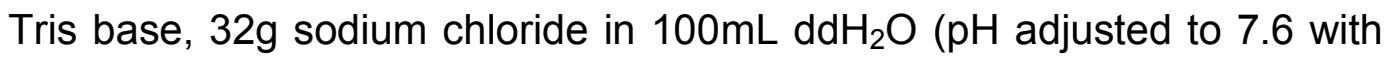
concentrated hydrochloric acid), with $100 \mu \mathrm{L}$ Tween 20) for 1 hour at room temperature. The membranes were incubated with rabbit anti-mouse primary antibody overnight at $4^{\circ} \mathrm{C}$.

All antibodies were purchased from Cell Signaling (Danvers, MA) unless otherwise specified. All antibodies were suspended in $5 \%$ milk non-fat milk made with TBS-T for 1-2 hours at room temperature or overnight at $4^{\circ} \mathrm{C}$. Antibody concentrations were as follows: Peli1 1:250 (Thermo Scientific), PDCD4 1:500, SPRY1 1:200 (Santa Cruz Biotechnology, Inc, Dallas, TX), SPRY2 1:1000, and SPRY4 1:500 (Thermo Scientific).

Following incubation with each antibody, membranes were washed three times with TBS-T for 10 minutes. Subsequently the membranes were 
incubated with rabbit anti-mouse primary antibody for housekeeping protein $\beta$-actin $(1: 10,000)$ or glyceraldehyde 3 -phosphate dehydrogenase (GAPDH 1:10,000) and then with goat anti-rabbit secondary antibody $(1: 5,000)$.

Pierce ECL Western Blotting Substrate (Thermo Scientific) was applied to the membrane as per the manufacturer's instructions. CL-XPosure ${ }^{\mathrm{TM}}$ Film (Thermo Scientific) was used to expose the membrane for $15 \mathrm{~min}$. The resultant image was developed, fixed, scanned and quantified using ImageJ (National Institutes of Health, Bethesda, MD).

\section{x. MiRNA Transfection}

To elucidate the anti-inflammatory effect of miRNA-21 on the macrophage expression of cytokines, we transfected primary peritoneal macrophages with mimics and antagomirs. MiRNA mimics are double-stranded RNAs that are processed by Dicer and are incorporated into the RISC, acting in the same way as endogenous miRNAs. The miRNA inhibitors in contrast are single-stranded anti-sense RNAs that bind to the target miRNA which leads to its degradation. The negative control has a hairpin structure like the endogenous pre-miRNA, and is also processed by Dicer, but the sequence is not complementary to any known gene, and therefore has no active function with the cell.

For this experiment, the primary peritoneal macrophages from naïve wild type C57BL/6 mice were suspended at $0.42 \times 10^{6}$ in RPMI-1640 medium 
with $10 \%$ fetal bovine serum, $1 \%$ L-glutamine and $1 \%$ antibiotic/antimycotic. Cells were immediately transfected. MirVana® mimic, inhibitor and negative control to mmu-miR-21-5p (Life technologies, Carlsbad, CA) were assembled with N-TER peptides (Sigma Aldrich) as per manufacturer's protocol.

$0.25 \times 10^{6}$ macrophages were incubated in a concentration of $120 \mathrm{nM}$ of mimic, antagomir, or negative control for 24 hours in at $37^{\circ} \mathrm{C}$ with $5 \% \mathrm{CO}_{2}$ in cell suspension. After 24 hours, the samples were diluted with a further $600 \mu \mathrm{L}$ of media and stimulated with LPS $100 \mathrm{ng} / \mathrm{mL}$. Six or 24 hours after LPS stimulation, the culture media was collected for cytokine measurement and the macrophages processed for RNA isolation and subsequent analysis of miRNA expression. An $\mathrm{N}$ of 1 was used for macrophages from a single mouse used for mimic, antagomir, and negative control.

\section{xi. Phosflow Pathway Analysis}

Immortalized macrophages from miRNA- $21^{+/+}$and miRNA-21-- mice were resuspended at $0.5 \times 10^{6} / \mathrm{mL}$ RPMI-1640 medium with $10 \%$ fetal bovine serum, $0.5 \%$ L-glutamine and $0.5 \%$ antibiotic/antimycotic. Cells in suspension were rested overnight at $37^{\circ} \mathrm{C}$ in a humidified incubator with $5 \% \mathrm{CO}_{2}$ prior to stimulation. After stimulation with LPS $(100 \mathrm{ng} / \mathrm{mL})$, cells were incubated for the indicated time periods. For baseline pathway 
activation determination, similarly cultured unstimulated miRNA- $21^{+/+}$and miRNA-2 $21^{-/}$macrophages were used.

Following the indicated time, the cells were fixed immediately with formaldehyde (3.2\% pre-warmed), to maintain the phosphorylation status of the pathways. After washing, cells were permeablized with chilled $100 \%$ methanol. Cell samples were split for analysis of NF-KB or ERK activation. Intracellular staining occurred in the dark for 1 hour with phospho-NF-kB p65 or phospho-ERK AlexaFluor® 488 antibodies (Cell signal, Danvers, MA). After staining, cells were washed and resuspended in $300 \mu \mathrm{L}$ FBSstain buffer (2\% FBS in PBS, both Sigma Aldrich).

A FACS Calibur (BD Bioscience, San Jose, CA) was used to acquire the samples. We counted 10,000 events for each sample. CellQuest Pro (BD Bioscience) was used for analysis.

\section{xii. Peritonitis Models}

\section{Lipopolysaccharide Peritonitis}

Male C57BL/6 miRNA-2 $1^{+/+}$and miRNA-21 ${ }^{-/-}$mice aged 12-18 weeks were weighed, single housed and fasted for 3 hours prior to intra-peritoneal injection of 25mg/kg of E. coli LPS (E.Coli 055:B5; Sigma Aldrich). Surface temperature, daily weight and survival were recorded for up to 5 days. Mice were given food and water ad libitum. Preliminary experiments found the optimal dose for a $50 \%$ survival in the wild type mice was $25 \mathrm{mg} / \mathrm{kg}$ with 3 hours of fasting prior to induction of peritonitis (Figure 4). 
Figure 4: Lipopolysaccharide Peritonitis Survival Curves

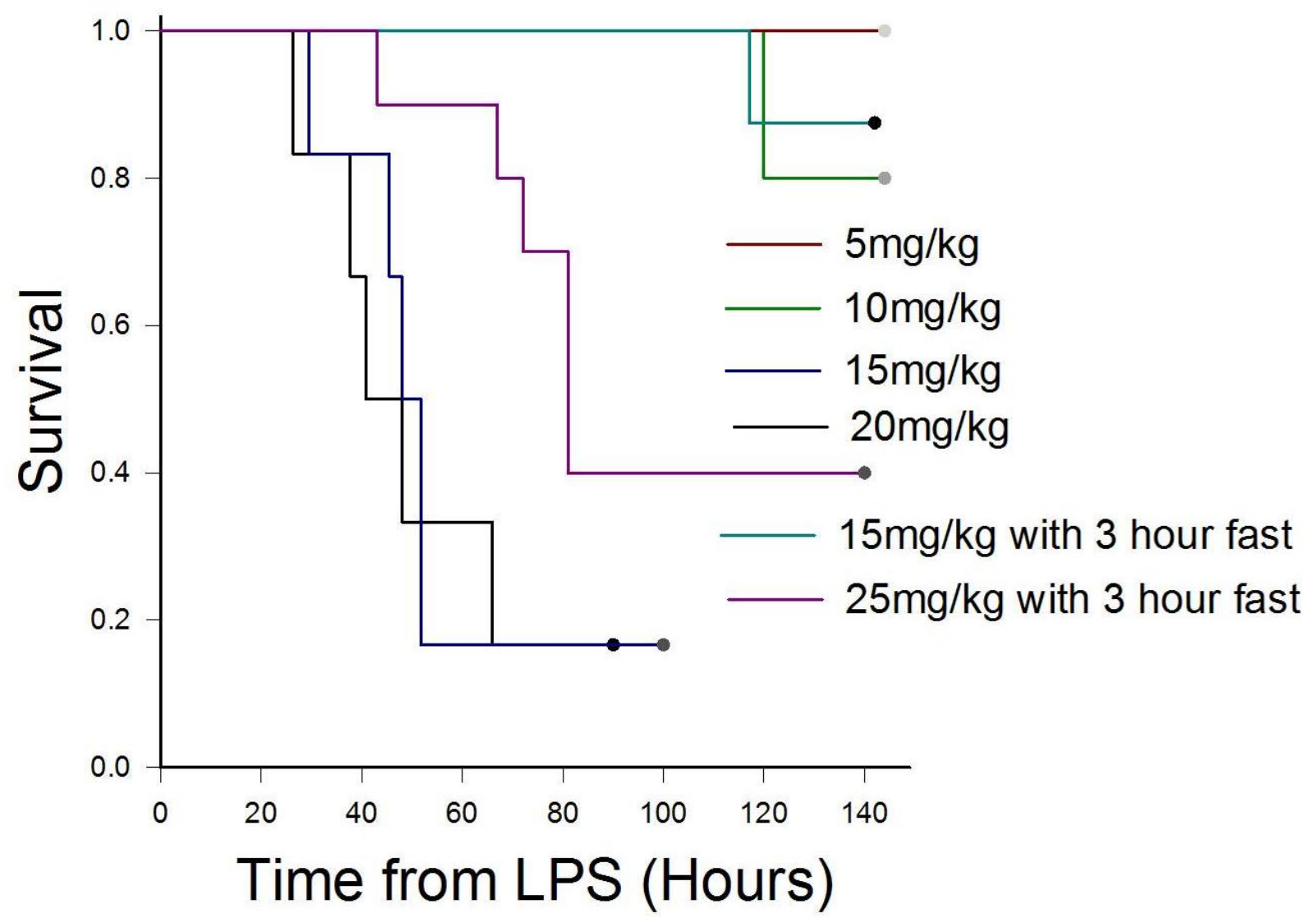

Multiple survival experiments were performed in wild type mice to find the optimal dose for a survival of $40-60 \%$. $25 \mathrm{mg} / \mathrm{kg}$ with 3 hour fast was selected for final experiments in miRNA-21+/+ and miRNA-21/- mice. 
Cecal Ligation and Puncture Peritonitis

Male C57BL/6 miRNA-2 $21^{+/+}$and miRNA-2 $21^{-/}$mice aged $12-18$ weeks were weighed prior to undergoing cecal ligation and puncture. Briefly, under isoflurane anesthesia, the abdomen was incised and, the cecum exteriorized and ligated $1 \mathrm{~cm}$ from the tip. A through and through puncture was made with a $20 \mathrm{G}$ needle, and the cecum returned to the abdomen. The peritoneal layer was closed with 3-0 Ticron and $50 \mu \mathrm{L}$ of $2 \%$ lignocaine applied to the suture line. Skin was closed with 3-0 silk. Post-operatively mice were given $600 \mu \mathrm{L}$ subcutaneous $0.9 \%$ saline and single housed. Surface temperature, daily weight and survival were recorded for up to 5 days. Mice were given food and water ad libitum.

\section{xiii. Statistical Analysis}

Data are shown as the mean \pm standard error. Sigma Plot 13.0 (Systat Software Inc, San Jose, CA) was used to perform Student's t-test, ANOVA and Linear Regression to determine statistical significance. A p value of $<0.05$ was considered significant. 
CHAPTER IV

MIRNA-21 EXPRESSION IN PERITONEAL MACROPHAGES

\section{Introduction}

Recent studies have shown a role for miRNA-21 in the regulation of the TLR-4 pattern recognition receptor, which is present on macrophages amongst other cells ${ }^{42,51}$. TLR-4 activation leads to the initiation of the innate immune response and release of pro- and anti-inflammatory cytokines. The expression of miRNA21 has been shown to increase in RAW264.7 cells following LPS stimulation ${ }^{51}$. The pattern of expression in primary peritoneal macrophages has yet to be ascertained. We propose that miRNA-21 expression in primary peritoneal macrophages increases after LPS stimulation.

\section{Results}

\section{MiRNA-21 Expression}

MiRNA-21 expression increased in a linear fashion following LPS stimulation of primary peritoneal macrophages to maximum fold change of 12 in the observation period $\left(R^{2}=0.82\right.$, Figure 5$)$. 
Figure 5: Peritoneal Macrophage MiRNA-21 Expression after

\section{Lipopolysaccharide}

A.

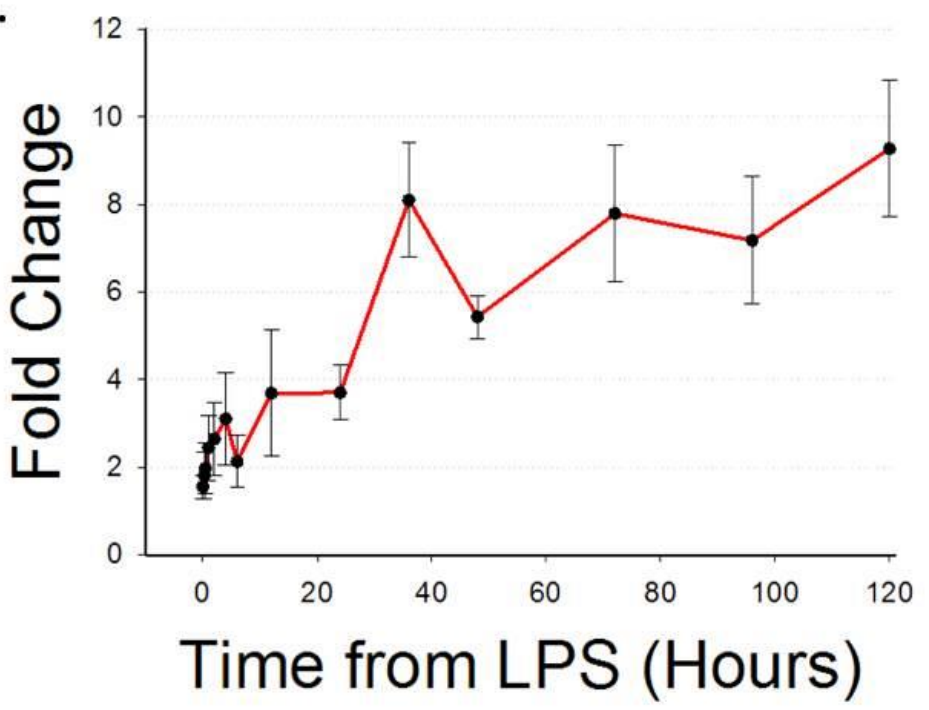

B.

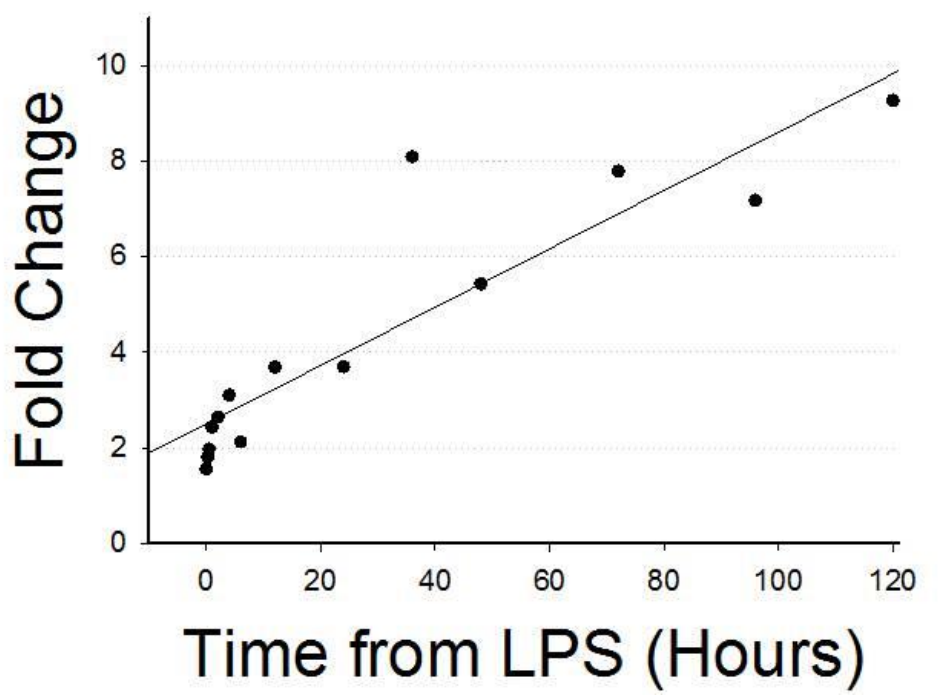

A) Peritoneal macrophage miRNA-21 expression after lipopolysaccharide (LPS) stimulation. $N=8$. B) Linear Regression $R^{2}=0.82, P=<0.001$. Data are shown Mean \pm SEM. 


\section{Secreted Cytokine Profile}

The pro-inflammatory cytokines TNF- $\alpha$ and IL-6, were increased from 15min after LPS stimulation (Figure 6). The levels of TNF- $\alpha$ peaked at 6 hours, were somewhat decreased at 24 hours, but after that remained elevated. IL-6 peaked at 12 hours and then plateaued. The anti-inflammatory cytokine IL-10 was also increased from $15 \mathrm{~min}$ after LPS stimulation, rising to a peak at 12 hours, and then decreasing to $60 \%$ of maximum at the end of the observed period (Figure 7).

\section{MiRNA-21 target mRNAs}

The mRNA levels of the miRNA-21 target PDCD4 decreased sharply for the first 3 hours following LPS stimulation (Figure 8 ). This was followed by an increase until 36 hours, and a subsequent decline, but always remained below baseline levels.

Peli1 mRNA levels increased following LPS stimulation to a peak at 3 hours (Figure 9). Levels returned to baseline at 24 hours and remained there for the remainder of the observation period.

SPRY1 and 4 followed a pattern similar to Peli1, with an initial peak at 1 hour, then returning to baseline around 24 and 6 hours respectively (Figure 10). SPRY1 remained at baseline, while SPRY4 became down-regulated from 24 hours. SPRY2 has an initial increase and return to baseline within the first 3 hours, followed by a slower, greater increase in mRNA levels over 36 - 96 hours which then declined. 
Figure 6: Peritoneal Macrophage Pro-inflammatory cytokines after Lipopolysaccharide

A.

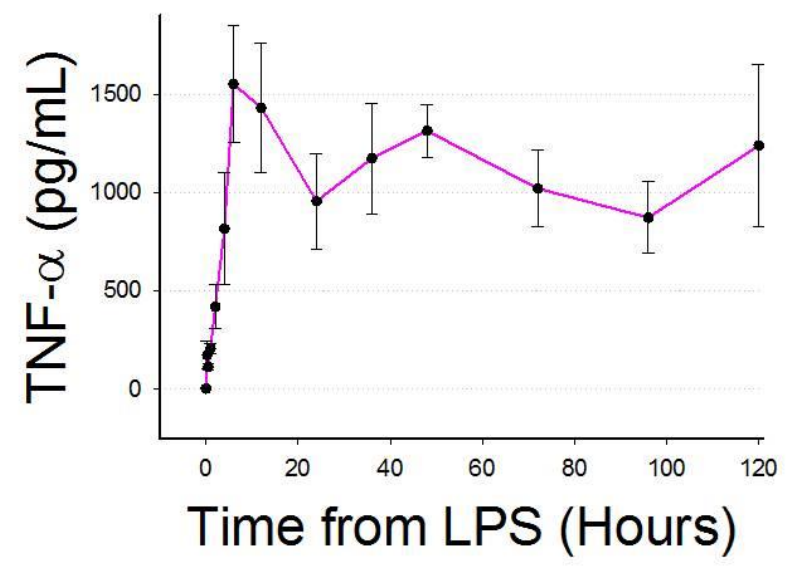

B.

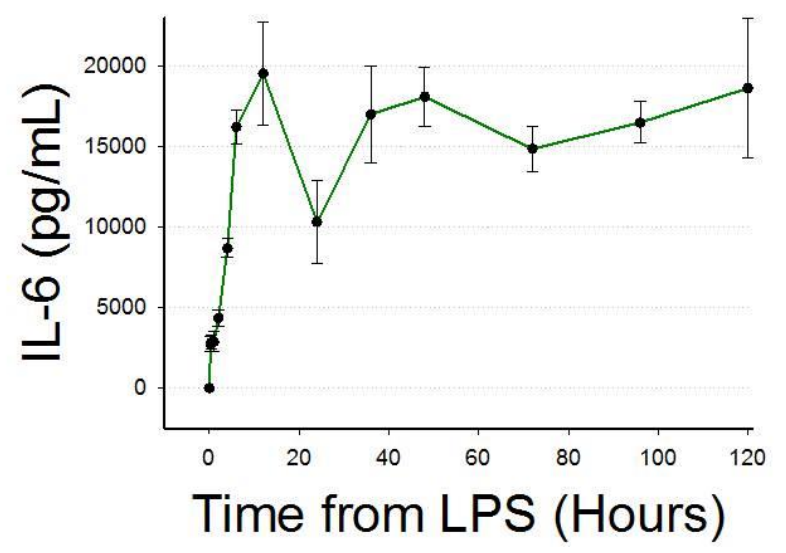

TNF- $\alpha$ and IL-6 concentrations from media of peritoneal macrophages after lipopolysaccharide (LPS) stimulation. A) TNF- $\alpha$ and B) IL-6. $N=8$. Data are shown Mean \pm SEM. 
Figure 7: Peritoneal Macrophage Anti-inflammatory cytokine after Lipopolysaccharide

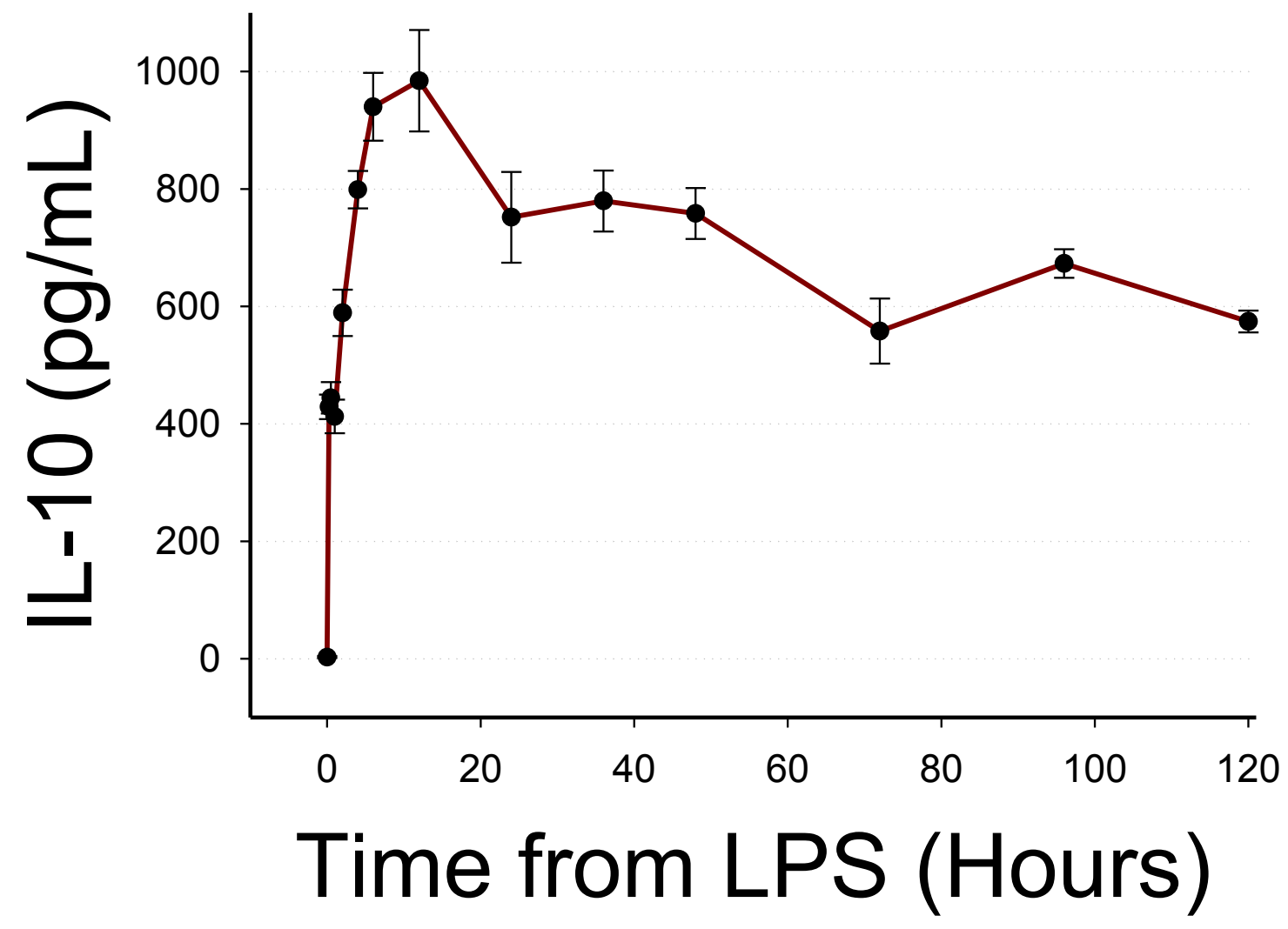

IL-10 concentrations from media of peritoneal macrophages after lipopolysaccharide (LPS) stimulation. $N=8$. Data are shown Mean $\pm S E M$. 
Figure 8: Peritoneal Macrophage PDCD4 mRNA expression after Lipopolysaccharide

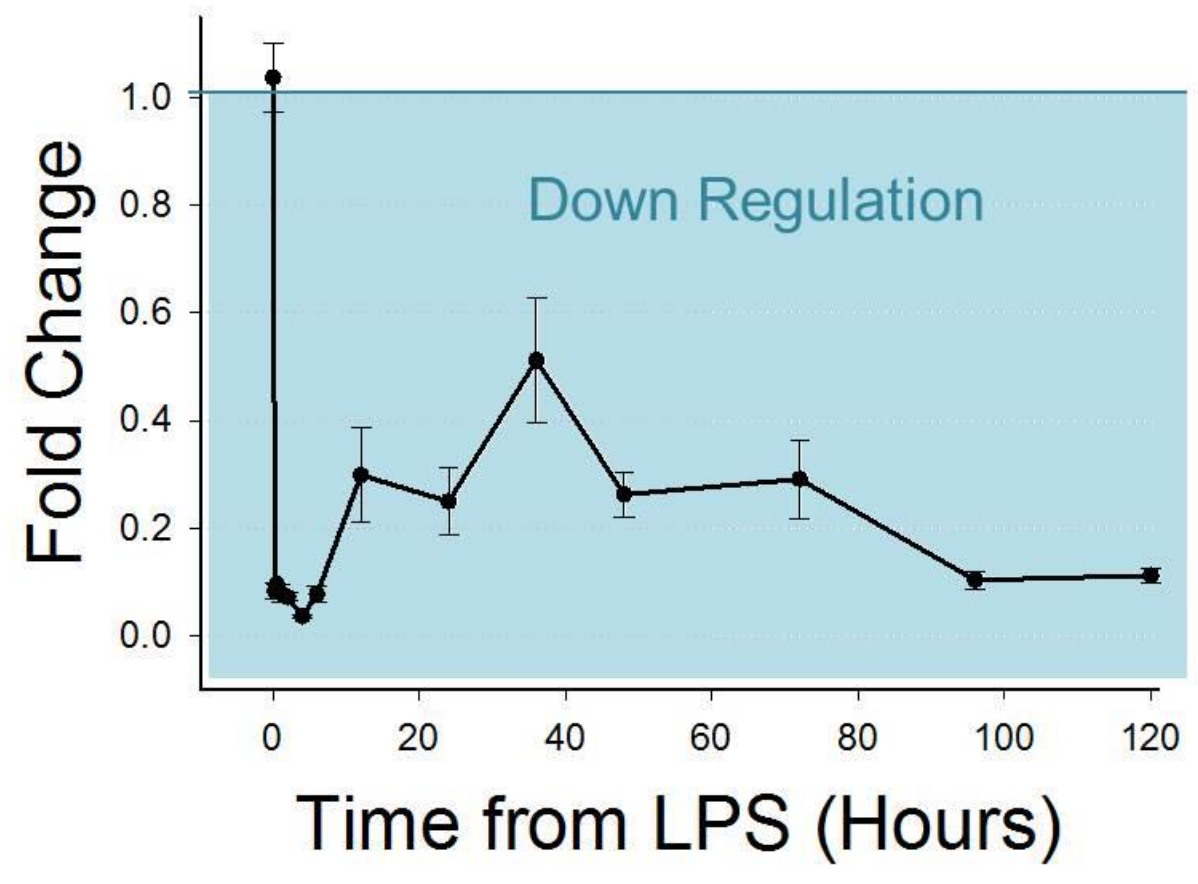

Peritoneal macrophage PDCD4 mRNA fold change after lipopolysaccharide (LPS) stimulation. $N=8$. Data are shown Mean \pm SEM. 
Figure 9: Peritoneal Macrophage Peli1 mRNA expression after Lipopolysaccharide

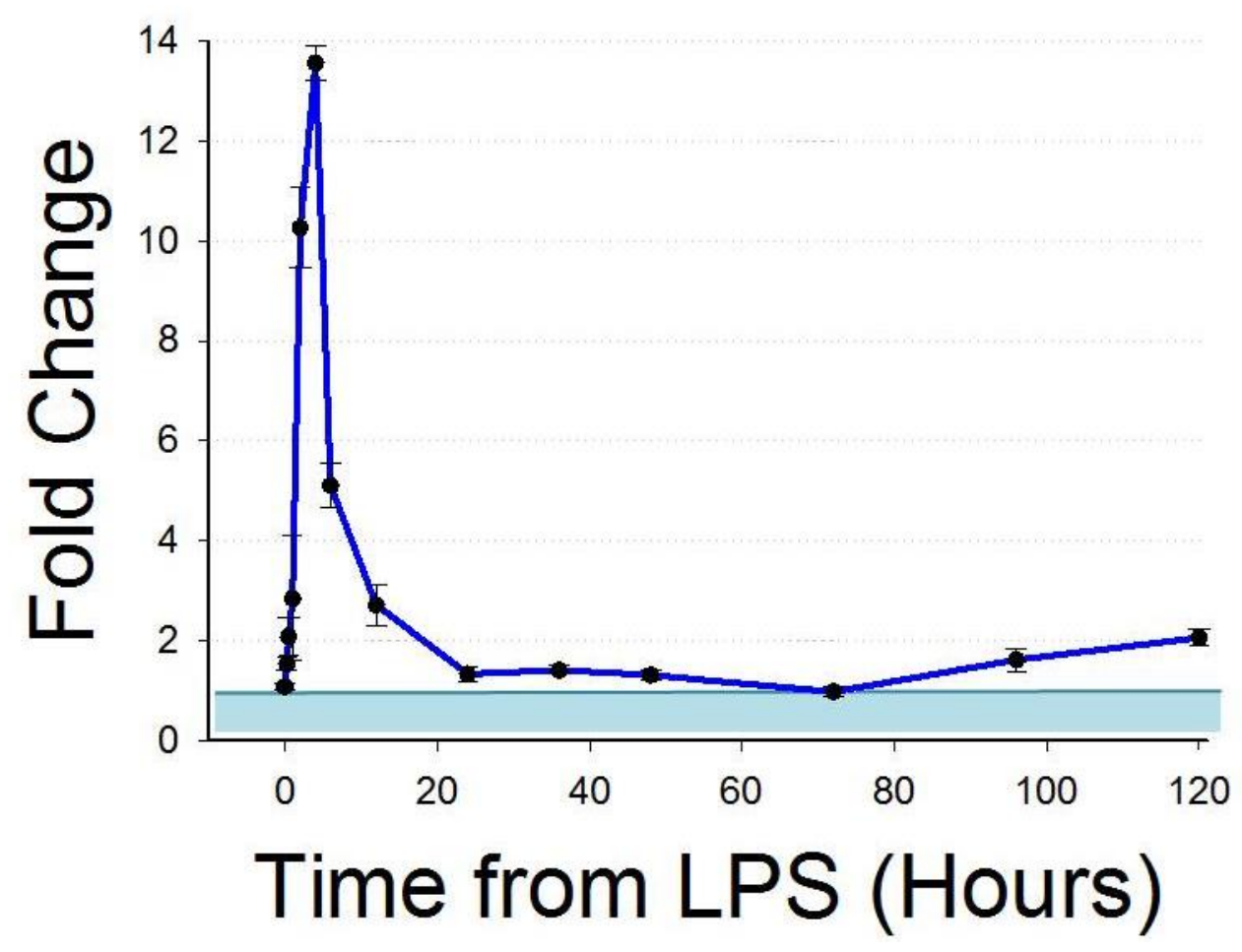

Peritoneal macrophage Peli1 mRNA fold change after lipopolysaccharide (LPS) stimulation peaked at 4 hours. $N=8$. Data are shown Mean \pm SEM. 
Figure 10: Peritoneal Macrophage SPRY mRNA expression after Lipopolysaccharide

A.

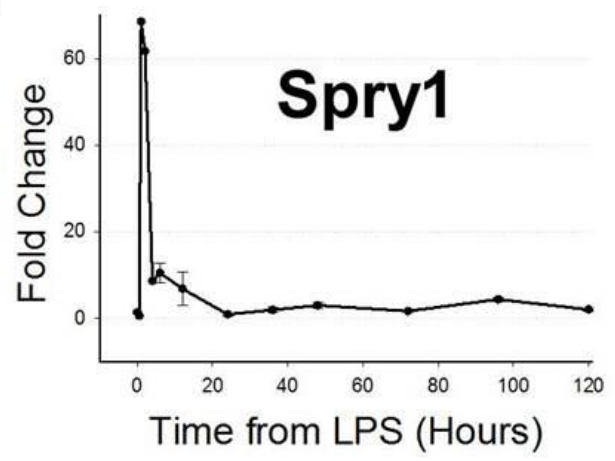

B.

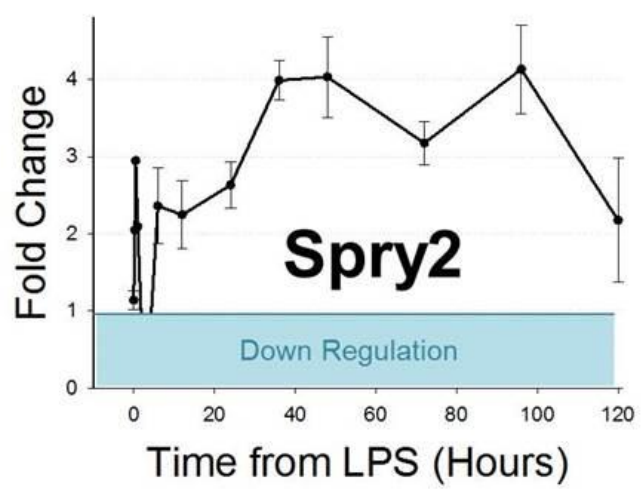

C.

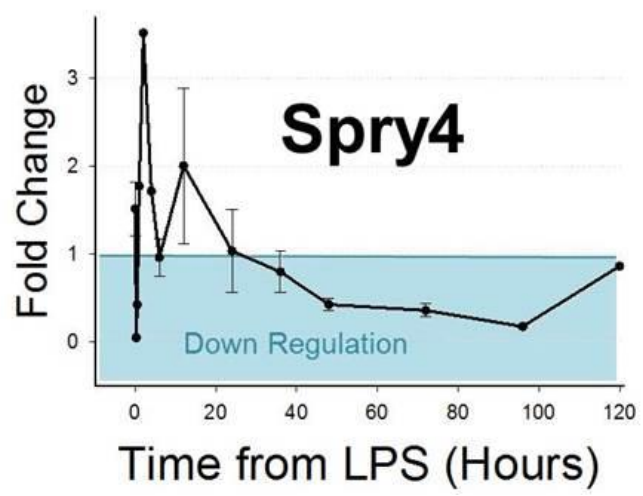

Peritoneal macrophage mRNA fold change after lipopolysaccharide (LPS) stimulation. A) SPRY 1 B) SPRY 2 C) SPRY 4. $N=8$. Data are shown Mean \pm SEM. 


\section{Discussion}

We found that there is a linear increase in the expression of miRNA-21 following LPS stimulation in primary peritoneal macrophages. This observation is consistent with previous data in a RAW264.7 mouse macrophage immortalized cell line ${ }^{51}$.

The observed rise in TNF- $\alpha$, IL-6 and IL-10 following stimulation of our macrophages-enriched population occurs, concurrently. More recent perceptions of the interactions between pro- and anti-inflammatory responses to LPS stimulation have noted that these responses occur simultaneously, though the downstream effects maybe more delayed in the classical anti-inflammatory response ${ }^{25}$. The initial decrease in the mRNA levels of PDCD4 and the steep increase seen in Peli1, SPRY1 and 4 are due to the initial stimulation with LPS. MiRNA-21 is induced steadily over time, and needs to be incorporated into the RISC before these miRNAs can act to reduce mRNA levels or affect protein translation. A delay in miRNA action is therefore expected. Together these data do not give an obvious picture of miRNA-21 effects on target mRNA and subsequent cytokine production. Confirmation of the regulatory effects of miRNA21 on TLR-4 signaling, requires modulation of miRNA-21 expression. The macrophages were rested overnight following isolation and resuspension at the required concentration. We have seen previously that centrifugation is able to activate macrophages, changing cytokine profiles, therefore in order to see the response to a single LPS challenge, and avoid any tolerance effects, we allowed the cells to return to a 'normal' state prior to LPS stimulation. 
Our observation period ended at 120 hours, as attempts at longer periods of observation resulted in unviable primary peritoneal cells. The miRNA-21 expression was still increasing at that time point, and it would be advantageous to understand for how long the miRNA-21 levels increase following LPS stimulation, to ascertain the duration of miRNA-21 effect. 


\section{CHAPTER V}

\section{MIRNA-21 HAS ANTI-INFLAMMATORY EFFECTS IN PERITONEAL}

\section{MACROPHAGES}

\section{Introduction}

We have seen that miRNA-21 expression is increased in peritoneal macrophages after LPS stimulation in vitro. The purpose of the next series of experiments was to confirm the proposed anti-inflammatory role of miRNA-21 on the production of TNF- $\alpha$ and IL-10. Based on our search of available literature, we propose that miRNA-21 decreases TNF- $\alpha$ and increases IL-10 production by a dual mechanism. Two proven targets of miRNA-21, PDCD4 and Peli1 are positive regulators of the TLR -4 signaling pathway ${ }^{36,51,61}$. Inhibition of PDCD4 and Peli1 by miRNA-21 decreases the signaling of the TLR-4 pathway and results in a decreased expression of TNF- $\alpha$ and its translation into protein, which is then secreted. In contrast, the SPRY proteins are negative regulators of the TLR-4 signaling pathway. Inhibition of SPRY expression leads to an increase in ERK activation which leads to an increase in IL-10 expression and production. Successful modulation of TNF- $\alpha$ and IL-10 secretion by manipulation of miRNA21 expression may have potential therapeutic applications. For this purpose we modulated the expression of miRNA-21 in primary peritoneal macrophages with mimics and antagomirs. 


\section{Results}

Over-expression and Suppression of miRNA-21

Transfection of both mimics and antagomirs into primary peritoneal macrophages was successful (Figure 11). The mimics achieved on average 1000- and 56-fold increase in miRNA-21 levels at 6 and 24 hours respectively $(P<0.001$ and 0.029$)$. The antagomirs suppressed miRNA by 8 -fold at 6 hours $(p<0.001)$ after LPS and 37-fold after 24 hours though this was not statistically significant. Mimic and antagomir miRNA-21 levels were compared to the negative control at that time point.

Effect of miRNA-21on TNF- $\alpha$ at 6 and 24 hours

Manipulation of miRNA-21 expression led to changes in TNF- $\alpha$ concentration at both 6 and 24 hours after LPS stimulation (Figure 12). Over-expression of miRNA-21 resulted in a significant decrease in TNF- $\alpha$ at 6 hours $(p=0.037)$ but not 24 hours. Suppression of miRNA-21 significantly increased the TNF- $\alpha$ produced at both 6 hours $(p=0.037)$ and 24 hours $(p=0.012)$.

Effect of miRNA-21on IL-10 at 6 and 24 hours

Modulation of miRNA-21 levels did not affect the levels of IL-10 at either time point after LPS stimulation (Figure 13). At 24 hours there was a trend towards increased IL-10 in the mimic-transfected macrophages; however the effects were not consistent between mice. 
Figure 11: MiRNA-21 Expression after Transfection

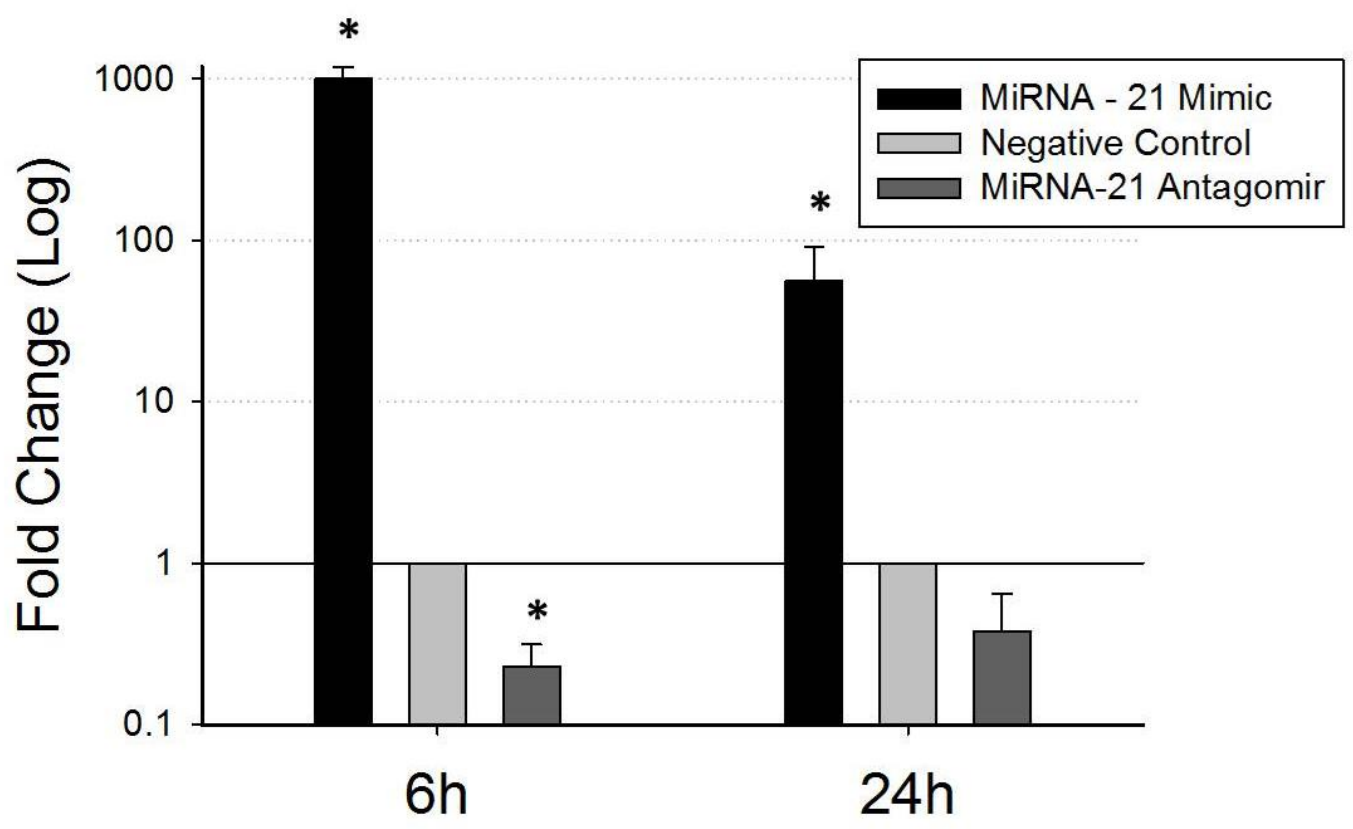

Transfection with MiRNA-21 Mimic led to significant over expression of miRNA21 at both 6 and 24 hours after lipopolysaccharide (LPS) stimulation. The use of antagomirs led suppressed miRNA-21 expression at both points, though only statistically at 6 hours. $N=9$. Data are shown Mean \pm SEM. *indicates $p<0.05$ vs. Negative Control. 
Figure 12: Effect of MiRNA-21 on TNF- $\alpha$

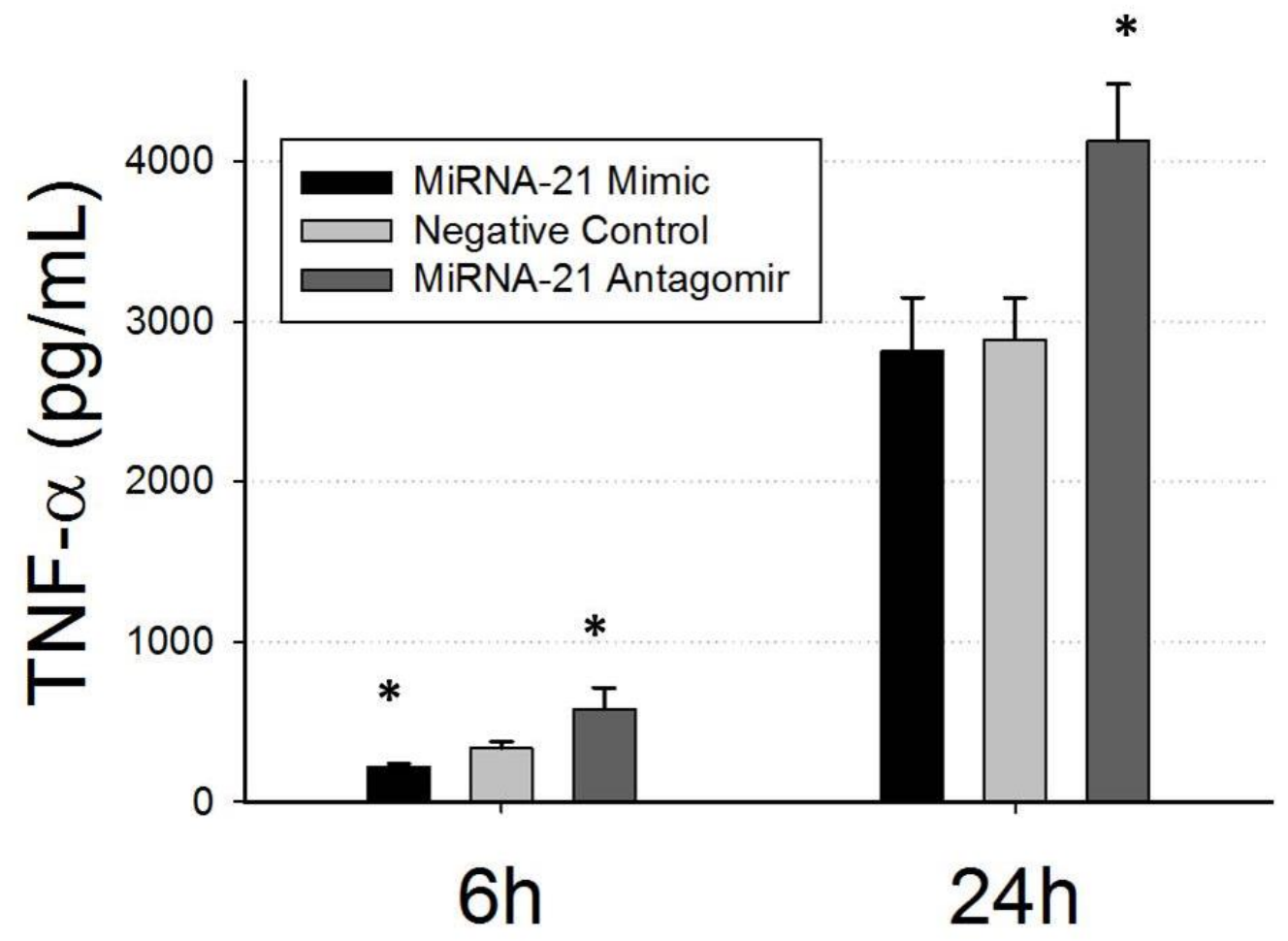

Modulation of miRNA-21 expression showed the expected results. Suppression of miRNA-21 significantly increased TNF- $\alpha$. Over expression significantly reduced TNF- $\alpha$ at 6 hours after lipopolysaccharide (LPS) stimulation but not after 24 hours. $N=9$. Data are shown Mean \pm SEM. *indicates $p<0.05$ vs. Negative Control. 
Figure 13: Effect of MiRNA-21 on IL-10

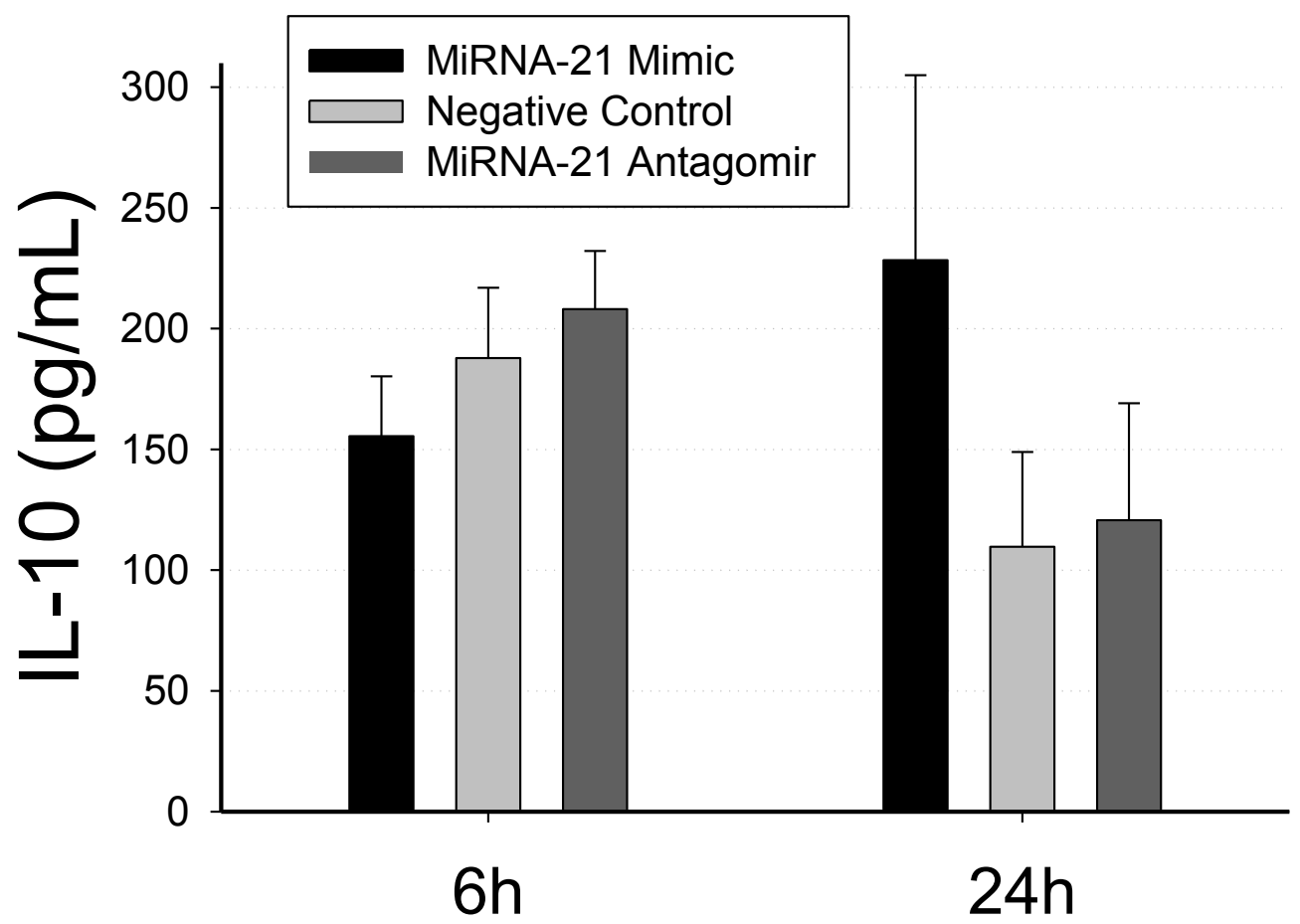

Modulation of miRNA-21 expression was not successful in modulating IL-10 secretion in primary peritoneal macrophages at either time point after lipopolysaccharide (LPS) stimulation. $N=9$. Data are shown Mean \pm SEM. 


\section{Discussion}

MiRNA-21 has anti-inflammatory effects on the primary peritoneal macrophage response to LPS. MiRNA-21 decreases the activation of the TLR-4 pathway by inhibiting PDCD4 and Peli1. These in turn decrease the activation of NF-KB and the transcription of TNF- $\alpha$, its translation into protein and subsequent release from the macrophage in response to LPS. We proposed that miRNA-21 acts to ameliorate the pro-inflammatory response by reducing levels of pro-inflammatory cytokines such as TNF- $\alpha$, though regulation of the TLR-4 MyD88 signaling cascade, likely through the actions of proved targets PDCD4 and Pelino1. MiRNA-21 also targets the Sprouty proteins which inhibit signaling in the ERK arm of the MAPK signaling cascade, suggesting an increase in miRNA-21 levels would also increase IL-10 production.

We have seen in previous experiments that miRNA-21 is induced in primary peritoneal macrophages by stimulation with LPS (Figure 5) ${ }^{51}$. At 6 hours we have a 1000 fold increase in miRNA-21 and only a 64 fold increase at 24 hours. This is due to the normalization of miRNA-21 in the transfection samples. MiRNA-21 levels in the negative control are physiologically lower at 6 hours compared to those seen at 24 hours, and therefore provide a lower baseline for comparison. Modulation of miRNA-21 expression is sufficient to significantly change TNF- $\alpha$ expression in all cases except in the mimic-transfected cells at 24 hours. This may be due to competing endogenous RNAs (ceRNAs). Recent literature has suggested a new component to miRNA regulation, the miRNA sponge or ceRNAs ${ }^{96-99}$. These miRNA sponges contain multiple binding sites for 
the miRNA of interest, and can act as effectively as artificial antisense oligonucleotides ${ }^{100}$. Therefore the artificial up-regulation of miRNA-21 in peritoneal macrophages by mimics could be counteracted by a known or unknown mRNA target acting as a ceRNA. Each miRNA has hundreds of potential targets based on gene sequencing, with only a few experimentally verified. A miRNA sponge for miRNA-21 has not yet been identified, however PTEN, a target of miRNA-21 in tumor cells has been implicated in other networks 101.

In these experiments, miRNA-21 expression in peritoneal macrophages peaks at a 10 fold up-regulation at 120 hours after LPS stimulation. Contrastingly, we see a thousand fold up-regulation in the mimic-transfected macrophages, but this is still insufficient to elicit a significant change in the IL-10 production. There is no difference in IL-10 concentrations at either time point, though there is a trend towards higher levels in the mimic-transfected macrophages at 24 hours. We proposed that the effects of miRNA-21 on IL-10 production are regulated through the ERK signaling cascade. MiRNA-21 inhibits the Sprouty proteins, which in turn inhibit the ERK cascade. There are 4 Sprouty isoforms, all of which are theoretical targets of miRNA-21. Higher levels of miRNA-21 may be required to sufficiently inhibit the protein levels, in order to see a change in IL-10 production, even at 24 hours. We have shown that successful transfection of peritoneal macrophages results in changes in TNF- $\alpha$ concentrations, which are directly linked to survival in sepsis. 


\section{CHAPTER VI}

\section{MIRNA-21 HAS ANTI-INFLAMMATORY EFFECTS IN BONE MARROW}

\section{MACROPHAGES}

\section{Introduction}

In previous experiments we have seen that successful inhibition of miRNA-21 with antagomir-transfected primary peritoneal macrophages resulted in lower levels of TNF- $\alpha$ production. The purpose of the next experiment was to confirm these results in a macrophage cell line utilizing miRNA- $21^{+/+}$and miRNA-2 $21^{-/-}$ bone marrow derived macrophage cell lines. Inhibition of endogenous miRNAs with transfection is often incomplete, as transfection efficiency can vary from cell to cell within a treated sample. However, the use of an immortalized cell line from transgenic mice will likely yield novel data as to the importance of the gene in regulation of the TLR-4 signaling pathway.

We propose that using the miRNA-21/- bone marrow derived macrophage cell line will add important additional data regarding miRNA-21 regulation of the pattern of cytokine production following LPS stimulation. 


\section{Results}

Effect of miRNA-21 knockdown on TNF- $\alpha$

MiRNA-21 knockdown was confirmed by PCR. Knockdown of miRNA-21 expression led to changes in TNF- $\alpha$ concentration from 6 hours after LPS stimulation (Figure 14). TNF- $\alpha$ concentration was significantly higher at 6 and 24 hours $(p<0.05)$, and trending towards significance at 48 hours $(p=0.059)$ in the miRNA-2 $1^{-/-}$macrophages.

Effect of miRNA-21 knockdown on IL-6

IL-6 concentration also changed after LPS stimulation in miRNA-21 $1^{-1}$ macrophages (Figure 15). IL-6 was significantly higher at 24 and 48 hours $(p<0.05)$ in the miRNA-21/- macrophages.

Effect of miRNA-21 knockdown on IL-10

Knockdown of miRNA-21 expression led to changes in IL-10 concentration at early time points after LPS stimulation (Figure 16). The concentration of IL-10 in the cell culture media was significantly lower from 1 hour after LPS in the miRNA$21^{-/-}$macrophages and did not reach miRNA-2 $1^{+/+}$levels until 24 hours $(p<0.05)$.

Effect of miRNA-21 on target proteins

PDCD4 protein abundance was similar in both miRNA- $21^{+/+}$and miRNA-21-1macrophages both at baseline before LPS stimulation and 24 hours afterwards (Figure 17). No difference was detected in Peli1 protein abundance at 24 hours after LPS stimulation (Figure 18). SPRY 1 and 2 protein levels were not different 
Figure 14: TNF- $\alpha$ in Bone Marrow derived Macrophages

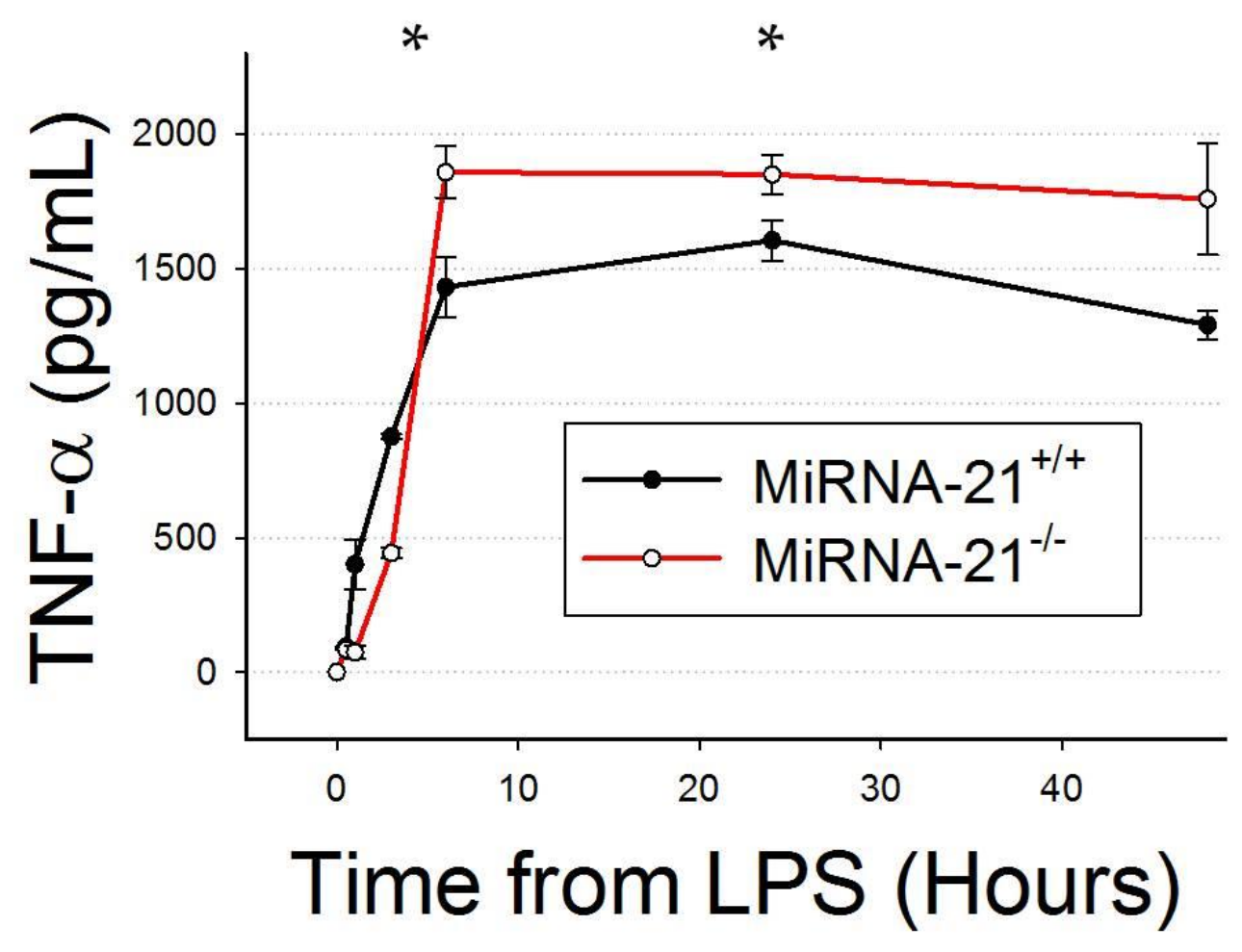

Knockdown of miRNA-21 led to significant increase in TNF-a levels following lipopolysaccharide (LPS) stimulation. $N=8$. Data are shown Mean $\pm S E M$. *indicates $p<0.05$ 
Figure 15: IL-6 in Bone Marrow derived Macrophages

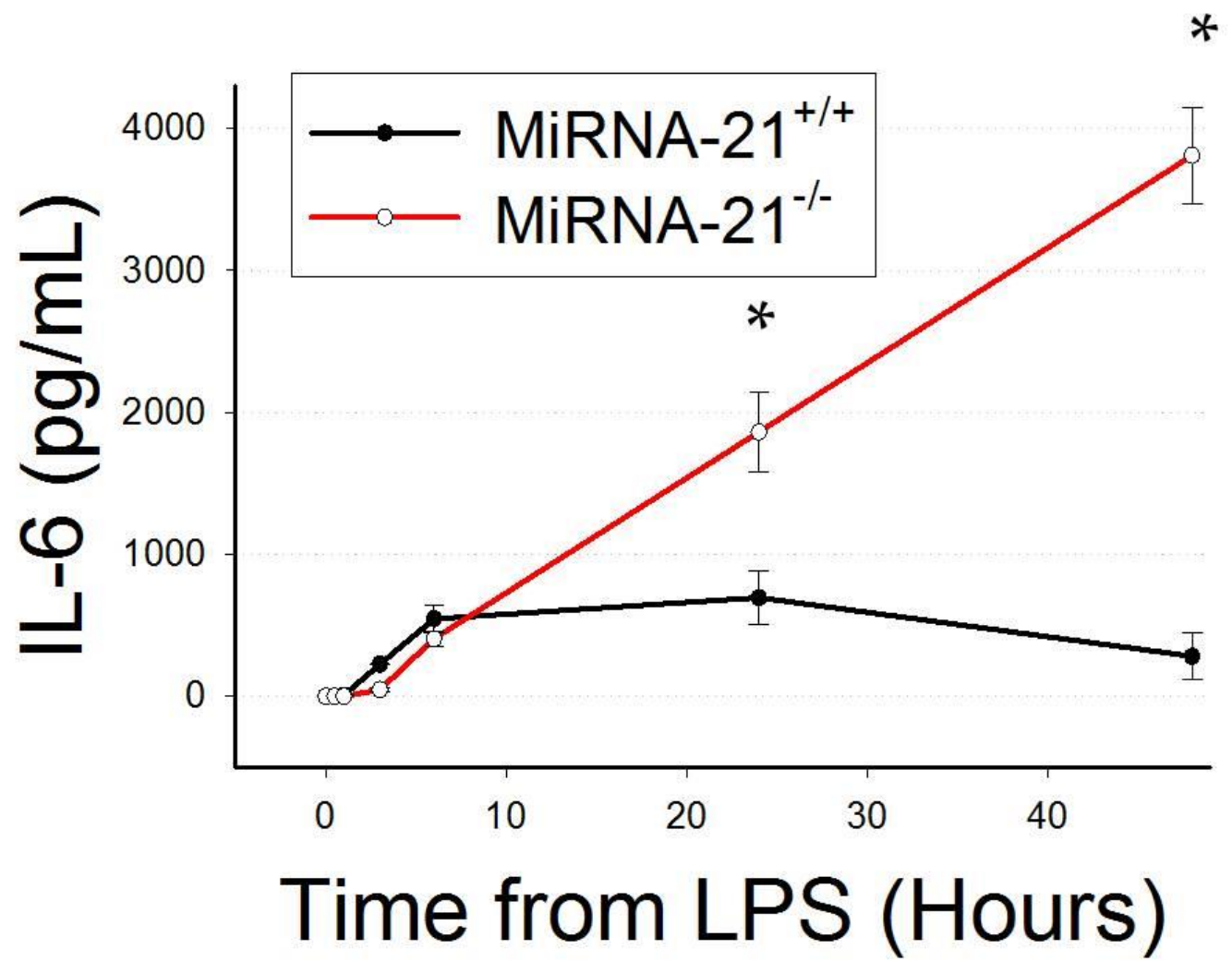

Knockdown of miRNA-21 led to significant increase in IL-6 levels following lipopolysaccharide (LPS) stimulation. $N=8$. Data are shown Mean \pm SEM. ${ }^{*}$ indicates $p<0.05$. 
Figure 16: IL-10 in Bone Marrow derived Macrophages

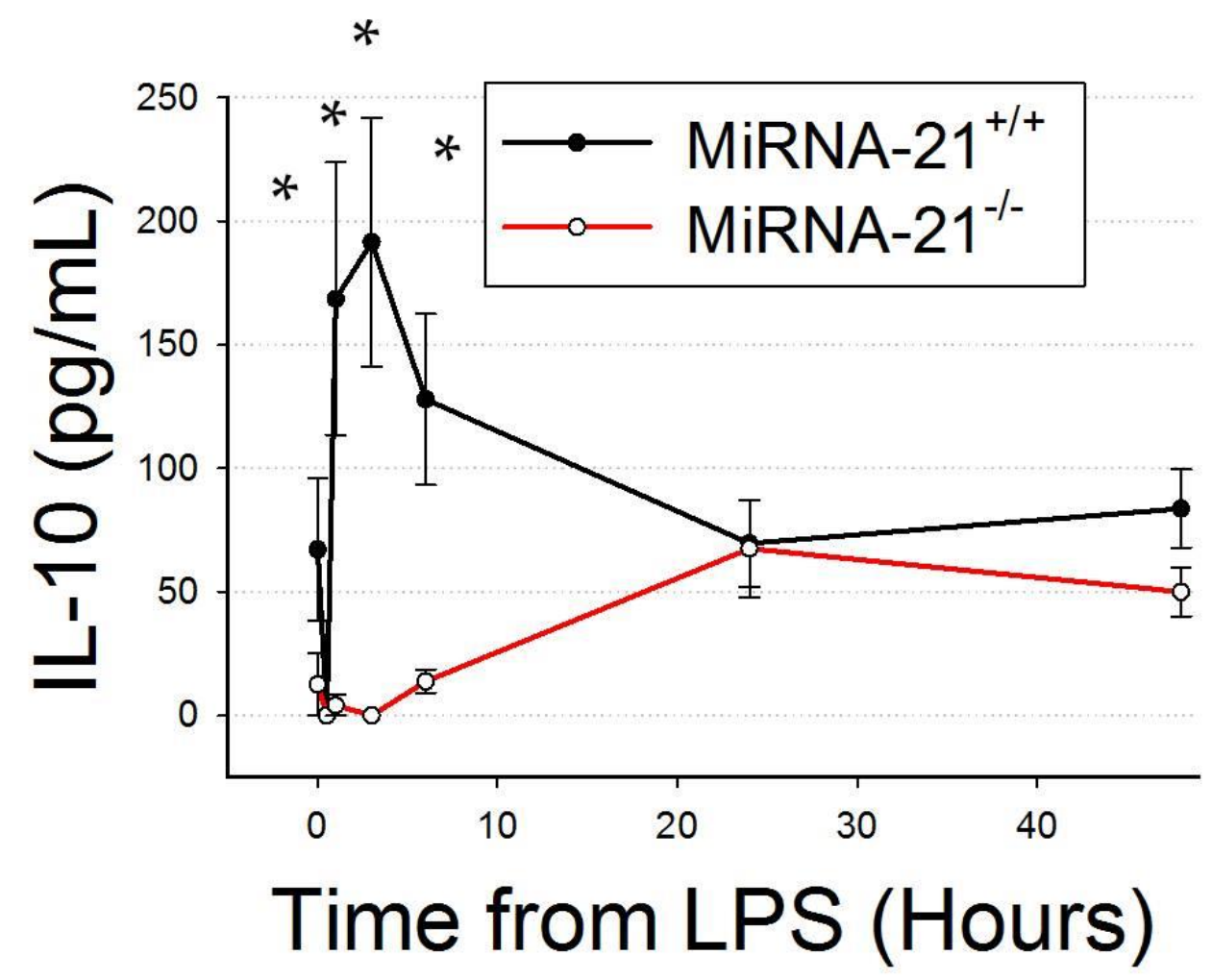

Knockdown of miRNA-21 led to significant decrease in IL-10 levels at early time points following lipopolysaccharide (LPS) stimulation. $N=8$. Data are shown Mean \pm SEM. *indicates $p<0.05$ 
Figure 17: PDCD4 in Bone Marrow derived Macrophages

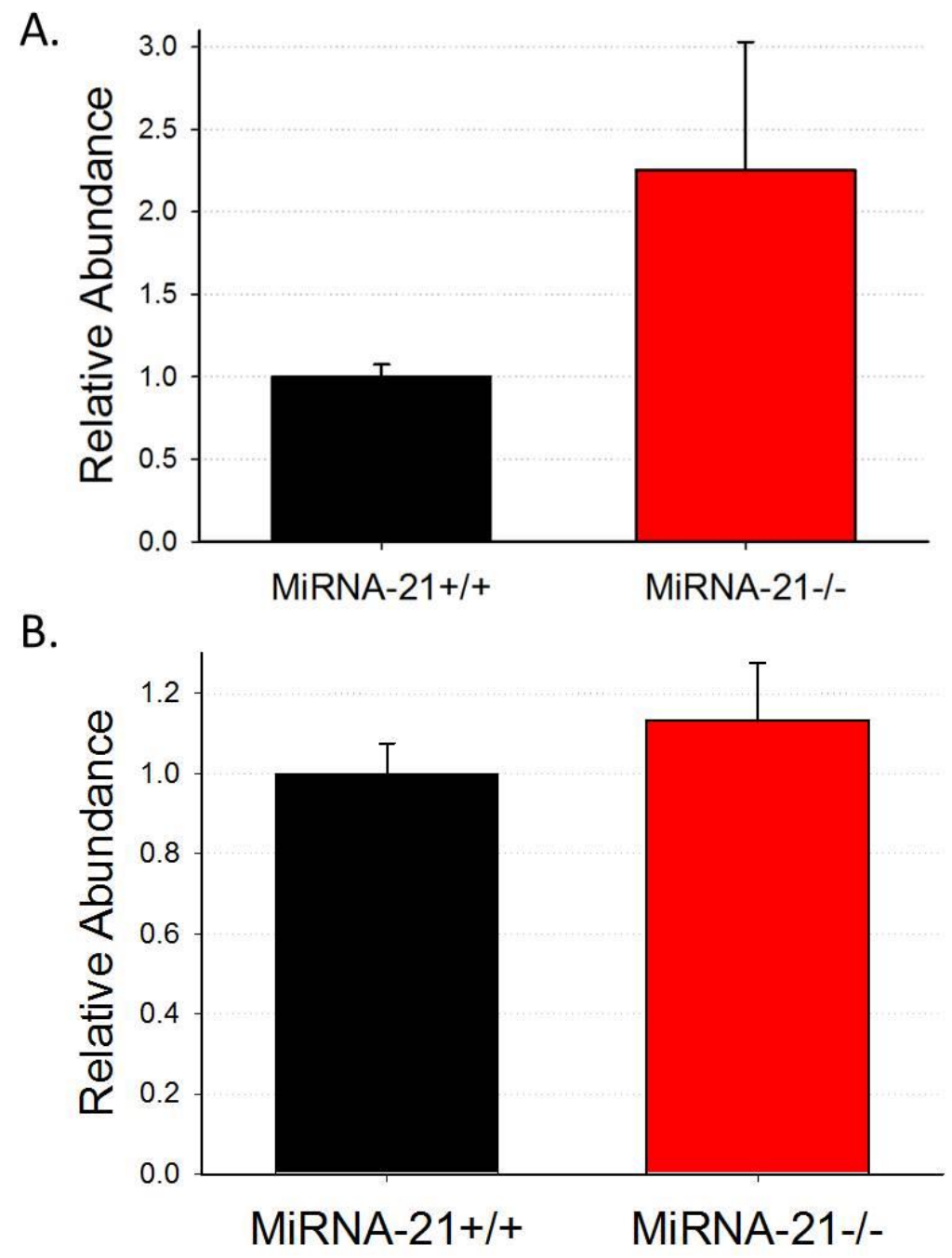

Knockdown of miRNA-21 did not lead to a significant change in PDCD4 protein at $A$ ) Baseline or B) 24 hours following lipopolysaccharide (LPS) stimulation. $N=3$ Data are shown Mean \pm SEM. 
Figure 18: Peli1 in Bone Marrow derived Macrophages

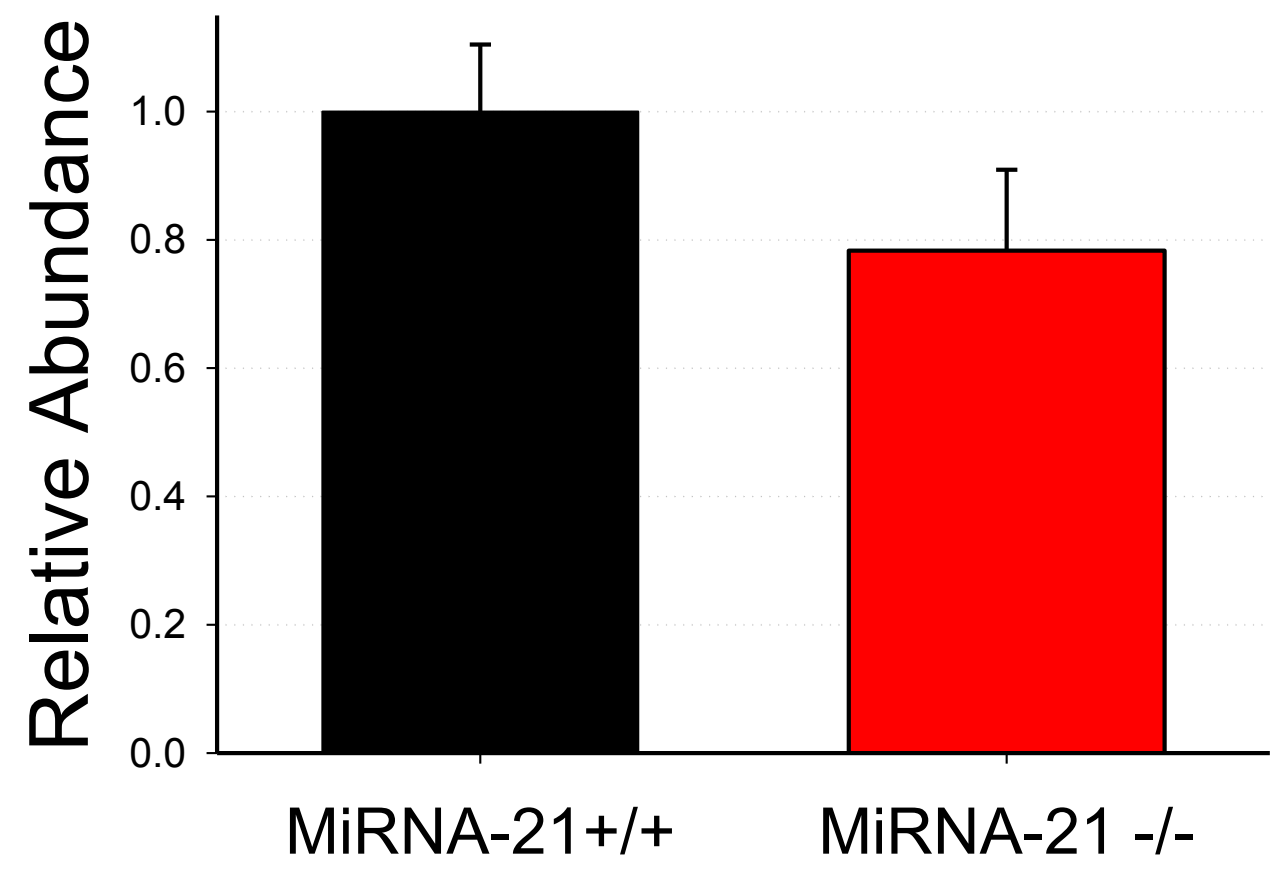

Knockdown of miRNA-21 did not lead to a significant change in Peli1 protein at 24 hours following lipopolysaccharide (LPS) stimulation. $N=4$. Data are shown Mean \pm SEM. 
between miRNA-21 $1^{+/+}$and miRNA-21 $1^{-/-}$macrophages 24 hours after LPS stimulation (Figure 19). SPRY 4 protein was not detectable in either cell line after 24 hours with LPS.

\section{Discussion}

Knockdown of miRNA-21 in the bone marrow derived macrophage cell line confirmed the anti-inflammatory effects of miRNA-21 seen on TNF- $\alpha$ concentrations in the antagomir-transfected primary peritoneal macrophages. Concentrations of another pro-inflammatory cytokine IL-6, were also significantly higher after LPS stimulation in miRNA-21 $1^{-/-}$compared to miRNA-2 $1^{+/+}$ macrophages, though at later time points. From our data in primary peritoneal cells, we observed that Peli1 mRNA expression is induced by LPS stimulation, at a faster rate than miRNA-21. The time taken for miRNA-21 to be transcribed, processed, incorporated into the RISC and to act on Peli1 mRNA may be the delay observed between LPS stimulation and the change in TNF- $\alpha$ production seen between miRNA- $21^{+/+}$and miRNA- $21^{-/-}$macrophages.

In the transfected primary peritoneal macrophages we were surprised not to see any changes in IL-10 concentration with either the mimics or antagomirs. The miRNA-2 $21^{-/}$macrophages had significantly lower levels of IL-10 at early time points after LPS stimulation. MiRNAs act by inhibiting protein translation; therefore if a miRNA is constitutively turned off, as in knockout cells, we propose that there will be higher baseline levels of that protein expressed within the cell. 
Figure 19: SPRY 1 and 2 in Bone Marrow derived Macrophages

A.

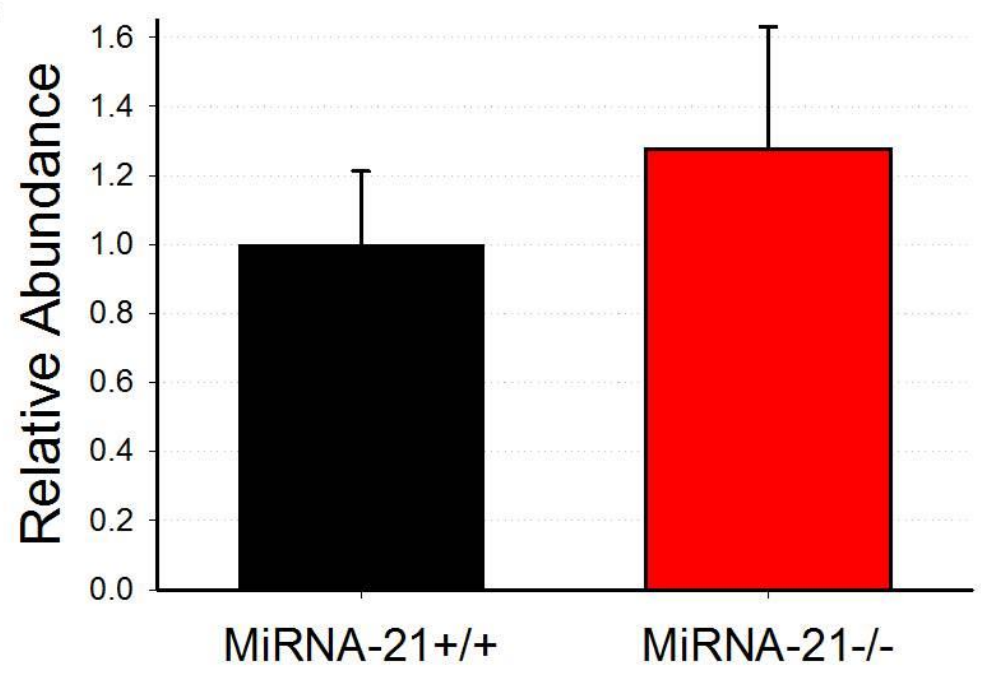

B.

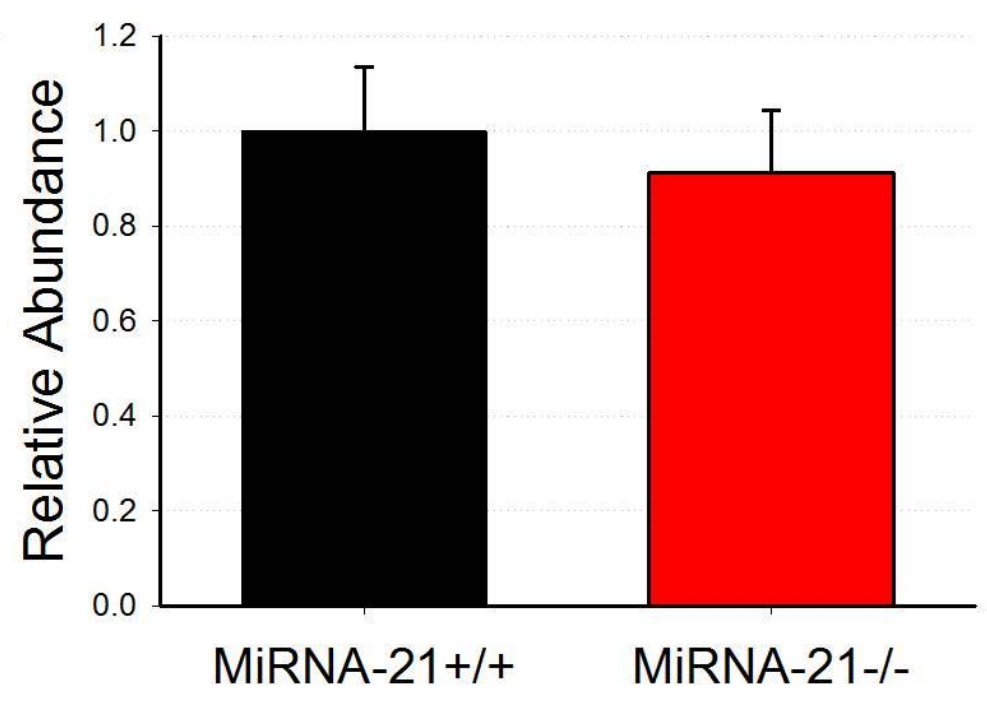

Knockdown of miRNA-21 did not lead to a detectable change in A) SPRY 1 or B) $S P R Y 2$ levels at 24 hours following lipopolysaccharide (LPS) stimulation. $N=4$ Data are shown Mean \pm SEM. 
Sprouty proteins inhibit the ERK signaling cascade, which in turn leads to a reduced IL-10 expression; this correlates with the lower levels of IL-10 seen in the miRNA-2 $21^{-1-}$ macrophages, where we would expect to see higher levels of Sprouty.

The observed changes in cytokine production between miRNA- $21^{+/+}$and miRNA$21^{-/-}$cells leads to an expectation that we will detect associated differences in the miRNA-21 target proteins, with higher levels present in the miRNA-21-1- cell lines. There was a trend towards higher levels of PDCD4 at baseline (no LPS) in the miRNA-21-1- cell line (Figure 17A). However, at 24 hours no difference was detectable.

PDCD4 protein has been shown to be reduced following LPS stimulation at 24 hours in RAW264.7 cells, mouse bone marrow derived macrophages and human peripheral blood monocytes, with the same dose as used in these experiments ${ }^{51}$. Knockdown of PDCD4 protein levels was shown with pro-miRNA21 in RAW264.7 cells with and without LPS stimulation. This is contrary to what we saw in our results. This may be due to differences in cell culture concentrations, as we increased our cell concentration in order to increase the protein yield for western blot samples. The difference in protein levels may be more subtle than we are able to detect.

We did not discern any significant difference between the levels of Peli1, SPRY 1,2 or 4 at 24 hours after LPS stimulation. Peli $1^{-/}$mice have been used to ascertain the impact of Peli1 on LPS signaling through TLR-4, however the link 
between miRNA-21 and Peli1 has only been studied in liver regeneration, and there was no causal time delay between miRNA-21 up-regulation and the changes in Peli1 mRNA ${ }^{36,61}$. There are no data with which to compare our Peli1 protein findings in macrophages after LPS.

SPRY proteins have not previously been directly linked to TLR-4 signaling, though they have been shown to inhibit p38 in the MAPK pathway of interferon receptor signaling in mouse embryonic fibroblasts ${ }^{102}$. The experimental verification of SPRY proteins as targets of miRNA-21 have occurred in other nonmacrophage cell types ${ }^{73,92}$. SPRY proteins are induced by ERK activation ${ }^{66}$. The similarities between the abundance in both miRNA- $21^{+/+}$and miRNA-2 $21^{-/-}$ macrophage cell lines may be because the SPRY proteins do not have an important role to play in TLR-4 signaling. Further experiments using either silencing RNA (siRNA) or SPRY protein knockouts will add data to inform whether SPRY proteins modulate TLR-4 signaling.

We have corroborated our previous data that miRNA-21 changes the macrophage cytokine profile in response to LPS stimulation. We believe that he likely candidate as the most important miRNA-21 target protein in regulating TLR-4 signaling from our data is PDCD4. 


\section{CHAPTER VII}

\section{MIRNA-21 AFFECTS NF-KB AND ERK SIGNALING IN BONE MARROW}

\section{MACROPHAGES}

\section{Introduction}

Intracellular signaling pathways allow cells to respond to external stimuli. Pattern recognition receptors on both the cell surface and within the cell identify pathogen associated molecular proteins to activate an appropriate immune response. Two important pathways in macrophages are the NF-kB and MAPK pathways. Activation of these pathways results in the release of cytokines to orchestrate the immune response to the invading pathogen. Cytokines act both locally and systemically. Pro-inflammatory cytokine release leads to the local recruitment of immune cells from the vasculature, and also the development of the systemic acute phase response and fever. These effects combine to enhance host defense against such pathogens and directly combat the infection.

Manipulation of these pathways therefore has the potential to affect the way macrophages respond to pathogens. MiRNA-21 has been shown to inhibit the production of PDCD4 and Peli1 proteins which both affect the TLR-4 signaling cascade ${ }^{51,61}$. Knockout of Peli1 affects NF-KB activation following LPS 
stimulation ${ }^{36}$. The ERK arm of the MAPK pathway in macrophages has been previously linked to IL-10 production ${ }^{88}$. SPRY proteins have been shown to inhibit the ERK signaling pathway ${ }^{66,69,103}$. SPRY proteins are targets of miRNA$21^{73,92}$.

We propose that knockout of miRNA-21 will lead to increased NF-kB activation which would explain the higher levels of TNF- $\alpha$ seen after LPS stimulation in these cells. We also hypothesize that decreased ERK activation in the miRNA$21^{-/-}$macrophages may account for the lower levels of IL-10 seen at the early time points.

\section{Results}

Activation of the NF-KB pathway

There was a maximal increase in the levels of NF-kB 10 minutes after LPS stimulation (Figure 20). This elevation continued throughout the observed 2 hour period. There was no difference in activation between miRNA- $21^{+/+}$and miRNA$21^{-1-}$ bone marrow derived macrophages. Where comparing relative activation, the cells were more similar.

\section{Activation of the ERK pathway}

The pattern of ERK phosphorylation after LPS stimulation is unclear (Figure 21). The relative activation shows a higher peak in the miRNA- $21^{+/+}$macrophages than miRNA-2 $1^{-1-}$ cells. 
Figure 20: NF-kB Activation after Lipopolysaccharide in Bone Marrow derived Macrophages

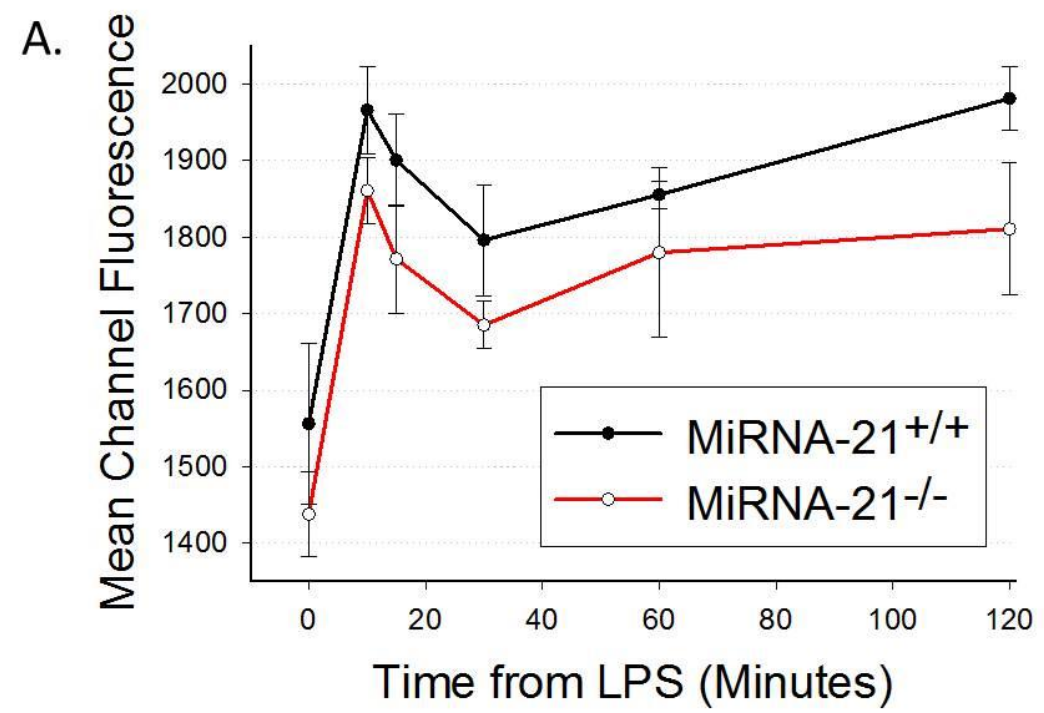

B.

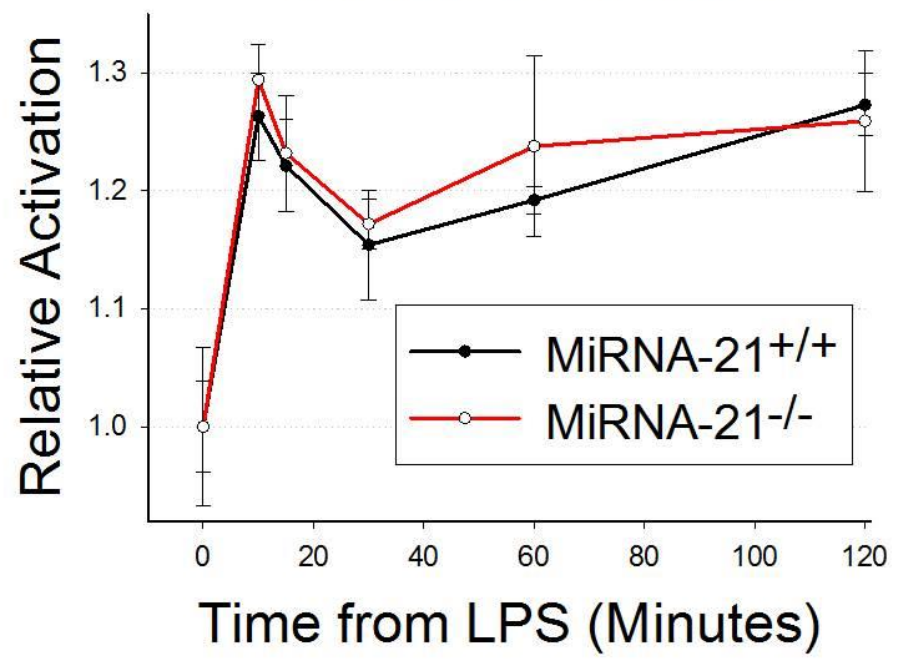

Activation of NF-KB p65 subunit was not different between miRNA-21 $1^{+/+}$and miRNA-21\% bone marrow derived macrophage cell lines after lipopolysaccharide (LPS) stimulation. A) Mean channel fluorescence B) Relative Activation. $N=4$. Data are shown Mean \pm SEM. 
Figure 21: ERK Activation after Lipopolysaccharide in Bone Marrow derived Macrophages

A.

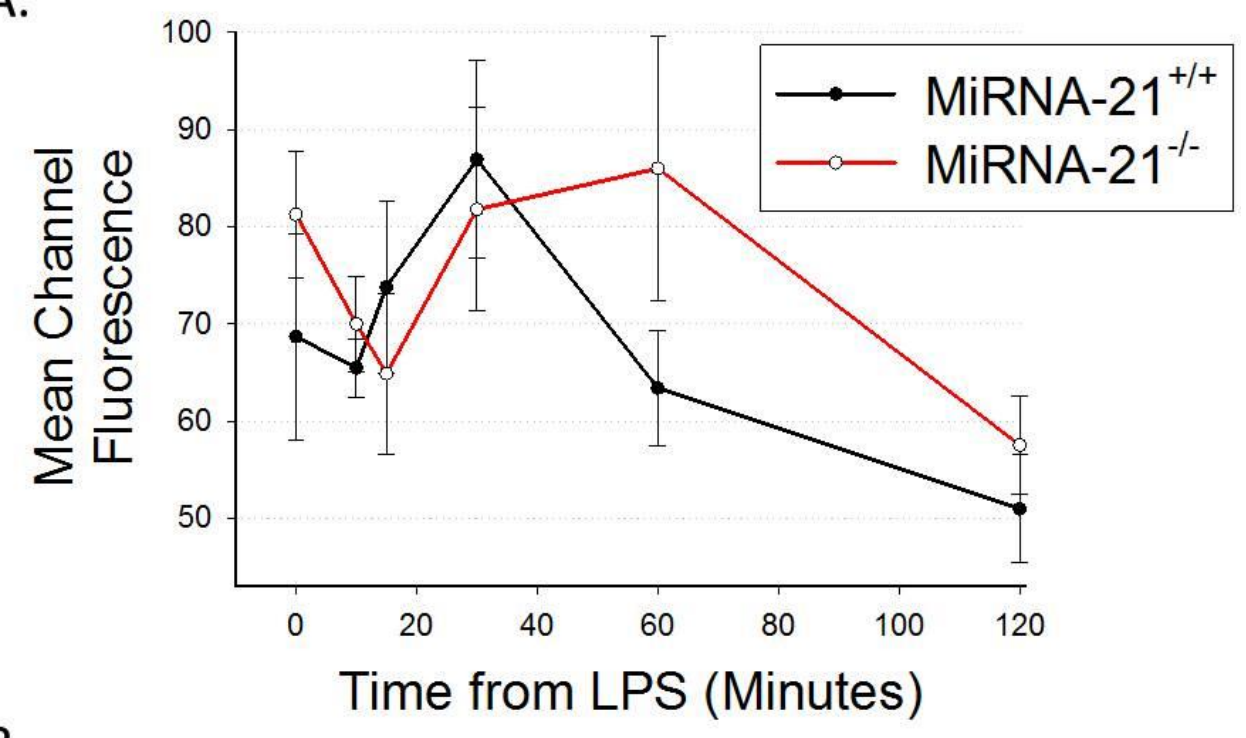

B.

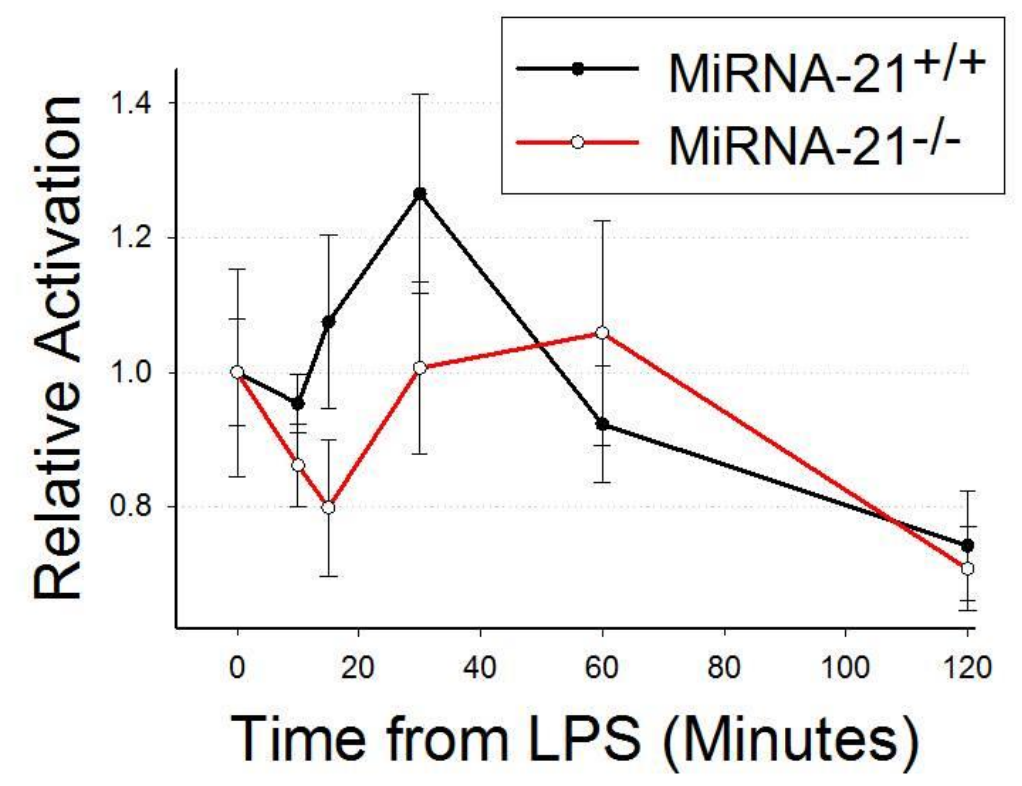

Activation of ERK was not significantly different between miRNA-21 $21^{+/+}$and miRNA-21\% bone marrow derived macrophage cell lines after lipopolysaccharide (LPS) stimulation. A) Mean channel fluorescence B) Relative Activation. $N=4$. Data are shown Mean \pm SEM. 


\section{Discussion}

Changes in TNF- $\alpha$ production have been shown to be associated with NF-KB activation ${ }^{77,}{ }^{78}$. However, we were unable to show an association in this experiment between the production of miRNA-21 and the activation of NF-KB despite changes in TNF- $\alpha$ between the cell lines (Figure 14). We did show the speed at which NF-KB is activated following LPS stimulation, and that it continues for at least 2 hours (Figure 20). There are 5 subunits of NF-kB, and we only studied activation of p65, it may be that another subunit is important for miRNA21 related effects, as the NF-KB p50 subunit is the key regulator in LPS-tolerant transition to a M2 polarized phenotype in macrophages ${ }^{104}$.

The pattern of ERK activation seen in our bone marrow macrophage cell lines is unclear. The relative activation shows a higher peak in the miRNA-21/+ macrophages which has been noted to correlate with higher IL-10 levels ${ }^{79,88}$.

The absence of a difference seen between these cell lines maybe related to the cell type. These are immortalized bone marrow derived macrophages that are grown in cell culture and split before they become confluent. They are not peritoneal macrophages that have been nurtured in an organic environment, and the long-term culture may have affected the signaling pathways.

There is also a question of how closely bone marrow derived macrophages are related to peritoneal macrophages. Although a recent study shows that peritoneal macrophages have increased expression of proteases and acute phase factors, with down regulation of the production of several chemokines compared to blood 
monocytes. There are other studies that show that the monocytes present in blood migrate to the tissues including the peritoneum to become resident macrophages ${ }^{105,106}$. Further work has been done by Ghosn who identified 2 subgroups of $\mathrm{CD} 11 \mathrm{~b}+\mathrm{F} 4 / 80+$ macrophages found within the peritoneal cavity ${ }^{107}$. These have been termed large and small peritoneal macrophages due to size distinctions. Large peritoneal macrophages make up $90 \%$ of the peritoneal macrophage population in the naive abdomen and have higher levels of CD11b and F4/80. Both are able to phagocytose bacteria. Two days after LPS stimulation, the small macrophages become the dominate cell type, and cell marker data suggests that they have differentiated from blood monocytes. Despite the absence of evidence seen in this experiment, we can extrapolate that miRNA-21 affects the TLR-4 signaling pathway, though the changes to NF-KB and ERK activation may be too subtle for us to detect with this technique. 


\section{CHAPTER VIII \\ INFLUENCE OF MIRNA-21 ON SURVIVAL IN \\ LIPOPOLYSACCHARIDE PERITONITIS}

\section{Introduction}

Despite having a tried and tested treatment for peritonitis and the ability to predict those with a higher risk of morbidity and mortality with various scoring systems, we still do not know why some patients are unable to contain and eliminate an infection, resulting in a persistence of bacteria in the peritoneum. Some investigators have theorized that this is due to a failure of the host immune response to clear the infection, and that augmentation or modulation of the immune response may benefit bacterial clearance in these patients. Several immune-modulators have been tested in clinical trials following success in a lab environment, however without success in a clinical setting ${ }^{16,17}$.

Recent studies have shown that mice with knockdown of PDCD4 and Pelino 1 genes have a greater survival to LPS peritonitis than their wild type counterparts 36, 51. These proteins affect downstream signaling of TLR-4 through MyD88 and NF-KB. MiRNA-21 has been shown to target both these proteins and is itself induced after LPS administration in macrophages ${ }^{51}$. Based on these data we predicted that miRNA-21 knockout mice would have a decrease survival 
to induced peritonitis. MiRNA-21 production is stimulated through TLR-4 signaling, so we used a model of intra-peritoneal LPS to induce peritonitis. LPS is considered to be an important inducer of the septic response and intra-peritoneal LPS is more likely to induce a hyperdynamic cardiovascular response than intravenous (IV) administration and is thus a better model for the human condition ${ }^{16}$.

\section{Results}

\section{Lipopolysaccharide Peritonitis}

Surface temperature and weight decreased in all mice following induction of peritonitis with LPS (Figures 22 and 23). Failure to regain temperature and weight was predictive of subsequent death. The miRNA- $21^{+/+}$mice began to die after 24 hours, the miRNA-21/- mice after 40 hours (Figure 24). Significantly, more miRNA-21 $1^{-/-}$mice died compared with miRNA-2 $21^{+/+}$mice $(p=0.002)$.

\section{Discussion}

This study was performed in a constant room temperature at $28^{\circ} \mathrm{C}$, and all mice had reduced their body temperature following intra-peritoneal administration of LPS. This is typical of the response seen to induced sepsis in mice; however in patients the induction of fever is seen. Recent data suggest that the surroundings 
Figure 22: Mouse Surface Temperatures after Lipopolysaccharide Peritonitis

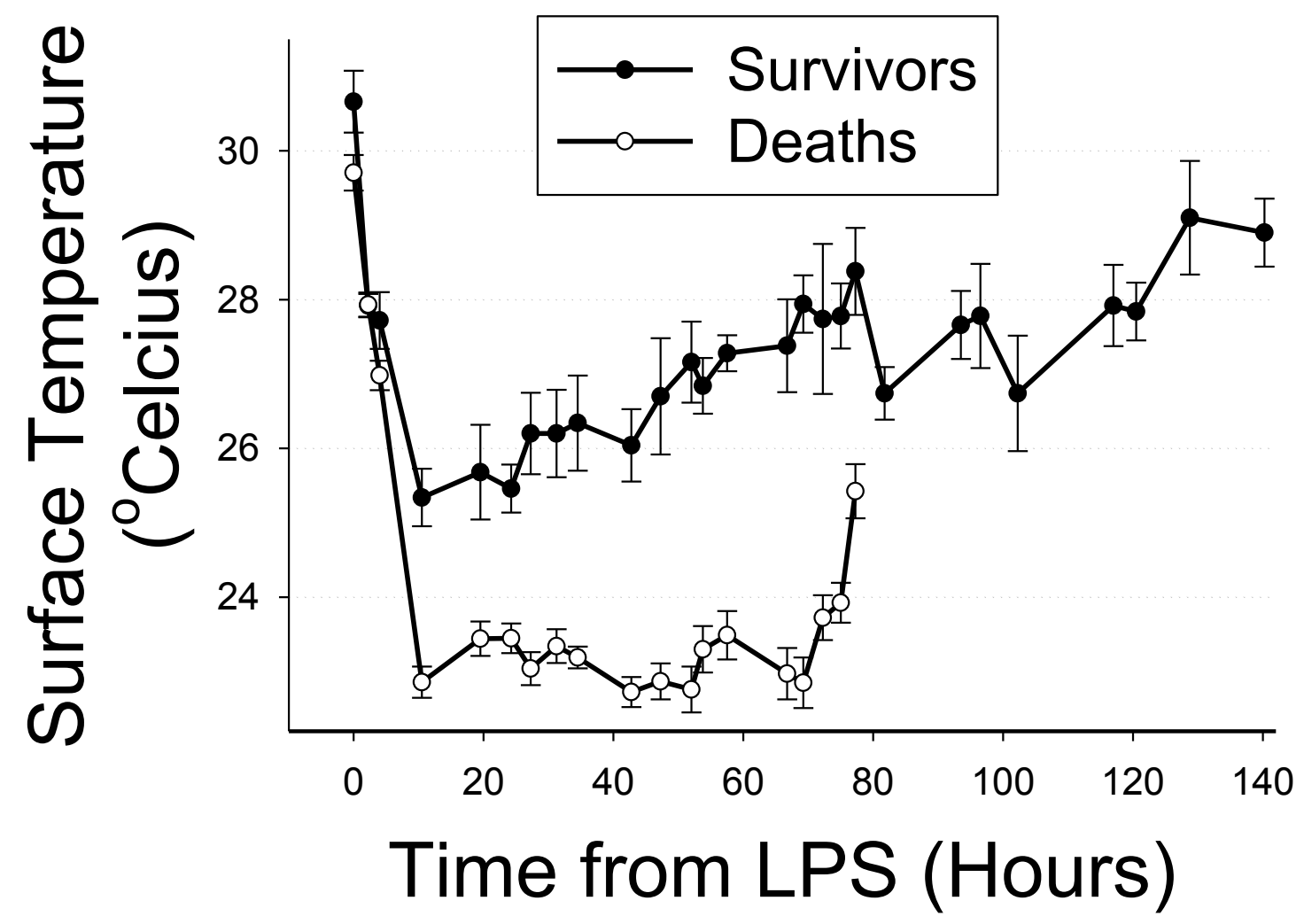

Surface temperature decreased in all mice following intra-peritoneal administration of lipopolysaccharide (LPS). The mice that died during the observation period remained lower than those that survived. MiRNA-21+/+ and miRNA-21\% mice were included in this figure. Survivors $N=5$, Deaths $N=21$. Data are shown Mean \pm SEM. 
Figure 23: Mouse Weight after Lipopolysaccharide Peritonitis
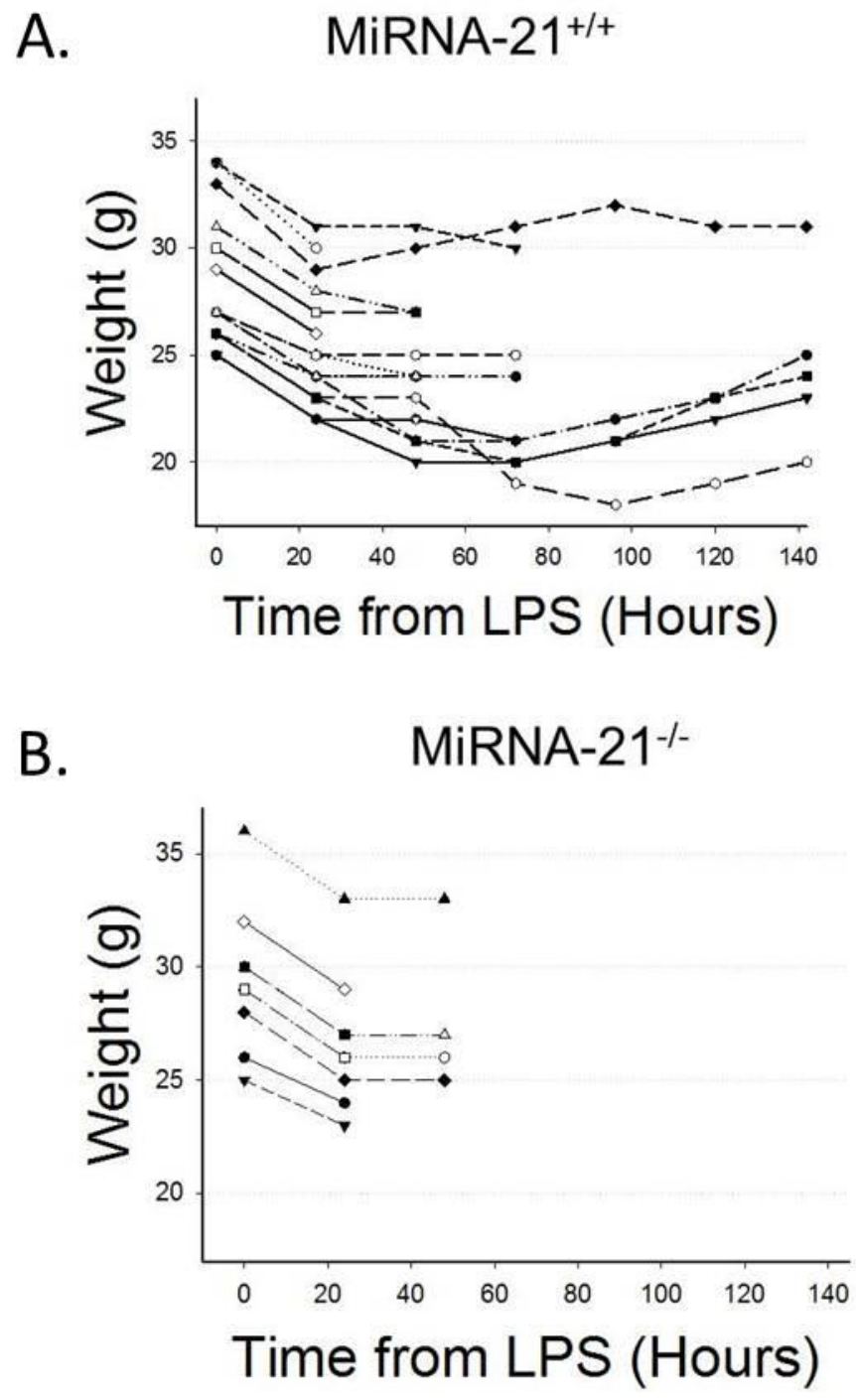

Weight decreased in all mice following intra-peritoneal administration of lipopolysaccharide (LPS). The mice that died during the observation period did not recover the weight lost. Mice that survived were regaining weight by the

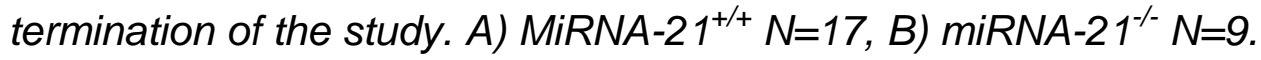


Figure 24: Survival after Lipopolysaccharide Peritonitis

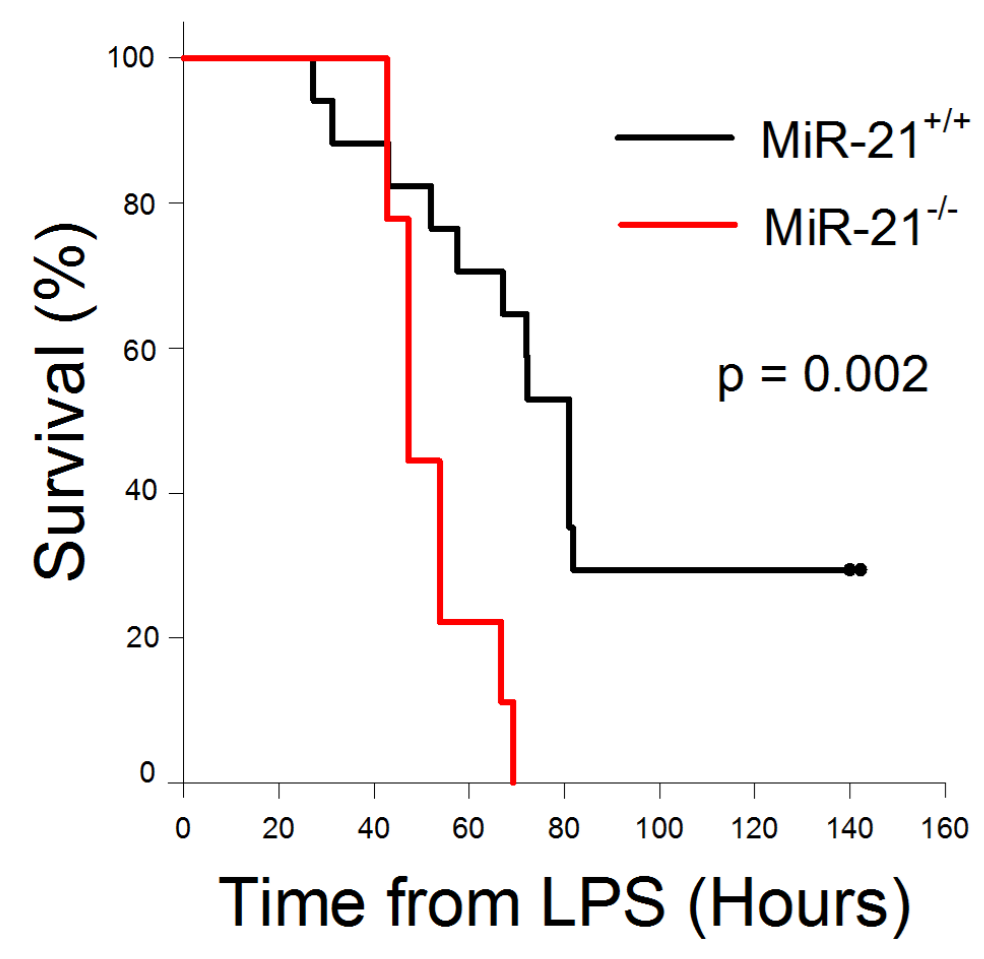

MiRNA-21 confers a significant survival benefit in response to $25 \mathrm{mg} / \mathrm{kg}$

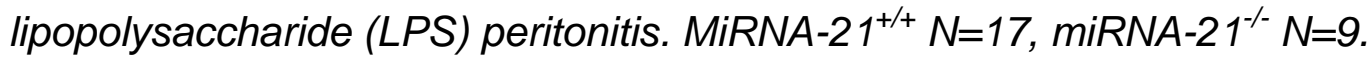


in which mice are kept impacts the temperature response ${ }^{108,109}$. Below a room temperature of $30^{\circ} \mathrm{C}$, mice are already working to maintain body temperature, and are thus unable to generate enough heat to produce the fever response usually associated with sepsis. This leads to the hypothermic response seen and thus subsequent experiments should ideally be performed in a room at $30^{\circ} \mathrm{C}$. All mice lost weight following induction of peritonitis. This is indicative of the increased metabolic demand placed on the body. Only animals that survived the observation period gained weight following peritonitis (Figure 23). We have used weight loss as a predictor of mortality in previous models of peritonitis ${ }^{110}$.

The knockdown of miRNA-21 confers a survival benefit in LPS peritonitis (Figure 24). Mortality due to LPS is associated with cardiac dysfunction related to intravascular inflammation and thrombosis in microvasculature function ${ }^{111}$. This impairment in microcirculation leads to multiple organ failure, disseminated intravascular coagulation (DIC) and death ${ }^{112,113}$. Inhibition of platelet adhesion through GPIb-IX binding decreases the mortality of LPS challenged mice ${ }^{114}$. TNF- $\alpha$ activates the common pathway of coagulation, leading to thrombotic consequences ${ }^{115}$. The cardiopulmonary dysfunction seen in animal models of sepsis can be attenuated by monoclonal TNF- $\alpha$ antibody ${ }^{116}$.

TNF- $\alpha$ is an important cytokine mediator of sepsis, essential to the generation of the innate immune response to infection. It is found in the circulation following administration of LPS, and when given directly mimics many of the physiological and laboratory features following intravenous LPS ${ }^{117}$. However plasma levels of TNF- $\alpha$ following endotoxin are an order of magnitude higher than circulating 
levels in sepsis ${ }^{16,118-120}$. If one of the downstream effects of miRNA-21 is to decrease circulating TNF- $\alpha$ levels, this correlates with the fact that the higher levels of TNF- $\alpha$ seen following LPS peritonitis are attenuated and therefore survival is improved in miRNA-2 $1^{+/+}$mice compared to miRNA-2 $21^{-/-}$mice. In miRNA-21-/- mice there would be no amelioration of the already high TNF- $\alpha$ levels seen after administration of LPS, and therefore these mice have a higher mortality. TNF- $\alpha$ blockade alone is not sufficicent to reduce mortality following LPS peritonitis in animals or when administered in clinical trials, and indeed higher doses of TNF- $\alpha$ blockade increases mortality ${ }^{120,121}$. IL-10 had been shown to reduce mortality in a lethal model of LPS peritonitis ${ }^{87}$. These data suggests that it is not TNF- $\alpha$ alone, but a combination of factors by which miRNA-21 reduced mortality in our experiment.

Our initial experiment focused on the TLR-4 pathway by inducing peritonitis with a specific ligand. However, LPS is a single protein from the outer membrane of a single organism (E.coli), given at a single point in time, which signals through a single pattern recognition receptor and triggers the innate immune response through the TLR-4 pathway. In reality, secondary peritoneal infection is polymicrobial, with entry of multiple enteric bacteria into the peritoneum, resulting in the continuous migration of bacteria into the vascular space, mainly through the subdiaphragmatic lymphatics. This results in multiple PAMPs and DAMPs being recognized by PRRs and the activation of multiple signaling pathways. Cecal Ligation and Puncture is a more representative model of peritonitis that will 
better assess if this promising effect of miRNA-21 on mortality in peritonitis would be beneficial in a patient population ${ }^{90}$. 


\section{CHAPTER IX}

\section{INFLUENCE OF MIRNA-21 ON SURVIVAL IN CECAL LIGATION AND PUNCTURE PERITONITIS}

\section{Introduction}

Our previous experiments have shown that expression of miRNA-21 confers a survival benefit in a lipopolysaccharide model of peritonitis. Previous studies of immune modulators in sepsis that have used LPS peritonitis as an experimental model, that showed a difference in outcome in animal studies, have not translated into differences in clinical studies ${ }^{122}$. This is because LPS induced inflammation is not an accurate mimic of the human disease state. LPS is an outer membrane protein from a gram negative bacterium (often $E$. coli) that signals through a single pattern recognition receptor (TLR-4) and triggers the innate immune response through a single pathway. It is also given as a single bolus, whereas in most human infections bacteria are released and multiply in the bloodstream of the host more slowly over time. For these reasons we felt it was important to assess the influence of miRNA-21 on survival in a more clinically relevant model of peritonitis, CLP. The CLP model combines the entry of enteric bacteria into the peritoneum together with an ischemic focus and is thus closer to peritonitis as seen in patients. If miRNA-21 is to be a potential 
immune modulator in a clinical setting, then it will need to show a difference in more clinically relevant animal models of peritonitis such as CLP. We propose that miRNA-21 will show a survival difference between the miRNA-2 $21^{+++}$and miRNA-21/- mice following CLP.

\section{Results}

Surface temperature and weight decreased in all mice following induction of peritonitis with CLP (Figure 25). Surface temperature improved in the mice that survived, though never recovered to baseline levels during the observation period. There was no difference in survival following induction of peritonitis with

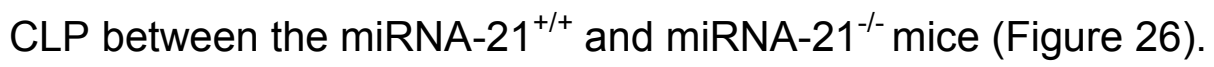

\section{Discussion}

MiRNA-21 confers a survival benefit in LPS peritonitis but not after CLP. This is a result that has also been seen with other potential immune modulators ${ }^{120}$. LPS is a ligand for TLR-4, and thus triggers the immune response through this single pathway. As miRNA-21 is induced by and acts on the TLR-4 pathway, it is therefore logical that we see a difference in survival between miRNA- $21^{+/+}$and miRNA-21-- mice after LPS induced peritonitis.

In contrast CLP is a combination of ischemia, foreign body reaction and polymicrobial infection from the enteric bacteria of the gut. This leads to a live 
Figure 25: Surface Temperature and Weight in mice after Cecal Ligation and Puncture

A.

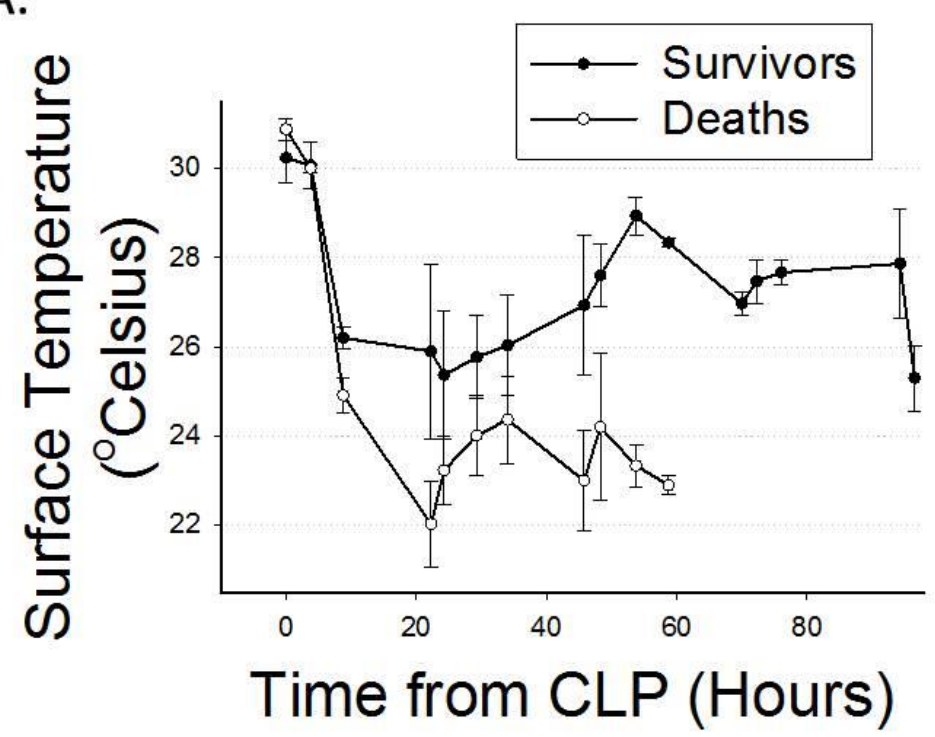

B.

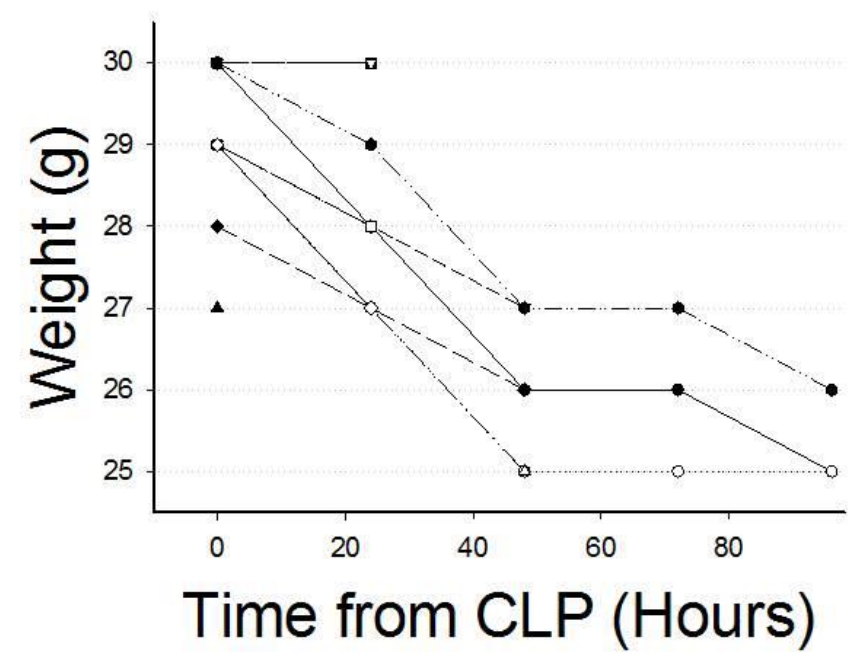

Surface temperature and weight decreased in all mice following induction of peritonitis with 20G cecal ligation and puncture (CLP). The mice that died during the observation period had lower temperatures than those that survived. MiRNA$21^{+/+}$and miRNA-21/\% mice were included in this figure. Survivors $N=8$, Deaths $N=12$. 
Figure 26: Survival after 20G Cecal Ligation and Puncture

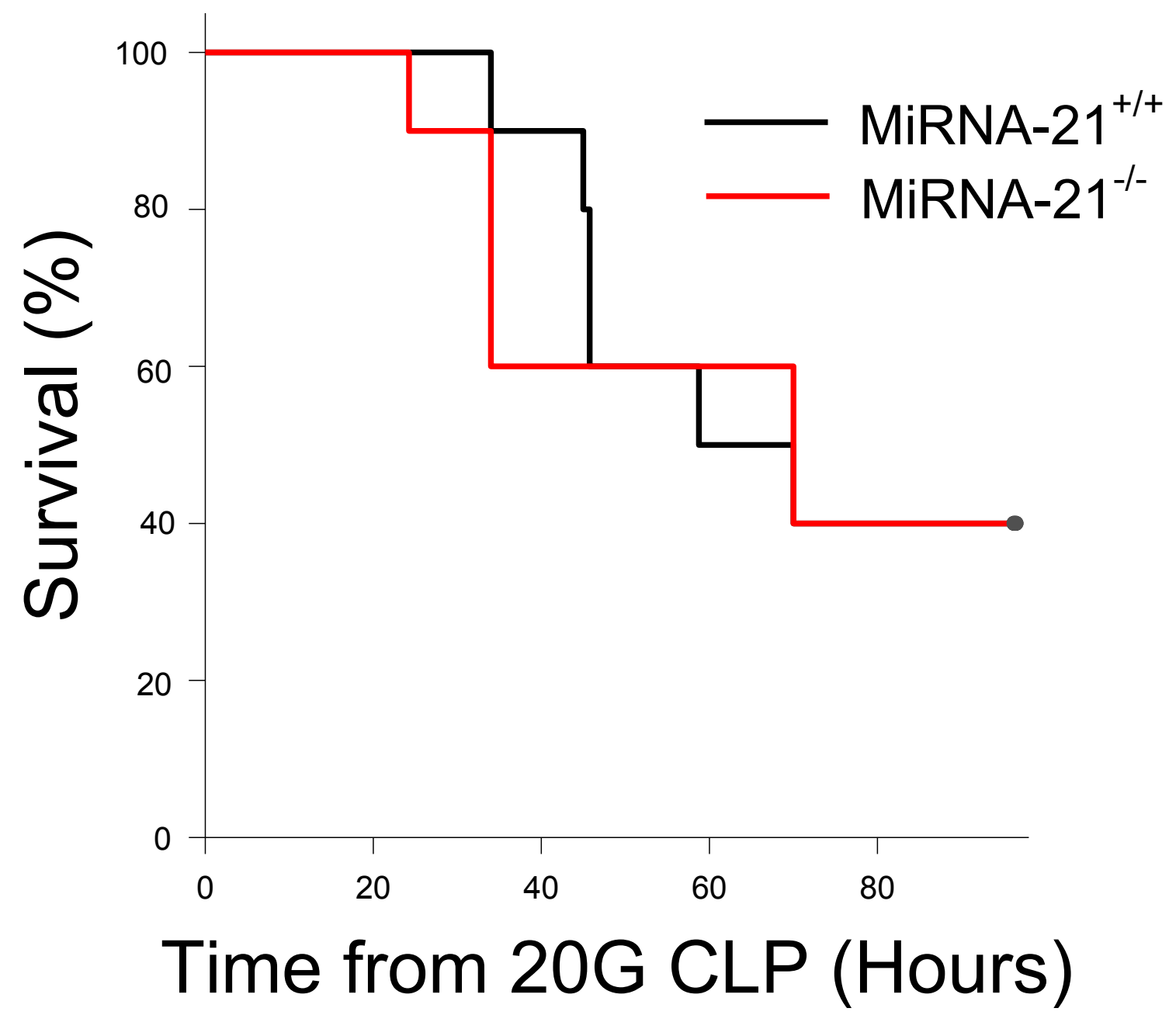

MiRNA-21 does not convey a survival benefit in response to peritonitis by 20G cecal ligation and puncture (CLP). $N=10$. 
bacterial infection with a multitude of exogenous mediators such as microbial DNA, lipoteichoic acid, peptidoglycan and other cell wall components which signal through multiple pathways such as TLR-2, TLR-6, TLR-9, NOD-like receptors as well as TLR-4 to initiate the immune response. LPS peritonitis is induced by an intra-peritoneal bolus, which induces an initial response that does not need to escalate over time. The infection seen after CLP involves cecal necrosis, with multiplying species of bacteria within the peritoneum and eventual bacteremia over time. The infection becomes walled off in an abscess cavity over the first 72 hours, and is eventually extruded through the abdominal wall if the animal survives ${ }^{123}$. This ongoing contamination in CLP requires a more complex continued immune response.

TNF- $\alpha$ is an important cytokine mediator of sepsis, essential to the generation of the innate immune response to infection. It is found in the circulation following administration of LPS, and when given directly mimics many of the physiological and laboratory features following intravenous LPS ${ }^{117}$. The level of circulating TNF- $\alpha$ has a positive correlation with mortality ${ }^{110,124}$. Reducing the levels of circulating TNF- $\alpha$ using anti-TNF- $\alpha$ monoclonal antibodies in experimental animal models of sepsis using LPS and gram negative bacteria, has had some success in decreasing mortally across a range of species ${ }^{124-126}$. Animals unable to produce TNF- $\alpha$ in response to infection did worse than endotoxin sensitive mice, demonstrating that a proportional immune response is required ${ }^{127}$. However plasma levels of TNF- $\alpha$ following LPS administration are an order of magnitude higher than circulating levels in polymicrobial sepsis ${ }^{16,118-120,128}$. TNF- $\alpha$ blockade 
has been shown to be ineffective or detrimental in mice following induction of peritonitis with CLP 119,120 . This is consistent with clinical trials of TNF- $\alpha$ antagonists that did not show an improved survival, and at higher doses increased mortality $17,129,130$.

MiRNA-21 decreases circulating TNF- $\alpha$, and therefore will have more effect on the higher levels of TNF- $\alpha$ seen following LPS peritonitis. The attenuation of TNF- $\alpha$ that occurs in miRNA- $21^{+/+}$mice may be related to the subsequent improved survival. MiRNA-2 $21^{-/-}$mice do not have the same amelioration of the high TNF- $\alpha$ concentration seen after administration of LPS. In CLP there are lower levels of circulating TNF- $\alpha$, and therefore the effects of miRNA-21 on TNFa levels will be reduced, and potentially insufficient to have an effect on mortality. TNF- $\alpha$ is not the only factor important in the pathophysiology of sepsis, as a reduction in TNF-a has no effect on neutrophil infiltration of the lung, as a major cause of mortality following CLP ${ }^{120}$. These data demonstrate that TNF- $\alpha$ is not the mediator of lethality in polymicrobial peritonitis, yet has a role to play with a multitude of other mediators.

TLR-4 signaling produces multiple cytokines, both pro- and anti-inflammatory in response to stimulation with LPS, both through the NF-KB and ERK pathways. Following CLP, TLR-4 gene expression and protein abundance was increased in liver and lung compared with controls and correlates with mortality ${ }^{131}$. Inflammation, tissue damage and lethality are diminished in the absence of TLR4 signaling ${ }^{132}$. 
With these data TLR-4 antagonists have been developed, which competitively bind to TLR-4, preventing LPS interaction, and have been shown to decrease pro-inflammatory cytokine release and inhibit the development of inflammation ${ }^{133-135}$. However the ACCESS randomized clinical trial of Eritoran ${ }^{\circledR}$, an antagonist of the MD2-TLR-4 complex, did not show any significant difference when trialed in patients with severe sepsis ${ }^{136}$. In contrast M62812, a molecule that inhibits TLR-4 signal transduction, has shown an increased survival in both Dgalactosamine-sensitized endotoxin shock model and 18G CLP model at 24 hours ${ }^{134}$. However increased survival over a longer time period was not reported.

One group has looked further into the role of TLR-4 on different cells types. Using a 22G CLP model a global TLR-4 deletion and myeloid (neutrophil and macrophages) TLR-4 deletion had $100 \%$ mortality compared to $40 \%$ in the wild type mice after 7 days ${ }^{137}$. Bacterial clearance from the circulation and peritoneum in these mice was significantly impaired compared to wild type. The failure to clear bacteria correlated with an increase in inflammatory markers, even in the absence of TLR-4 on myeloid cells. Efficiency of bacterial clearance in this model determines survival and the magnitude of the immune response, which are in turn determined by LPS recognition by TLR-4 on macrophages. TLR-4 on macrophages is therefore important for the stimulation of bacterial phagocytosis in polymicrobial sepsis.

The cause of mortality related to LPS peritonitis differs from that seen after CLP 90. LPS mortality is associated with cardiac dysfunction and related to 
intravascular inflammation and thrombosis in the microvasculature ${ }^{111}$. This impairment in the microcirculation leads to multiple organ failure, disseminated intravascular coagulation (DIC) and death ${ }^{112,113}$. TNF- $\alpha$ activates the common pathway of coagulation, leading to thrombotic consequences ${ }^{115}$. The cardiopulmonary dysfunction seen in animal models of sepsis can be attenuated by monoclonal TNF- $\alpha$ antibody ${ }^{116}$.Suppression of LPS-induced up-regulation of inflammatory cytokines, by TLR-4 signal transduction inhibitor M62812, also led to suppression of pro-coagulant activity in peripheral mononuclear cells ${ }^{134}$. Upregulation of pro-coagulant activity in leukocytes and down-regulation of anticoagulant activity in endothelial cells leads to microthrombosis in several organs, leading to multiple organ failure. Inhibition of platelet adhesion through GPIb-IX binding also decreases the mortality of LPS challenged mice ${ }^{114}$.

After CLP animals develop an initial hyper dynamic cardiovascular response, similar to that seen in patients with increased cardiac output and decreased systemic vascular resistance ${ }^{90}$. This develops into systemic bacteraemic infection and sepsis, which progressively become cardiovascular collapse due to septic shock and death days after the initial insult, similar to the condition seen in peritonitis patients who die from multiple organ failure days after the onset of infection. CLP using a $16 \mathrm{G}$ double puncture technique leads to a significant cardiac dysfunction, shown by a decreased ejection fraction by $25.7 \%{ }^{138}$. There is also a component of lung injury due to neutrophil infiltration ${ }^{139}$. Innate immunity also participates in polymicrobial sepsis-induced acute kidney injury through the MyD88 pathway, by leading to an increased migration of neutrophils 
to the kidney, increased production of pro-inflammatory cytokines, vascular permeability, hypoxia and apoptosis of tubular cells ${ }^{140}$. TLR- ${ }^{-/-}$mice had decreased renal injury at 24 hours with a diminished systemic cytokine response following $23 \mathrm{G}$ CLP ${ }^{140}$. CLP and LPS both enhance thrombotic occlusion in wildtype mice ${ }^{141}$. LPS, but not CLP, increased plasma VWF antigen relative to controls. CLP alternatively enhanced thrombosis in TLR-4 and VWF-deficient strains. As miRNA-21 has not been shown to have a regulatory role in other immune signaling pathways, the redundancy present from the multiple pathways stimulated in CLP may minimize the effects of miRNA-21 in this peritonitis model.

These experiments used whole body knockout mice to model an absence of miRNA-21. As these mice survived to 12 weeks and beyond we know that miRNA-21 is not essential for animal survival. We do not know what adaptions have occurred within the mouse, specifically in the immune system in order to compensate for the missing miRNA-21, though there were no significant changes in hemopoetic cells populations seen in the blood, peritoneum or bone marrow on flow cytometry (data not shown). Creation of a model that has inducible knockdown of miRNA-21 in only the macrophage population would be ideal to truly see the effect of macrophage miRNA-21 in these models of peritonitis. A closer model would be to transplant bone marrow from miRNA-2 $21^{--}$mice into miRNA- $21^{+/+}$mice, as then the subsequent miRNA-21 knockdown would be confined to only the hematological cells. However, this would still allow for adaptations to occur within the immune system. 
Although mortality is a definitive end-point most patients survive an episode of peritonitis with modern therapy. MiRNA-21 may still ameliorate the severity of infection without affecting mortality rate. In patients, decreasing the need for organ support and intensive care would be a significant step forward in improving the patient experience, decreasing length of stay and subsequent health care costs. 


\section{CHAPTER X \\ MIRNA-21 EXPRESSION IN PERITONEAL MACROPHAGES \\ FOLLOWING CECAL LIGATION AND PUNCTURE PERITONITIS}

\section{Introduction}

Cecal ligation and puncture is among the most representative models of human peritonitis. Multiple pathways are stimulated by the polymicrobial infection from enteric bacteria. These pathways stimulate cell activation and trigger secondary cascades, resulting in cytokine and chemokine release. MiRNA-21 regulates the TLR-4 signaling cascade, one of many that are activated by polymicrobial intraabdominal infection. We saw no difference in survival between miRNA- $21^{+/+}$and miRNA-21/- mice following $20 \mathrm{G}$ CLP. We propose, based on these data, that despite the absence of a difference in survival, we will see a difference in the levels of miRNA-21 in the macrophage population and the intra-peritoneal cytokine profile. 


\section{Results}

\section{MiRNA-21 Expression}

MiRNA- $21^{-/-}$was confirmed by RT-qPCR. In miRNA- $21^{+/+}$mice miRNA-21 expression was initially down-regulated in the $\mathrm{F} 4 / 80+$ peritoneal macrophage population at 6 and 24 hours following CLP (Figure 27). At 48 hours the expression was up-regulated by 500 fold but with a wide range of variation.

\section{Cell Populations}

MiRNA- $21^{+/+}$and miRNA-2 $21^{--}$mice had no difference in the number of peritoneal exudate cells harvested from the peritoneum at 6,24 or 48 hours after $20 \mathrm{G}$ CLP (Figure 28). The number of macrophages isolated was not different between the groups, nor the macrophage population as a percentage of the total number of PEC cells (Figure 29).

Effect of miRNA-21on Peritoneal Cytokines levels

Following 20G CLP TNF- $\alpha$ was higher in the peritoneal lavage media from miRNA- $21^{+/+}$mice at 6 hours $(p=0.009)$, but no different at 24 and 48 hours (Figure 30). IL-6 concentrations peaked at 6 hours after CLP, but was no different in the peritoneum between miRNA- $21^{+/+}$and miRNA-2 $21^{-/-}$mice (Figure 31). Similarly IL-10 levels were maximally elevated at 6 hours, with the same pattern occurring in both miRNA-2 $1^{+/+}$and miRNA-2 $1^{-/-}$mice (Figure 32). 
Figure 27: Peritoneal Macrophage MiRNA-21 Expression after Cecal Ligation and Puncture

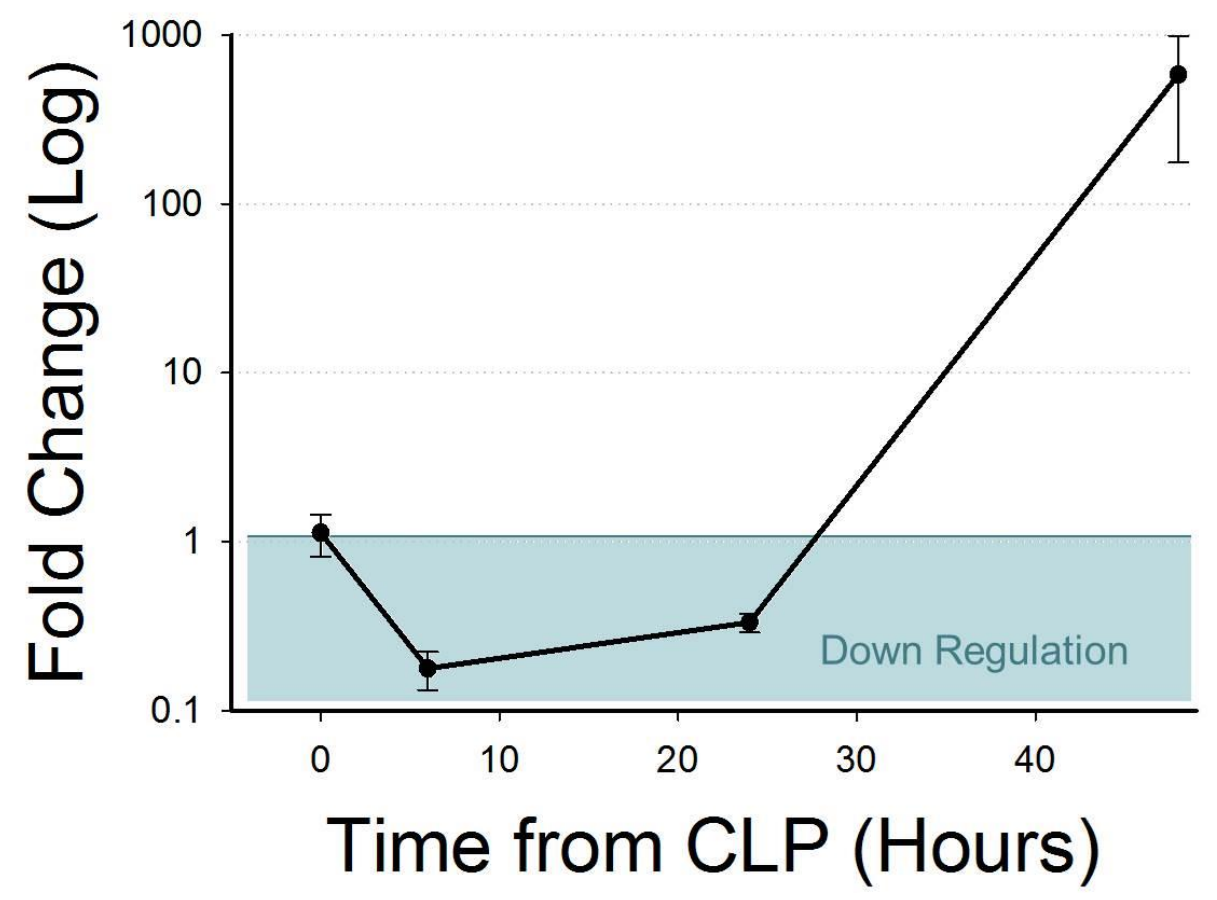

Peritoneal macrophage miRNA-21 expression after 20G cecal ligation and puncture $(C L P) . N=7$. Data are shown Mean \pm SEM. 
Figure 28: Peritoneal Exudate Cell counts after Cecal Ligation and Puncture

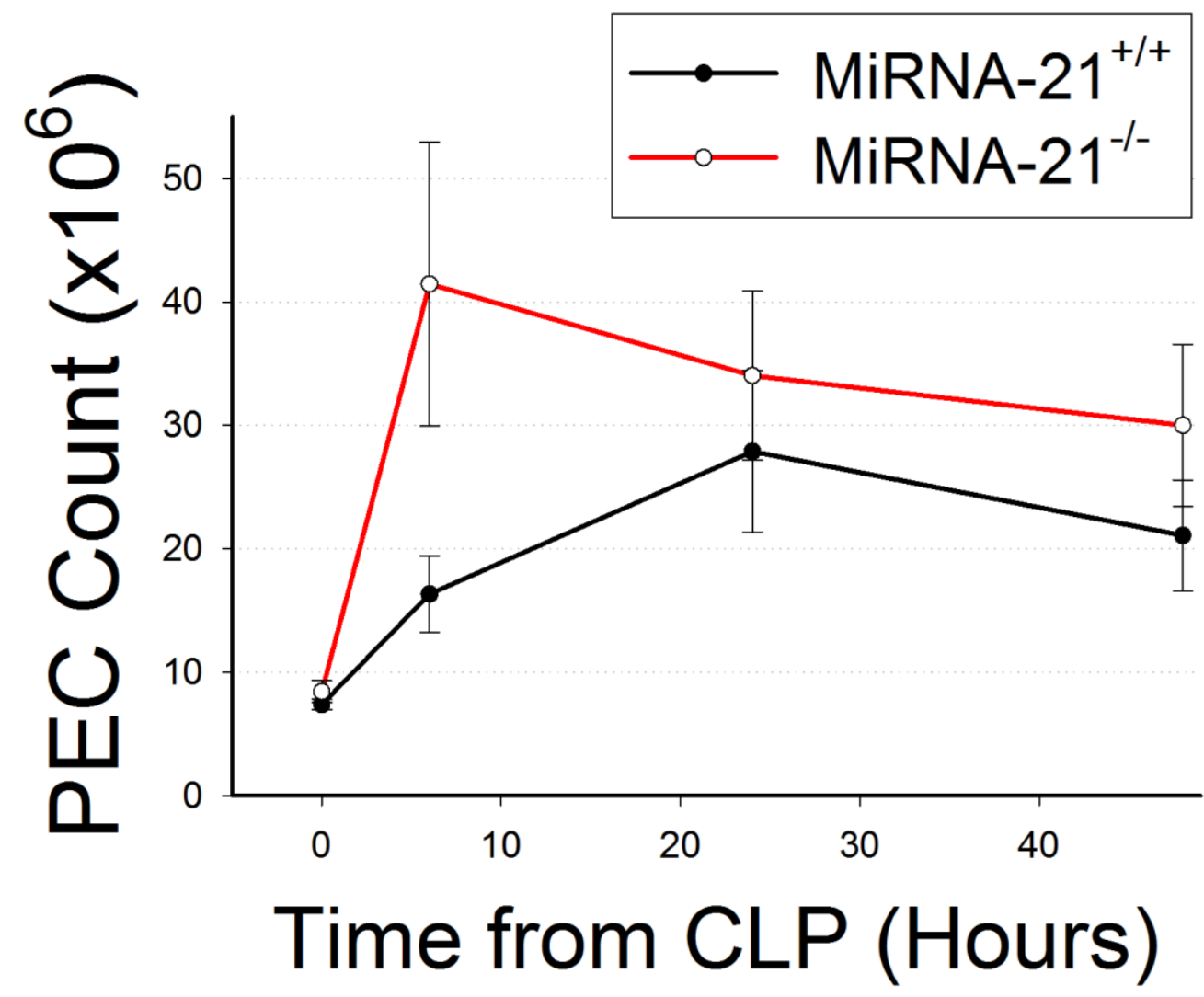

There is no difference in the number of peritoneal exudate cells between miRNA$21^{+/+}$and miRNA-21\% mice following cecal ligation and puncture (CLP). N=7-8. Data are shown Mean \pm SEM. 
Figure 29: Peritoneal Macrophages after Cecal Ligation and Puncture
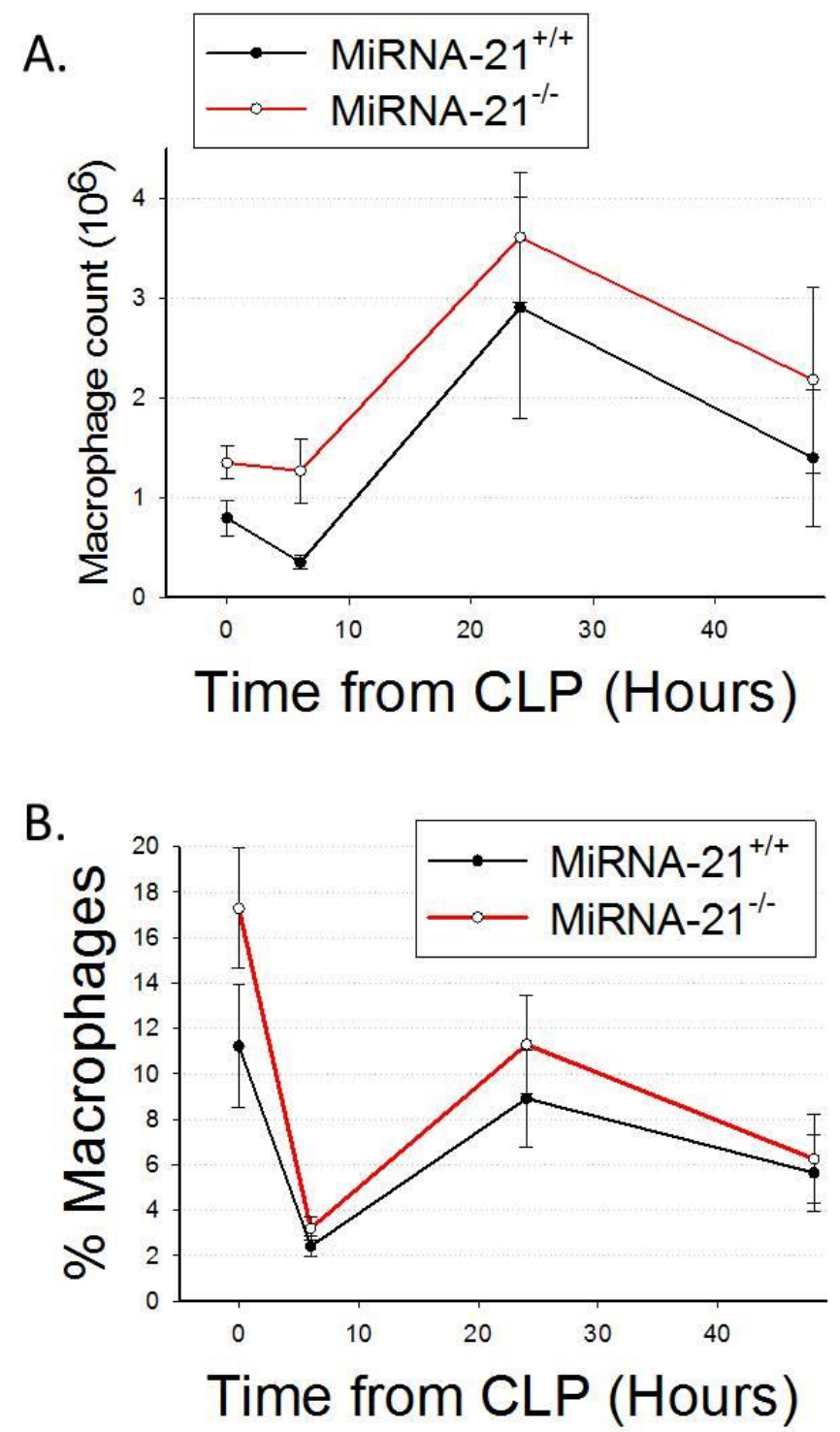

A) There is no difference in the number of peritoneal macrophages between miRNA-21+/ and miRNA-2 $1^{-/}$mice, not $B$ ) the percentage of the total peritoneal population following cecal ligation and puncture (CLP). N=7-8. Data are shown Mean \pm SEM. 
Figure 30: Peritoneal TNF- $\alpha$ after Cecal Ligation and Puncture

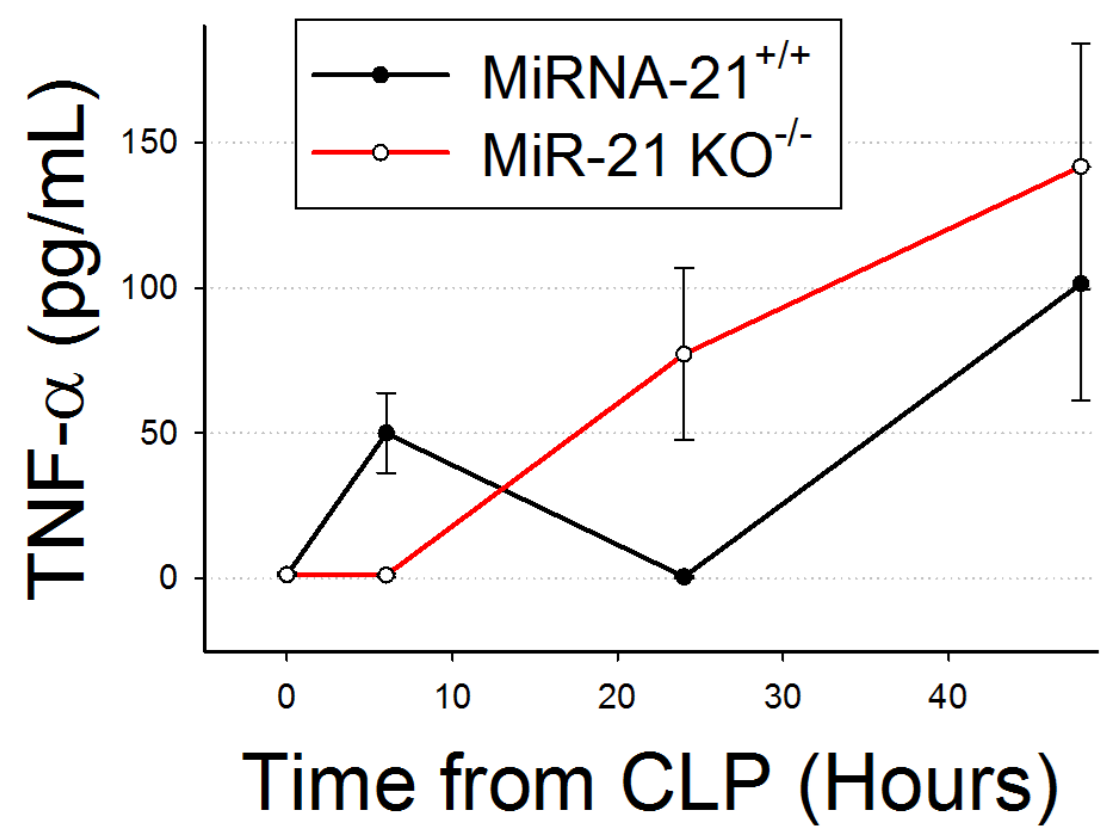

There is no difference in the peritoneal TNF- $\alpha$ levels between miRNA-21+/+ and miRNA-21\% mice following cecal ligation and puncture (CLP). N=7-8. Data are shown Mean \pm SEM. 
Figure 31: Peritoneal IL-6 after Cecal Ligation and Puncture

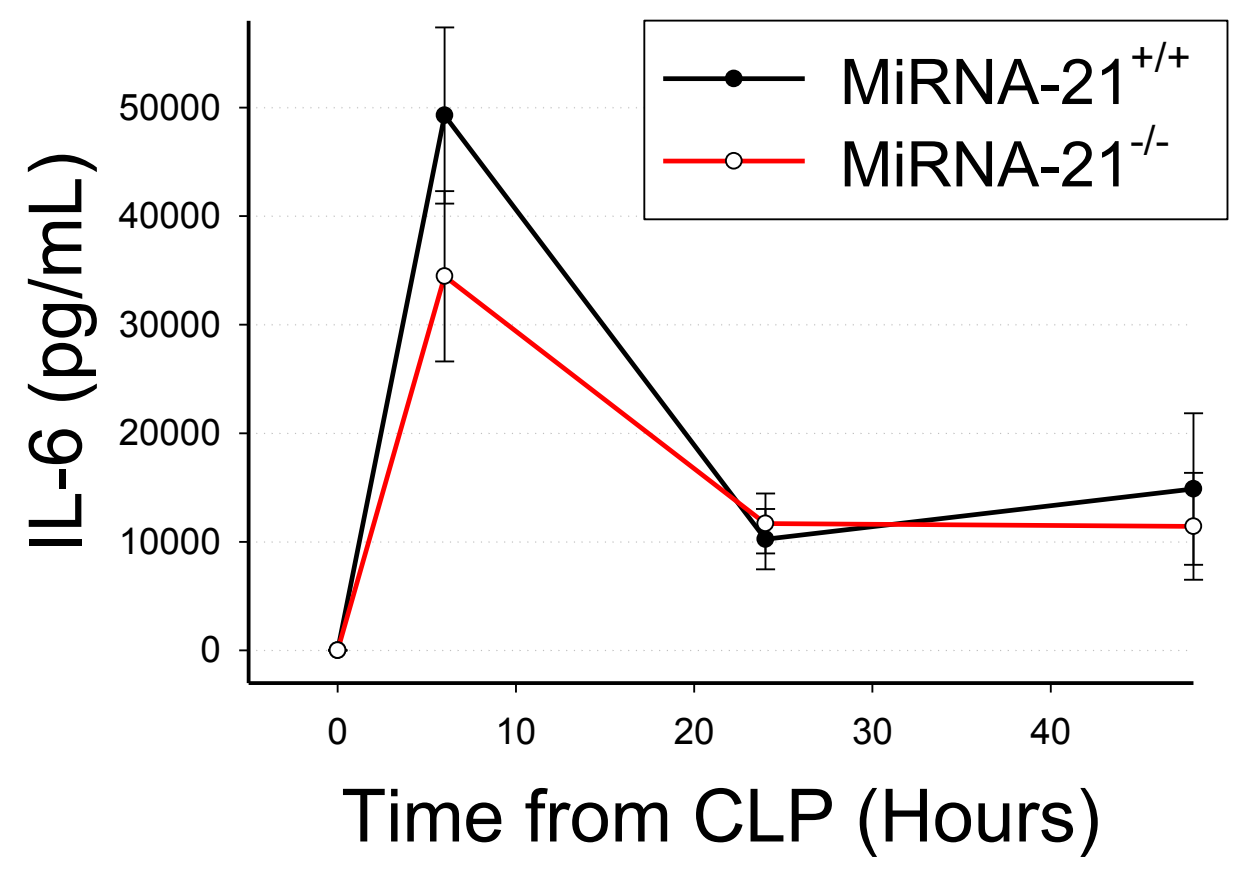

There is no difference in the peritoneal IL-6 between miRNA-2 $1^{+/+}$and miRNA$21^{-/}$mice following cecal ligation and puncture (CLP). N=7-8. Data are shown Mean \pm SEM. 
Figure 32: Peritoneal IL-10 after Cecal Ligation and Puncture

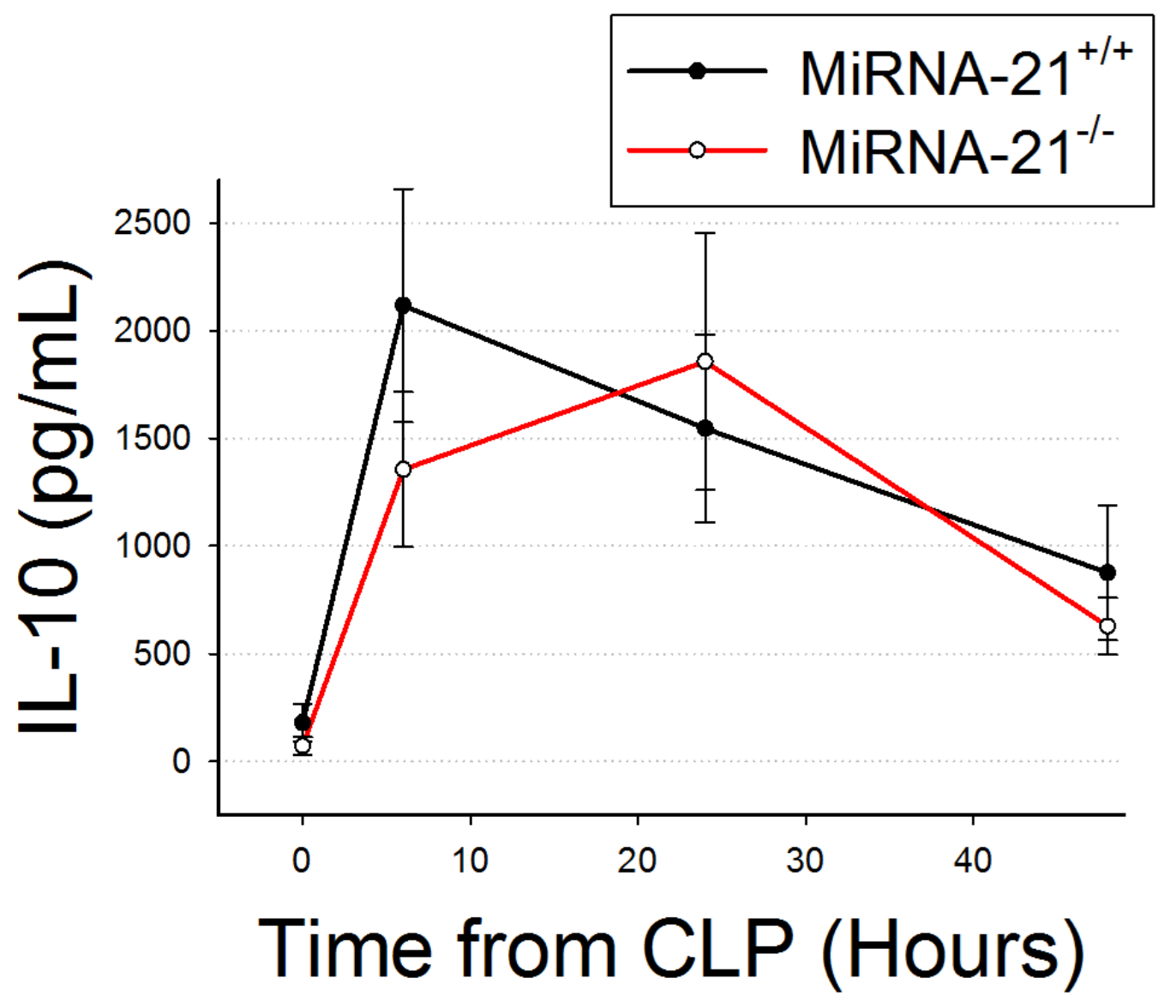

There is no difference in the peritoneal IL-10 between miRNA-21 $1^{+/}$and miRNA$21^{-/}$mice following cecal ligation and puncture (CLP). N=7-8. Data are shown Mean \pm SEM. 


\section{Discussion}

We have shown that after CLP there is an initial down-regulation in MiRNA-21 expression followed by a delayed up-regulation at 48 hours. This is in direct contrast to LPS, which shows a linear up-regulation of miRNA-21 after stimulation. This early down-regulation in the macrophages at 6 hours may be due to a delay in the stimulation of TLR-4 by bacteria migrating from the lumen of the bowel into the peritoneum. However this would not explain the data from the 24 hour time point.

Exosomes are $40-10 \mathrm{~nm}$ membrane vesicles that are secreted by cells as part of cell-cell communication. Recent studies have shown that miRNA-21 is secreted in exosomes into peritoneal fluid at higher levels in ovarian serous carcinoma than normal controls ${ }^{54}$. Exosomal miRNA-21 expression has also been upregulated in serum in esophageal cancer and cervicovaginal lavage in cervical

cancer ${ }^{142,143}$. If intra-cellular macrophage miRNA-21 was secreted into the peritoneum following CLP, this may account for the decreased expression seen within the cells at 6 and 24 hours.

We observed no difference between miRNA-2 $21^{+/+}$and miRNA-2 $21^{-/-}$mice in PEC cell count, total macrophage count or macrophages as a percentage of the total number of PEC cells. TNF- $\alpha$ was higher in the peritoneal lavage media from miRNA-2 $21^{+/+}$mice at 6 hours. All other cytokines were similar regardless of the presence or absence of miRNA-21. 
These data partially explain why there was no difference in survival observed between miRNA-2 $21^{+/+}$and miRNA-2 $21^{-/-}$mice following induction of peritonitis with 20G CLP. Collectively our data suggest that TLR-4 signaling has a definite role to play in the innate immune response to peritonitis, though the redundancy of multiple pathways stimulated in following induction of peritonitis with CLP may minimize the effects of miRNA-21 in this model.

Although miRNA-21 did not show a survival benefit, we believe that there may still be a therapeutic role for miRNA-21 in a clinical setting. Further experiments are required to ascertain the presence and pattern of exosomal or free miRNA-21 in peritoneal fluid, both in the normal and infected abdomen. Examination of abdominal washings or drain fluid in post-operative surgical patients, will likely yield novel data about the role of miRNA-21 in peritonitis. Although knockout of miRNA-21 was not effective in changing survival, there may be a role for increasing miRNA-21 expression within the peritoneum to affect the severity of infection without affecting mortality rate. 


\section{CHAPTER XI}

\section{CONCLUSIONS AND OVERVIEW}

The early innate immune response to invading microbes during peritonitis is largely orchestrated by the peritoneal macrophage. These cells have three basic functions: phagocytosis, antigen presentation, and protein secretion. Macrophages have been classed into two phenotypes - M1, the classical or proinflammatory macrophage that produces TNF- $\alpha$, IL-1, IL-6, nitric oxide and has strong microbial activity, and M2 or alternatively activated macrophages that produce IL-10, Arginase-1 and Mrc1 (CD206) and are involved in preventing excessive injury in the host tissue remodeling ${ }^{144,}{ }^{145}$. Macrophages can be converted from one phenotype into another. The key transcription factors involved in macrophage polarization are STATs, NF-kB, and camp-responsive element-binding protein (CREB). Therapeutic targeting to change the polarization of macrophages is still in the primordial phase of development, but the microenvironment and anatomical location of the cells are important ${ }^{145,}{ }^{146}$. We have shown that miRNA-21 modulates the cytokine output of peritoneal macrophages, from a pro- to anti-inflammatory profile, suggesting that miRNA-21 is involved in macrophage polarization. The reduction in TNF- $\alpha$ and IL-6 together with the increase observed in IL-10 production in response to LPS with increased miRNA-21 may indicate a role in the transition of macrophages to a M2 
alternative activation state. Further characterization of whether there is any difference in the M2 expressed genes such as Arginase-1, chitinase 3-like 3 (Ym1), and Mrc1 (CD206) between miRNA-2 $1^{-/-}$and miRNA-21 ${ }^{+/+}$cells should yield novel data to clarify the active mechanisms involved in the transition of the early innate immune response to peritonitis.

Indeed, a study of microbial tolerance has shown that a LPS-tolerant state leads to a M2 polarized phenotype in macrophages ${ }^{104}$, and the NF-KB p50 subunit is the key regulator in this transformation. Our experiments focused on the p65 subunit, and this may contribute to why differences in the activation of NF-KB were not observed in these experiments.

Recent reports in the literature have postulated an early/acute hyperinflammatory and a late/chronic hypo-inflammatory phase in response to sepsis $84,113,147,148$. This immunosuppression phase in late sepsis leads to mortality from persisting primary infection or an opportunistic new infection, otherwise known as the two hit model. Some data suggest that altered myeloid maturation or differentiation may be important. Adoptive transfer of $\mathrm{CD}_{3} 4^{+}$hematopoietic stem-progenitor cells after CLP improved survival by $65 \%$. Cell transfer resulted in no change in the early hyper-inflammatory response, but corrected the later immunosuppression, increasing circulating pro-inflammatory cytokines, enhancing phagocytic activity and clearing bacterial peritonitis. It is likely that these new cells differentiated into competent immune cells in the blood and tissue, reversing or replacing hyporesponsive endotoxin-tolerant cells in the peritoneum ${ }^{149}$. We have no current data about the role of miRNA-21 in this late 
stage of sepsis, though theoretically if it is still active, then inhibition of miRNA-21 to change to a more pro-inflammatory response maybe potentially beneficial.

There are numerous limitations on this work. The isolation process may have activated macrophages, though we tried to counteract any effects by using a gentle process and resting the cells for 24 hours prior to use to alleviate some of these effects on subsequent stimulation. Bone marrow derived macrophage cell lines were used to evaluate the absence of miRNA-21, however these macrophages are an immortalized cell line, which are not primary peritoneal macrophages. These cells are likely to be phenotypically or genetically different from primary peritoneal macrophages and therefore are only able to approximate what is occurring in the peritoneum. The evaluation of the individual cell type responses in vitro also need to be related to what in occurring in vivo as cells do not respond alone, multiple cells types communicate and respond to infectious stimuli together.

In conclusion, we found that miRNA-21 expression increases in macrophages after LPS stimulation. MiRNA-21 decreases TNF- $\alpha$ and IL-6 production, while increasing IL-10. The mechanism by which the expression of these cytokines was modulated is not clear from these experiments. PDCD4 has emerged as the most likely target protein to be effecting the cytokine modulation, though NF-KB activation was not different.

MiRNA-21 is beneficial in survival from an LPS model of peritonitis but not after CLP, as it does not have sufficient power to change the peritoneal cytokine 
profile that is associated with mortality. Although miRNA-21 did not change survival after CLP, there may still be a therapeutic role in peritonitis that warrants further investigation. If miRNA-21 can ameliorate the severity of infectious sequelae, that would be clinically beneficial. The healthcare costs involved with intensive care and multi-organ support are significant. Reducing admission to or length of stay in the intensive care unit would positively impact the care of patients with peritonitis.

MiRNA-21 is present in plasma and peritoneal fluid ${ }^{50,54,150}$. There are currently no data on the presence and pattern of exosomal or free miRNA-21 in peritoneal fluid, in either the normal or infected abdomen. Isolation of miRNA-21 from perioperative abdominal washings undergoing abscess drainage or drain fluid in post-operative surgical patients would improve our understanding of the course of miRNA-21 secretion in response to clinical peritonitis. Future animal experiments could determine if the addition of exogenous miRNA-21 to the peritoneum after CLP is able to modulate the local immune response in vivo.

We hypothesized that the outcome of peritonitis can be modulated by miRNA-21 through down regulation of NF-KB signaling that affects macrophage cytokine release, to diminish local inflammation. These findings demonstrate that although miRNA-21 is beneficial in modulating the macrophage response to LPS, the effect is buried in the multiple pathways activated after the clinically more relevant model of CLP. The improved understanding of the anti-inflammatory effects of miRNA-21 in macrophage response to peritonitis may result in a targeted therapy to intervene in clinical peritonitis. 


\section{REFERENCES}

1. Weiss G, Steffanie W, Lippert H. [peritonitis: Main reason of severe sepsis in surgical intensive care]. Zentralblatt fur Chirurgie. 2007;132:130-137

2. Polk HC, Jr. Generalized peritonitis: A continuing challenge. Surgery. $1979 ; 86: 777-778$

3. Wickel DJ, Cheadle WG, Mercer-Jones MA, Garrison RN. Poor outcome from peritonitis is caused by disease acuity and organ failure, not recurrent peritoneal infection. Annals of surgery. 1997;225:744-753; discussion 753-746

4. Chromik AM, Meiser A, Holling J, Sulberg D, Daigeler A, Meurer K, Vogelsang $\mathrm{H}$, Seelig $\mathrm{MH}$, Uhl W. Identification of patients at risk for development of tertiary peritonitis on a surgical intensive care unit. Journal of gastrointestinal surgery : official journal of the Society for Surgery of the Alimentary Tract. 2009;13:1358-1367

5. Mazuski JE, Solomkin JS. Intra-abdominal infections. The Surgical clinics of North America. 2009;89:421-437, ix

6. Weiss $\mathrm{G}$, Meyer F, Lippert H. Infectiological diagnostic problems in tertiary peritonitis. Langenbeck's archives of surgery / Deutsche Gesellschaft fur Chirurgie. 2006;391:473-482 
7. Biffl WL, Kaups KL, Cothren CC, Brasel KJ, Dicker RA, Bullard MK, Haan JM, Jurkovich GJ, Harrison P, Moore FO, Schreiber M, Knudson MM, Moore EE. Management of patients with anterior abdominal stab wounds: A western trauma association multicenter trial. The Journal of trauma. 2009;66:1294-1301

8. Marshall JC. Intra-abdominal infections. Microbes and infection / Institut Pasteur. 2004;6:1015-1025

9. Billing A, Frohlich D, Schildberg FW. Prediction of outcome using the mannheim peritonitis index in 2003 patients. Peritonitis study group. The British journal of surgery. 1994;81:209-213

10. Sawayama H, Tomiyasu S, Kanemitsu K, Matsumoto T, Tanaka H, Baba H. Colonic perforation due to colorectal cancer: Predicting postoperative organ failure with a preoperative scoring system and selecting the optimal surgical method based on the prognosis. Surgery today. 2012;42:10821087

11. Viehl CT, Kraus R, Zurcher M, Ernst T, Oertli D, Kettelhack C. The acute physiology and chronic health evaluation ii score is helpful in predicting the need of relaparotomies in patients with secondary peritonitis of colorectal origin. Swiss medical weekly. 2012;142:w13640

12. Thorsen K, Soreide JA, Soreide K. Scoring systems for outcome prediction in patients with perforated peptic ulcer. Scandinavian journal of trauma, resuscitation and emergency medicine. 2013;21:25 
13. Panhofer P, Izay B, Riedl M, Ferenc V, Ploder M, Jakesz R, Gotzinger P. Age, microbiology and prognostic scores help to differentiate between secondary and tertiary peritonitis. Langenbeck's archives of surgery / Deutsche Gesellschaft fur Chirurgie. 2009;394:265-271

14. Wong PF, Gilliam AD, Kumar S, Shenfine J, O'Dair GN, Leaper DJ. Antibiotic regimens for secondary peritonitis of gastrointestinal origin in adults. Cochrane database of systematic reviews. 2005:CD004539

15. de Ruiter J, Weel J, Manusama E, Kingma WP, van der Voort PH. The epidemiology of intra-abdominal flora in critically ill patients with secondary and tertiary abdominal sepsis. Infection. 2009;37:522-527

16. Deitch EA. Animal models of sepsis and shock: A review and lessons learned. Shock. 1998;9:1-11

17. Opal SM. Clinical trial design and outcomes in patients with severe sepsis. Shock. 2003;20:295-302

18. van Till JW, van Veen SQ, van Ruler O, Lamme B, Gouma DJ, Boermeester MA. The innate immune response to secondary peritonitis. Shock. 2007;28:504-517

19. Murphy K, Travers P, Walport M, Janeway C. Janeway's immunobiology. New York: Garland Science; 2008.

20. Bianchi ME. Damps, pamps and alarmins: All we need to know about danger. Journal of leukocyte biology. 2007;81:1-5

21. Cristofaro P, Opal SM. The toll-like receptors and their role in septic shock. Expert opinion on therapeutic targets. 2003;7:603-612 
22. Striz I, Brabcova E, Kolesar L, Sekerkova A. Cytokine networking of innate immunity cells: A potential target of therapy. Clinical science. $2014 ; 126: 593-612$

23. Wynn TA, Chawla A, Pollard JW. Macrophage biology in development, homeostasis and disease. Nature. 2013;496:445-455

24. Laurin LP, Brissette MJ, Lepage S, Cailhier JF. Regulation of experimental peritonitis: A complex orchestration. Nephron. Experimental nephrology. 2012;120:e41-46

25. Xiao W, Mindrinos MN, Seok J, Cuschieri J, Cuenca AG, Gao H, Hayden DL, Hennessy L, Moore EE, Minei JP, Bankey PE, Johnson JL, Sperry J, Nathens AB, Billiar TR, West MA, Brownstein BH, Mason PH, Baker HV, Finnerty CC, Jeschke MG, Lopez MC, Klein MB, Gamelli RL, Gibran NS, Arnoldo B, Xu W, Zhang Y, Calvano SE, McDonald-Smith GP, Schoenfeld DA, Storey JD, Cobb JP, Warren HS, Moldawer LL, Herndon DN, Lowry SF, Maier RV, Davis RW, Tompkins RG. A genomic storm in critically injured humans. The Journal of experimental medicine. 2011;208:25812590

26. Kubicka U, Olszewski WL, Tarnowski W, Bielecki K, Ziolkowska A, Wierzbicki Z. Normal human immune peritoneal cells: Subpopulations and functional characteristics. Scandinavian journal of immunology. $1996 ; 44: 157-163$

27. Ajuebor MN, Das AM, Virag L, Szabo C, Perretti M. Regulation of macrophage inflammatory protein-1 alpha expression and function by 
endogenous interleukin-10 in a model of acute inflammation. Biochemical and biophysical research communications. 1999;255:279-282

28. Mercer-Jones MA, Heinzelmann M, Peyton JC, Wickel DJ, Cook M, Cheadle WG. The pulmonary inflammatory response to experimental fecal peritonitis: Relative roles of tumor necrosis factor-alpha and endotoxin. Inflammation. 1997;21:401-417

29. Mercer-Jones MA, Shrotri MS, Peyton JC, Remick DG, Cheadle WG. Neutrophil sequestration in liver and lung is differentially regulated by c-x-c chemokines during experimental peritonitis. Inflammation. 1999;23:305319

30. Beutler B, Du X, Poltorak A. Identification of toll-like receptor 4 (tlr4) as the sole conduit for Ips signal transduction: Genetic and evolutionary studies. Journal of endotoxin research. 2001;7:277-280

31. Hayden MS, Ghosh S. Shared principles in nf-kappab signaling. Cell. 2008;132:344-362

32. Akira S. TIr signaling. Current topics in microbiology and immunology. $2006 ; 311: 1-16$

33. Clemons-Miller AR, Cox GW, Suttles J, Stout RD. Lps stimulation of tnfreceptor deficient macrophages: A differential role for tnf-alpha autocrine signaling in the induction of cytokine and nitric oxide production. Immunobiology. 2000;202:477-492

34. Meng F, Lowell CA. Lipopolysaccharide (Ips)-induced macrophage activation and signal transduction in the absence of src-family kinases 
hck, fgr, and lyn. The Journal of experimental medicine. 1997;185:16611670

35. Janssens S, Beyaert R. Functional diversity and regulation of different interleukin-1 receptor-associated kinase (irak) family members. Molecular cell. 2003;11:293-302

36. Chang M, Jin W, Sun SC. Peli1 facilitates trif-dependent toll-like receptor signaling and proinflammatory cytokine production. Nature immunology. 2009;10:1089-1095

37. Jin W, Chang M, Sun SC. Peli: A family of signal-responsive e3 ubiquitin ligases mediating tIr signaling and t-cell tolerance. Cellular \& molecular immunology. 2012;9:113-122

38. Cui Q, Yu Z, Purisima EO, Wang E. Principles of microrna regulation of a human cellular signaling network. Molecular systems biology. 2006;2:46

39. Billeter AT, Barnett RE, Druen D, Polk HC, Jr., van Berkel VH. Microrna as a new factor in lung and esophageal cancer. Seminars in thoracic and cardiovascular surgery. 2012;24:155-165

40. Bartel DP. Micrornas: Genomics, biogenesis, mechanism, and function. Cell. 2004;116:281-297

41. Billeter AT, Druen D, Kanaan ZM, Polk HC, Jr. Micrornas: New helpers for surgeons? Surgery. 2012;151:1-5

42. O'Neill LA, Sheedy FJ, McCoy CE. Micrornas: The fine-tuners of toll-like receptor signalling. Nature reviews. Immunology. 2011;11:163-175 
43. Fire A, Xu S, Montgomery MK, Kostas SA, Driver SE, Mello CC. Potent and specific genetic interference by double-stranded rna in caenorhabditis elegans. Nature. 1998;391:806-811

44. Shin VY, Jin H, Ng EK, Cheng AS, Chong WW, Wong CY, Leung WK, Sung JJ, Chu KM. Nf-kappab targets mir-16 and mir-21 in gastric cancer: Involvement of prostaglandin e receptors. Carcinogenesis. 2011;32:240245

45. Fujita S, Ito T, Mizutani T, Minoguchi S, Yamamichi N, Sakurai K, Iba H. Mir-21 gene expression triggered by ap-1 is sustained through a doublenegative feedback mechanism. Journal of molecular biology. 2008;378:492-504

46. Jazbutyte $\mathrm{V}$, Thum $\mathrm{T}$. Microrna-21: From cancer to cardiovascular disease. Current drug targets. 2010;11:926-935

47. Hu Y, Correa AM, Hoque A, Guan B, Ye F, Huang J, Swisher SG, Wu TT, Ajani JA, Xu XC. Prognostic significance of differentially expressed mirnas in esophageal cancer. International journal of cancer. Journal international du cancer. 2011;128:132-143

48. Necela BM, Carr JM, Asmann YW, Thompson EA. Differential expression of micrornas in tumors from chronically inflamed or genetic $(\operatorname{apc}(\min /+))$ models of colon cancer. PloS one. 2011;6:e18501

49. Wijnhoven BP, Hussey DJ, Watson DI, Tsykin A, Smith CM, Michael MZ. Microrna profiling of barrett's oesophagus and oesophageal adenocarcinoma. The British journal of surgery. 2010;97:853-861 
50. Kanaan Z, Rai SN, Eichenberger MR, Roberts H, Keskey B, Pan J, Galandiuk S. Plasma mir-21: A potential diagnostic marker of colorectal cancer. Annals of surgery. 2012;256:544-551

51. Sheedy FJ, Palsson-McDermott E, Hennessy EJ, Martin C, O'Leary JJ, Ruan Q, Johnson DS, Chen Y, O'Neill LA. Negative regulation of trr4 via targeting of the proinflammatory tumor suppressor pdcd4 by the microrna mir-21. Nature immunology. 2010;11:141-147

52. Krichevsky AM, Gabriely G. Mir-21: A small multi-faceted rna. J Cell Mol Med. 2009;13:39-53

53. Vergoulis T, Vlachos IS, Alexiou P, Georgakilas G, Maragkakis M, Reczko M, Gerangelos S, Koziris N, Dalamagas T, Hatzigeorgiou AG. Tarbase 6.0: Capturing the exponential growth of mirna targets with experimental support. Nucleic acids research. 2012;40:D222-229

54. Cappellesso R, Tinazzi A, Giurici T, Simonato F, Guzzardo V, Ventura L, Crescenzi M, Chiarelli S, Fassina A. Programmed cell death 4 and microrna 21 inverse expression is maintained in cells and exosomes from ovarian serous carcinoma effusions. Cancer cytopathology. 2014

55. Lu Z, Liu M, Stribinskis V, Klinge CM, Ramos KS, Colburn NH, Li Y. Microrna-21 promotes cell transformation by targeting the programmed cell death 4 gene. Oncogene. 2008;27:4373-4379

56. Young MR, Santhanam AN, Yoshikawa N, Colburn NH. Have tumor suppressor pdcd4 and its counteragent oncogenic mir-21 gone rogue? Molecular interventions. 2010;10:76-79 
57. Schauvliege R, Janssens S, Beyaert R. Pellino proteins: Novel players in tlr and il-1r signalling. J Cell Mol Med. 2007;11:453-461

58. Song X, Qian Y. Peli1 sets the cns on fire. Nature medicine. 2013;19:536538

59. Chang M, Jin W, Chang JH, Xiao Y, Brittain GC, Yu J, Zhou X, Wang YH, Cheng X, Li P, Rabinovich BA, Hwu P, Sun SC. The ubiquitin ligase peli1 negatively regulates $t$ cell activation and prevents autoimmunity. Nature immunology. 2011;12:1002-1009

60. Moynagh PN. Peli1 (rel)ieves autoimmunity. Nature immunology. $2011 ; 12: 927-929$

61. Marquez RT, Wendlandt E, Galle CS, Keck K, McCaffrey AP. Microrna-21 is upregulated during the proliferative phase of liver regeneration, targets pellino-1, and inhibits nf-kappab signaling. American journal of physiology. Gastrointestinal and liver physiology. 2010;298:G535-541

62. Smith H, Liu XY, Dai L, Goh ET, Chan AT, Xi J, Seh CC, Qureshi IA, Lescar J, Ruedl C, Gourlay R, Morton S, Hough J, Mclver EG, Cohen P, Cheung PC. The role of tbk1 and ikkepsilon in the expression and activation of pellino 1. Biochem J. 2011;434:537-548

63. Goh ET, Arthur JS, Cheung PC, Akira S, Toth R, Cohen P. Identification of the protein kinases that activate the e 3 ubiquitin ligase pellino 1 in the innate immune system. Biochem J. 2012;441:339-346 
64. Hacohen N, Kramer S, Sutherland D, Hiromi Y, Krasnow MA. Sprouty encodes a novel antagonist of fgf signaling that patterns apical branching of the drosophila airways. Cell. 1998;92:253-263

65. Kim HJ, Bar-Sagi D. Modulation of signalling by sprouty: A developing story. Nature reviews. Molecular cell biology. 2004;5:441-450

66. Ozaki K, Kadomoto R, Asato K, Tanimura S, Itoh N, Kohno M. Erk pathway positively regulates the expression of sprouty genes. Biochemical and biophysical research communications. 2001;285:1084-1088

67. Impagnatiello MA, Weitzer S, Gannon G, Compagni A, Cotten M, Christofori G. Mammalian sprouty-1 and -2 are membrane-anchored phosphoprotein inhibitors of growth factor signaling in endothelial cells. The Journal of cell biology. 2001;152:1087-1098

68. Gross I, Bassit B, Benezra M, Licht JD. Mammalian sprouty proteins inhibit cell growth and differentiation by preventing ras activation. The Journal of biological chemistry. 2001;276:46460-46468

69. Sasaki A, Taketomi T, Kato R, Saeki K, Nonami A, Sasaki M, Kuriyama M, Saito N, Shibuya M, Yoshimura A. Mammalian sprouty4 suppresses rasindependent erk activation by binding to raf1. Nature cell biology. $2003 ; 5: 427-432$

70. Yusoff P, Lao DH, Ong SH, Wong ES, Lim J, Lo TL, Leong HF, Fong CW, Guy GR. Sprouty2 inhibits the ras/map kinase pathway by inhibiting the activation of raf. The Journal of biological chemistry. 2002;277:3195-3201 
71. Cabrita MA, Christofori G. Sprouty proteins, masterminds of receptor tyrosine kinase signaling. Angiogenesis. 2008;11:53-62

72. Edwin F, Anderson K, Ying C, Patel TB. Intermolecular interactions of sprouty proteins and their implications in development and disease. Molecular pharmacology. 2009;76:679-691

73. Bronnum H, Andersen DC, Schneider M, Sandberg MB, Eskildsen T, Nielsen SB, Kalluri R, Sheikh SP. Mir-21 promotes fibrogenic epithelial-tomesenchymal transition of epicardial mesothelial cells involving programmed cell death 4 and sprouty-1. PloS one. 2013;8:e56280

74. Barnes PJ. Nuclear factor-kappa b. The international journal of biochemistry \& cell biology. 1997;29:867-870

75. Karin M, Ben-Neriah Y. Phosphorylation meets ubiquitination: The control of nf-[kappa]b activity. Annual review of immunology. 2000;18:621-663

76. Perkins ND. Integrating cell-signalling pathways with nf-kappab and ikk function. Nature reviews. Molecular cell biology. 2007;8:49-62

77. Guha M, Mackman N. Lps induction of gene expression in human monocytes. Cellular signalling. 2001;13:85-94

78. Guha M, O'Connell MA, Pawlinski R, Hollis A, McGovern P, Yan SF, Stern D, Mackman N. Lipopolysaccharide activation of the mek-erk1/2 pathway in human monocytic cells mediates tissue factor and tumor necrosis factor alpha expression by inducing elk-1 phosphorylation and egr-1 expression. Blood. 2001;98:1429-1439 
79. Moore KW, de Waal Malefyt R, Coffman RL, O'Garra A. Interleukin-10 and the interleukin-10 receptor. Annual review of immunology. 2001;19:683765

80. Blick M, Sherwin SA, Rosenblum M, Gutterman J. Phase i study of recombinant tumor necrosis factor in cancer patients. Cancer research. $1987 ; 47: 2986-2989$

81. Natanson C, Eichenholz PW, Danner RL, Eichacker PQ, Hoffman WD, Kuo GC, Banks SM, MacVittie TJ, Parrillo JE. Endotoxin and tumor necrosis factor challenges in dogs simulate the cardiovascular profile of human septic shock. The Journal of experimental medicine. 1989;169:823-832

82. Kreil EA, Greene E, Fitzgibbon C, Robinson DR, Zapol WM. Effects of recombinant human tumor necrosis factor alpha, lymphotoxin, and escherichia coli lipopolysaccharide on hemodynamics, lung microvascular permeability, and eicosanoid synthesis in anesthetized sheep. Circulation research. 1989;65:502-514

83. Badiu DC, Paunescu V, Aungurenci A, Pasarica D. Proinflammatory cytokines in peritonitis. Journal of medicine and life. 2011;4:158-162

84. Remick DG, Bolgos GR, Siddiqui J, Shin J, Nemzek JA. Six at six: Interleukin- 6 measured $6 \mathrm{~h}$ after the initiation of sepsis predicts mortality over 3 days. Shock. 2002;17:463-467 
85. Remick DG, Bolgos G, Copeland S, Siddiqui J. Role of interleukin-6 in mortality from and physiologic response to sepsis. Infection and immunity. 2005;73:2751-2757

86. Ebong S, Call D, Nemzek J, Bolgos G, Newcomb D, Remick D. Immunopathologic alterations in murine models of sepsis of increasing severity. Infection and immunity. 1999;67:6603-6610

87. Howard M, Muchamuel T, Andrade S, Menon S. Interleukin 10 protects mice from lethal endotoxemia. The Journal of experimental medicine. $1993 ; 177: 1205-1208$

88. Saraiva M, O'Garra A. The regulation of il-10 production by immune cells. Nature reviews. Immunology. 2010;10:170-181

89. Loh PG, Yang HS, Walsh MA, Wang Q, Wang X, Cheng Z, Liu D, Song H. Structural basis for translational inhibition by the tumour suppressor pdcd4. The EMBO journal. 2009;28:274-285

90. Wichterman KA, Baue AE, Chaudry IH. Sepsis and septic shock--a review of laboratory models and a proposal. The Journal of surgical research. $1980 ; 29: 189-201$

91. Baker CC, Chaudry IH, Gaines HO, Baue AE. Evaluation of factors affecting mortality rate after sepsis in a murine cecal ligation and puncture model. Surgery. 1983;94:331-335

92. Ma X, Kumar M, Choudhury SN, Becker Buscaglia LE, Barker JR, Kanakamedala K, Liu MF, Li Y. Loss of the mir-21 allele elevates the expression of its target genes and reduces tumorigenesis. Proceedings of 
the National Academy of Sciences of the United States of America. 2011;108:10144-10149

93. Blasi E, Mathieson BJ, Varesio L, Cleveland JL, Borchert PA, Rapp UR. Selective immortalization of murine macrophages from fresh bone marrow by a raf/myc recombinant murine retrovirus. Nature. 1985;318:667-670

94. Mukhopadhyay A, Suttles J, Stout RD, Aggarwal BB. Genetic deletion of the tumor necrosis factor receptor p60 or p80 abrogates ligand-mediated activation of nuclear factor-kappa $b$ and of mitogen-activated protein kinases in macrophages. The Journal of biological chemistry. 2001;276:31906-31912

95. Livak KJ, Schmittgen TD. Analysis of relative gene expression data using real-time quantitative $\mathrm{pcr}$ and the 2(-delta delta $\mathrm{c}(\mathrm{t}))$ method. Methods. $2001 ; 25: 402-408$

96. Tay Y, Rinn J, Pandolfi PP. The multilayered complexity of cerna crosstalk and competition. Nature. 2014;505:344-352

97. Ebert PJ, Jiang S, Xie J, Li QJ, Davis MM. An endogenous positively selecting peptide enhances mature t cell responses and becomes an autoantigen in the absence of microrna mir-181a. Nature immunology. 2009;10:1162-1169

98. Salmena L, Poliseno L, Tay Y, Kats L, Pandolfi PP. A cerna hypothesis: The rosetta stone of a hidden rna language? Cell. 2011;146:353-358 
99. Sen R, Ghosal S, Das S, Balti S, Chakrabarti J. Competing endogenous rna: The key to posttranscriptional regulation. TheScientificWorldJournal. 2014;2014:896206

100. Ghosal S, Das S, Sen R, Basak P, Chakrabarti J. Circ2traits: A comprehensive database for circular rna potentially associated with disease and traits. Frontiers in genetics. 2013;4:283

101. Tay Y, Kats L, Salmena L, Weiss D, Tan SM, Ala U, Karreth F, Poliseno L, Provero P, Di Cunto F, Lieberman J, Rigoutsos I, Pandolfi PP. Codingindependent regulation of the tumor suppressor pten by competing endogenous mrnas. Cell. 2011;147:344-357

102. Sharma B, Joshi S, Sassano A, Majchrzak B, Kaur S, Aggarwal P, Nabet B, Bulic M, Stein BL, McMahon B, Baker DP, Fukunaga R, Altman JK, Licht JD, Fish EN, Platanias LC. Sprouty proteins are negative regulators of interferon (ifn) signaling and ifn-inducible biological responses. The Journal of biological chemistry. 2012;287:42352-42360

103. Sasaki A, Taketomi T, Wakioka T, Kato R, Yoshimura A. Identification of a dominant negative mutant of sprouty that potentiates fibroblast growth factor- but not epidermal growth factor-induced erk activation. The Journal of biological chemistry. 2001;276:36804-36808

104. Porta C, Rimoldi M, Raes G, Brys L, Ghezzi P, Di Liberto D, Dieli F, Ghisletti S, Natoli G, De Baetselier P, Mantovani A, Sica A. Tolerance and m2 (alternative) macrophage polarization are related processes orchestrated by p50 nuclear factor kappab. Proceedings of the National 
Academy of Sciences of the United States of America. 2009;106:1497814983

105. Selvarajan K, Moldovan L, Chandrakala AN, Litvinov D, Parthasarathy S. Peritoneal macrophages are distinct from monocytes and adherent macrophages. Atherosclerosis. 2011;219:475-483

106. Geissmann F, Jung S, Littman DR. Blood monocytes consist of two principal subsets with distinct migratory properties. Immunity. 2003;19:7182

107. Ghosn EE, Cassado AA, Govoni GR, Fukuhara T, Yang Y, Monack DM, Bortoluci KR, Almeida SR, Herzenberg LA, Herzenberg LA. Two physically, functionally, and developmentally distinct peritoneal macrophage subsets. Proceedings of the National Academy of Sciences of the United States of America. 2010;107:2568-2573

108. Cannon B, Nedergaard J. Nonshivering thermogenesis and its adequate measurement in metabolic studies. The Journal of experimental biology. $2011 ; 214: 242-253$

109. Karp CL. Unstressing intemperate models: How cold stress undermines mouse modeling. The Journal of experimental medicine. 2012;209:10691074

110. Barnett R, Keskey RC, Rao JM, Billeter AT, Kanaan Z, Cheadle WG. Poor outcome in bacterial peritonitis is associated with dysregulated micrornas and an increased inflammatory response. Surgery. 2013 
111. Drosatos K, Khan RS, Trent CM, Jiang H, Son NH, Blaner WS, Homma S, Schulze PC, Goldberg IJ. Peroxisome proliferator-activated receptorgamma activation prevents sepsis-related cardiac dysfunction and mortality in mice. Circulation. Heart failure. 2013;6:550-562

112. Hotchkiss RS, Karl IE. The pathophysiology and treatment of sepsis. The New England journal of medicine. 2003;348:138-150

113. Hotchkiss RS, Monneret G, Payen D. Immunosuppression in sepsis: A novel understanding of the disorder and a new therapeutic approach. The Lancet infectious diseases. 2013;13:260-268

114. Yin H, Stojanovic-Terpo A, Xu W, Corken A, Zakharov A, Qian F, Pavlovic S, Krbanjevic A, Lyubimov AV, Wang ZJ, Ware J, Du X. Role for platelet glycoprotein ib-ix and effects of its inhibition in endotoxemia-induced thrombosis, thrombocytopenia, and mortality. Arteriosclerosis, thrombosis, and vascular biology. 2013;33:2529-2537

115. van der Poll T, Buller HR, ten Cate $\mathrm{H}$, Wortel $\mathrm{CH}$, Bauer KA, van Deventer SJ, Hack CE, Sauerwein HP, Rosenberg RD, ten Cate JW. Activation of coagulation after administration of tumor necrosis factor to normal subjects. The New England journal of medicine. 1990;322:1622-1627

116. Walsh CJ, Sugerman HJ, Mullen PG, Carey PD, Leeper-Woodford SK, Jesmok GJ, Ellis EF, Fowler AA. Monoclonal antibody to tumor necrosis factor alpha attenuates cardiopulmonary dysfunction in porcine gramnegative sepsis. Archives of surgery. 1992;127:138-144; discussion 144135 
117. Michie HR, Spriggs DR, Manogue KR, Sherman ML, Revhaug A, O'Dwyer ST, Arthur K, Dinarello CA, Cerami A, Wolff SM, et al. Tumor necrosis factor and endotoxin induce similar metabolic responses in human beings. Surgery. 1988;104:280-286

118. Cannon JG, Tompkins RG, Gelfand JA, Michie HR, Stanford GG, van der Meer JW, Endres S, Lonnemann G, Corsetti J, Chernow B, et al. Circulating interleukin-1 and tumor necrosis factor in septic shock and experimental endotoxin fever. The Journal of infectious diseases. $1990 ; 161: 79-84$

119. Bagby GJ, Plessala KJ, Wilson LA, Thompson JJ, Nelson S. Divergent efficacy of antibody to tumor necrosis factor-alpha in intravascular and peritonitis models of sepsis. The Journal of infectious diseases. $1991 ; 163: 83-88$

120. Eskandari MK, Bolgos G, Miller C, Nguyen DT, DeForge LE, Remick DG. Anti-tumor necrosis factor antibody therapy fails to prevent lethality after cecal ligation and puncture or endotoxemia. J Immunol. 1992;148:27242730

121. Fisher CJ, Agosti JM, Opal SM, Lowry SF, Balk RA, Sadoff JC, Abraham E, Schein RMH, Benjamin E. Treatment of septic shock with the tumor necrosis factor receptor:Fc fusion protein. New Engl J Med. $1996 ; 334: 1697-1702$

122. Riedemann NC, Guo RF, Ward PA. Novel strategies for the treatment of sepsis. Nature medicine. 2003;9:517-524 
123. Godshall CJ, Scott MJ, Peyton JC, Gardner SA, Cheadle WG. Genetic background determines susceptibility during murine septic peritonitis. The Journal of surgical research. 2002;102:45-49

124. Jesmok G, Lindsey C, Duerr M, Fournel M, Emerson T, Jr. Efficacy of monoclonal antibody against human recombinant tumor necrosis factor in e. Coli-challenged swine. The American journal of pathology. $1992 ; 141: 1197-1207$

125. Fiedler VB, Loof I, Sander E, Voehringer V, Galanos C, Fournel MA. Monoclonal antibody to tumor necrosis factor--alpha prevents lethal endotoxin sepsis in adult rhesus monkeys. The Journal of laboratory and clinical medicine. 1992;120:574-588

126. Tracey KJ, Fong Y, Hesse DG, Manogue KR, Lee AT, Kuo GC, Lowry SF, Cerami A. Anti-cachectin/tnf monoclonal antibodies prevent septic shock during lethal bacteraemia. Nature. 1987;330:662-664

127. Cross AS, Sadoff JC, Kelly N, Bernton E, Gemski P. Pretreatment with recombinant murine tumor necrosis factor alpha/cachectin and murine interleukin 1 alpha protects mice from lethal bacterial infection. The Journal of experimental medicine. 1989;169:2021-2027

128. Evans GF, Snyder YM, Butler LD, Zuckerman SH. Differential expression of interleukin-1 and tumor necrosis factor in murine septic shock models. Circulatory shock. 1989;29:279-290

129. Fisher CJ, Jr., Agosti JM, Opal SM, Lowry SF, Balk RA, Sadoff JC, Abraham E, Schein RM, Benjamin E. Treatment of septic shock with the 
tumor necrosis factor receptor:Fc fusion protein. The soluble tnf receptor sepsis study group. The New England journal of medicine.

$1996 ; 334: 1697-1702$

130. Abraham E, Wunderink R, Silverman H, Perl TM, Nasraway S, Levy H, Bone R, Wenzel RP, Balk R, Allred R, et al. Efficacy and safety of monoclonal antibody to human tumor necrosis factor alpha in patients with sepsis syndrome. A randomized, controlled, double-blind, multicenter clinical trial. Tnf-alpha mab sepsis study group. JAMA : the journal of the American Medical Association. 1995;273:934-941

131. Williams DL, Ha T, Li C, Kalbfleisch JH, Schweitzer J, Vogt W, Browder IW. Modulation of tissue toll-like receptor 2 and 4 during the early phases of polymicrobial sepsis correlates with mortality. Critical care medicine. $2003 ; 31: 1808-1818$

132. Qureshi ST, Lariviere L, Leveque G, Clermont S, Moore KJ, Gros P, Malo D. Endotoxin-tolerant mice have mutations in toll-like receptor 4 (tlr4). The Journal of experimental medicine. 1999;189:615-625

133. Fort MM, Mozaffarian A, Stover AG, Correia Jda S, Johnson DA, Crane RT, Ulevitch RJ, Persing DH, Bielefeldt-Ohmann H, Probst P, Jeffery E, Fling SP, Hershberg RM. A synthetic tlr4 antagonist has anti-inflammatory effects in two murine models of inflammatory bowel disease. $J$ Immunol. 2005;174:6416-6423

134. Nakamura M, Shimizu Y, Sato Y, Miyazaki Y, Satoh T, Mizuno M, Kato Y, Hosaka Y, Furusako S. Toll-like receptor 4 signal transduction inhibitor, 
m62812, suppresses endothelial cell and leukocyte activation and prevents lethal septic shock in mice. European journal of pharmacology. 2007;569:237-243

135. Jung K, Lee JE, Kim HZ, Kim HM, Park BS, Hwang SI, Lee JO, Kim SC, Koh GY. Toll-like receptor 4 decoy, toy, attenuates gram-negative bacterial sepsis. PloS one. 2009;4:e7403

136. Opal SM, Laterre PF, Francois B, LaRosa SP, Angus DC, Mira JP, Wittebole X, Dugernier T, Perrotin D, Tidswell M, Jauregui L, Krell K, Pachl J, Takahashi T, Peckelsen C, Cordasco E, Chang CS, Oeyen S, Aikawa N, Maruyama T, Schein R, Kalil AC, Van Nuffelen M, Lynn M, Rossignol DP, Gogate J, Roberts MB, Wheeler JL, Vincent JL, Group AS. Effect of eritoran, an antagonist of md2-tlr4, on mortality in patients with severe sepsis: The access randomized trial. JAMA : the journal of the American Medical Association. 2013;309:1154-1162

137. Deng M, Scott MJ, Loughran P, Gibson G, Sodhi C, Watkins S, Hackam D, Billiar TR. Lipopolysaccharide clearance, bacterial clearance, and systemic inflammatory responses are regulated by cell type-specific functions of tIr4 during sepsis. J Immunol. 2013;190:5152-5160

138. Gao M, Ha T, Zhang X, Liu L, Wang X, Kelley J, Singh K, Kao R, Gao X, Williams D, Li C. Toll-like receptor 3 plays a central role in cardiac dysfunction during polymicrobial sepsis. Critical care medicine. 2012;40:2390-2399 
139. Hadjiminas DJ, McMasters KM, Robertson SE, Cheadle WG. Enhanced survival from cecal ligation and puncture with pentoxifylline is associated with altered neutrophil trafficking and reduced interleukin-1 beta expression but not inhibition of tumor necrosis factor synthesis. Surgery. 1994;116:348-355

140. Castoldi A, Braga TT, Correa-Costa M, Aguiar CF, Bassi EJ, Correa-Silva R, Elias RM, Salvador F, Moraes-Vieira PM, Cenedeze MA, Reis MA, Hiyane MI, Pacheco-Silva A, Goncalves GM, Saraiva Camara NO. TIr2, tlr4 and the myd88 signaling pathway are crucial for neutrophil migration in acute kidney injury induced by sepsis. PloS one. 2012;7:e37584

141. Patel KN, Soubra SH, Lam FW, Rodriguez MA, Rumbaut RE. Polymicrobial sepsis and endotoxemia promote microvascular thrombosis via distinct mechanisms. Journal of thrombosis and haemostasis : JTH. 2010;8:1403-1409

142. Liu J, Sun H, Wang X, Yu Q, Li S, Yu X, Gong W. Increased exosomal microrna-21 and microrna-146a levels in the cervicovaginal lavage specimens of patients with cervical cancer. Int J Mol Sci. 2014;15:758-773

143. Tanaka $\mathrm{Y}$, Kamohara H, Kinoshita K, Kurashige J, Ishimoto T, Iwatsuki M, Watanabe M, Baba H. Clinical impact of serum exosomal microrna-21 as a clinical biomarker in human esophageal squamous cell carcinoma. Cancer. 2013;119:1159-1167

144. Stein M, Keshav S, Harris N, Gordon S. Interleukin 4 potently enhances murine macrophage mannose receptor activity: A marker of alternative 
immunologic macrophage activation. The Journal of experimental medicine. 1992;176:287-292

145. Liu YC, Zou XB, Chai YF, Yao YM. Macrophage polarization in inflammatory diseases. International journal of biological sciences. $2014 ; 10: 520-529$

146. Sica A, Mantovani A. Macrophage plasticity and polarization: In vivo veritas. The Journal of clinical investigation. 2012;122:787-795

147. Osuchowski MF, Welch K, Yang H, Siddiqui J, Remick DG. Chronic sepsis mortality characterized by an individualized inflammatory response. $J$ Immunol. 2007;179:623-630

148. Xiao H, Siddiqui J, Remick DG. Mechanisms of mortality in early and late sepsis. Infection and immunity. 2006;74:5227-5235

149. Brudecki L, Ferguson DA, Yin D, Lesage GD, McCall CE, El Gazzar M. Hematopoietic stem-progenitor cells restore immunoreactivity and improve survival in late sepsis. Infection and immunity. 2012;80:602-611

150. Komatsu S, Ichikawa D, Takeshita H, Tsujiura M, Morimura R, Nagata H, Kosuga T, litaka D, Konishi H, Shiozaki A, Fujiwara H, Okamoto K, Otsuji E. Circulating micrornas in plasma of patients with oesophageal squamous cell carcinoma. British journal of cancer. 2011;105:104-111 


\title{
APPENDIX: ABBREVIATIONS
}

\author{
General Abbreviations \\ APACHE Acute Physiology and Chronic Health Evaluation \\ CLP Cecal Ligation and Puncture; peritonitis model \\ DIC Disseminated Intravascular Coagulation \\ ELISA Enzyme Linked Immunosorbent Assay \\ PEC Peritoneal Exudate Cells
}

\author{
Cell Biology \\ CREB CAMP-responsive Element-Binding Protein \\ ceRNA Competing Endogenous RNA \\ cDNA Complementary DNA \\ mRNA Messenger RNA; longer, single stranded RNA; template for protein \\ translation \\ miRNA MicroRNA; short single stranded RNA \\ Peli1 Pelino1; target of miRNA-21
}


PDCD4 Programmed Cell Death Protein 4; target of miRNA-21

RAW264.7 Mouse macrophage cell line

RISC RNA-Induced Silencing Complex

siRNA Silencing RNA; prevents translation of target mRNA into protein

SPRY Sprouty; target of miRNA-21

\section{Immunology}

CD206 Cluster of Differentiation 206; marker of M2 macrophages

DAMP Damage Associated Molecular Protein

IL-6 Interleukin-6; pro-inflammatory cytokine

IL-10 Interleukin-10; anti-inflammatory cytokine

LPS Lipopolysaccharide; part of the outer membrane of gram-negative bacteria; a DAMP

PAMP Pathogen Associated Molecular Protein; bacterial or viral peptide recognized by the immune system

PRR Pattern Recognition Receptor; receptors that recognize DAMPs and PAMPs

TLR Toll-Like Receptor; a PRR 
TNF- $\alpha \quad$ Tumor Necrosis Factor- $\alpha$; pro-inflammatory cytokine

Pathway

ELK1 part of the MAPK pathway

ERK Extracellular Signal Related Kinase; part of the MAPK pathway and important for IL-10 production

IKK Inhibitory Kappa Kinase; activator of NF-KB IKB

IKB Inhibitory kappa protein Beta

IRAK IL-1 Receptor Associated Kinase; central signaling protein of the TLR-4 pathway

JNK c-Jun N-terminal Kinase

MAPK Mitogen Activated Protein Kinases pathway; part of the TLR-4 signaling pathway

MyD88 Myeloid Differentiation Primary Response Gene 88; central signaling protein of TLR-4

NF-kB Nuclear Factor Kappa Beta; transcription factor of TLR-4 signaling

RIP1 TRIF-signaling adaptor kinase; interacts with Peli1

TRAF6 TNF-Receptor Associated Factor; central signaling protein of TLR-4 pathway 
TRAM TRIF-related Adapter Molecule

TRIF TIR-domain-containing adaptor-inducing interferon $\beta$ 


\section{CURRICULUM VITAE}

Personal details:

Rebecca Elise Barnett

D.O.B: $02 / 05 / 1982$

1639 Jaeger Avenue

email: rebarn02@louisville.edu

Louisville

Kentucky 40205

US mobile: +1502 7779661

USA

\section{Education:}

University of Louisville

$2012-2014$

Bournemouth University

2007-2008

Imperial College School of Medicine

$2000-2006$

Qualifications:

Membership of Royal College of Surgeons

PG Cert in Professional Practice: Medicine

Merit

2008

MBBS

Merit in Pharmacology 2006

BSc in Medical sciences with Haematology

$2: 1$

2004 


\section{Current Post:}

Research Fellow at University of Louisville and Robley Rex Veterans Affairs Hospital, Louisville, Kentucky, USA to Dr. William G. Cheadle. Additional Mentors: Dr. Susan Galandiuk and Dr. Hiram C. Polk Jr.

\section{Previous Appointments:}

Aug 2011 - Sept 2011 General and Colorectal Surgery Trust Grade SHO Mr Nick Markham; Mrs Katie Cross; Mr Mark Cartmell; Mr Anjum Arain North Devon District Hospital

Feb 2011 - Aug 2011 Orthopaedics CT2

Mr Colin Steinlechner North Devon District Hospital

Aug 2010 - Feb $2011 \quad$ General and Colorectal Surgery CT2

Mr Nick Markham; Mrs Katie Cross; Mr Mark Cartmell; Mr Anjum Arain North Devon District Hospital

Feb 2010 - Aug $2010 \quad$ General and Vascular Surgery CT1

Mr Afzaal Ahmad; Mr John Taylor North Devon District Hospital Aug 2009 - Feb $2010 \quad$ Emergency Medicine CT1

Mr Mike Roberts North Devon District Hospital

Dec 2009 - Jun $2010 \quad$ Medical Registrar

Dr Paul Laird; Dr John Burrell Lismore Base Hospital, Australia 
Oct $2009-$ Dec 2009

Emergency Medicine RMO

Dr Chris Gavaghan;

Lismore Base Hospital

Sept 2009 - Oct 2009 Medicine and Haematology Oncology Resident Medical Officer (RMO)

Dr David Jackson; Dr Adam Boyce Lismore Base Hospital

Apr 2009 - Aug $2008 \quad$ Haematology F2

Dr Andrew Bell; Dr Jason Mainwaring; Dr Fergus Jack

Poole General Hospital

Dec 2007 - April 2008 Dermatology and Rheumatology F2

Dr Selwyn Richards;

Poole General Hospital

Aug 2007 - Dec 2007

Mr James Pain;

Apr 2007 - Aug 2007

Dr Mike Masding;

Jan 2007 - Apr 2007

Dr Nick Sharer;

Dec 2006 - Jan 2007

Dr Mike Masding;

Aug 2006 - Dec 2006

Mr Shorland Hosking;
General and Breast Surgery F2

Poole General Hospital

Medicine and Endocrinology F1

Poole General Hospital
Medicine and Gastroenterology F1

Poole General Hospital

Medical Assessment Unit F1

Poole General Hospital

General and Upper GI Surgery F1

Poole General Hospital 


\section{Publications:}

1. Foundation Programme Assessments. Barnett RE, Hall SM, Masding MG. Clinical Tutor, 2008;13 (1)

2. MicroRNAs as a New Factor in Lung and Esophageal Cancer. Billeter AT, Barnett RE, Druen DW, Van Berkel VH, Polk Jr HC. Seminars in Thoracic Surgery. 2012 Autumn; 24(3):155-65.

3. Differential MicroRNA Expression Could Explain Microbial Tolerance in a Novel Chronic Peritonitis Model. Kanaan Z, Barnett R, Gardner S, Keskey B, Druen DW, Billeter AT, Cheadle WG. Innate Immunity. Innate Immunity. 2013;19(2);203-12.

4. A Natural Immunomodulator Attenuates the Systemic Inflammatory Response in Polymicrobial Peritonitis. Love K, Barnett RE, Holbrook I, Peyton J, Sonnenfeld G, Cheadle WG. Journal of Trauma and Acute Care Surgery. 2013 Jun; 74 (6):1411-18.

5. Accuracy of Computerized Tomography in Small Bowel Obstruction. Barnett RE, Younga J, Harris B, Keskey RC, Nisbett D, Perry J, Cheadle WG. American Surgeon. 2013 Jun; 79 (6):641-3.

6. Poor Outcome in Bacterial Peritonitis is Associated with Dysregulated MicroRNAs and an Increased Inflammatory Response. Barnett RE, Keskey RC, Rao JM, Billeter AT, Kanaan Z, Cheadle WG. Surgery. 2013 Sep; 154(3):521-7. 
7. Tension Free Open Mesh Cooper's Ligament Repair for Femoral Hernia. Barnett RE, Keskey RC, Byam J, Linsky PL, Mathis T, Cheadle WG. American Surgeon - Brief Report. 2013 Sep;79(9):952-3.

8. "Never Say Never Again" SIS Presidential Address 2013 Cheadle WG, Barnett RE.

Surgical Infection, 2014 Apr 30 Epub ahead of print

9. Small Bowel Trauma: Current Thinking in Diagnosis and Management Barnett RE, Love K, Sepulveda EA, Cheadle WG American Surgeon - Invited Review, In Press

10. Cecal Diverticulitis Mimicking Cecal Carcinoma Barnett RE, Rao JM, Ryan LE, Cheadle WG. American Surgeon - Brief Report EPub

11. Damage Control for Thoracic Trauma Mackowski MJ, Barnett RE, Harbrecht BG, Miller KR, Franklin GA, Smith JW, Richardson JD, Benns MV. American Surgeon. In Press 


\section{Book Chapters:}

1. Surgical Immunology Chapter. Cheadle WG, Billeter AT, Kanaan Z, Barnett RE.

Surgical Infection. Editor: Dr. Donald Fry. 2013.

2. Surgical Infection. Barnett RE \& Cheadle WG - Associate Editors. Selected Reading in General Surgery. Editor: Dr. Lewis Flint. 2013 Aug; $39(4)$

Presentations:

\section{International}

1. Expression of MiR-21 is advantageous in the Immune Response to Peritonitis

Barnett RE, Sepulveda E, Cheadle WG.

Plenary Session. Surgical Infection Society, Baltimore, MD May 2014

2. Secondary Bacterial Peritonitis in a Veteran Population - Poster

Barnett RE, Tabler BL, Rao JM, Cheadle WG.

May 2013

Surgical Infection Society - Europe, Prague, Czech Republic

3. Cecal Diverticulitis Mimics Cecal Cancer - Poster

Barnett RE, Rao JM, Mathis T, Cheadle WG.

May 2013

Surgical Infection Society - Europe, Prague, Czech Republic 
4. Large Bowel Pathology presenting as Small Bowel Obstruction is associated with a Poor Prognosis

Barnett RE, Younga JR, Cheadle WG.

VA Surgeons, Milwaukee, WI

Apr 2013

5. MicroRNA Expression in the Innate Immune Response to Peritonitis -

Poster

Barnett RE, Keskey RC, Ryan LE, Rao JM, Cheadle WG

Surgical Infection Society, Las Vegas, NV

Apr 2013

6. Computerized Tomography in Small Bowel Obstruction

Barnett RE, Younga J, Harris B, Keskey RC, Nisbett D, Perry J, Cheadle WG.

South Eastern Surgical Congress, FL

Feb 2013

7. Poor Outcome in Bacterial Peritonitis is Associated with Dysregulated MicroRNAs Resulting and an Increased Inflammatory Response Barnett RE, Keskey RC, Billeter AT, Cheadle WG.

Feb 2013

Academic Surgical Congress (Combined meeting of Society of University Surgeons and Association for Academic Surgery), New Orleans, LA

8. Dysregulation of miR-132 and -21 reduces $\mathrm{IL}-1 \beta$ levels in a novel model of chronic peritonitis.

Association of Veterans Affairs Surgeons, Miami Beach, FL Apr 2012 
9. Tension Free Open Mesh Cooper's Ligament Repair for Femoral Hernia Poster Keskey RC, Barnett RE, Byam J, Linsky P, Cheadle WG.

South Eastern Surgical Congress, AL

Feb 2012

\section{Regional}

10. Targets of MicroRNA-21 in Peritoneal Macrophages After LPS Stimulation - Poster Keskey RC, Rao JM, McKinley I, Lawson C, Barnett RE, Cheadle WG. Research Louisville! Sept 2013

11. MicroRNA Expression in Murine Cecal Ligation and Puncture Model Poster Ryan LE, Barnett RE, Keskey RC, Cheadle WG

Research Louisville!

12. MicroRNA Expression in the Innate Immune Response to Peritonitis -

Poster

Rao JM, Barnett RE, Keskey RC, Cheadle WG

Research Louisville!

Sept 2012 
13. Poole experience of NEW START Sentinel Lymph Node Biopsy programme.

Barnett RE, Evans A.

Wessex Breast Meeting.

Oct 2007

\section{Local}

14. The Role of MicroRNA-21 in the Regulation of the Early Innate Immune Response to Peritonitis

Nov 2013

Department of Molecular Cardiology Seminar, University of Louisville

15. The Role of MicroRNA-21 in the Regulation of the Early Innate Immune Response to Peritonitis

Price Seminar at Price Institute of Surgical Research, University of Louisville

Jun 2013

16. MicroRNAs in the Innate Immune Response to Peritonitis Department of Physiology Seminar, University of Louisville

Jan 2013

17. The National Health System: A British Institution Feb 2012 Price Seminar at Price Institute of Surgical Research, University of Louisville

18. Supracondylar fractures of the humerus in children audit

Jul 2011 Orthopaedic Teaching at North Devon District Hospital 
Surgical and Anaesthetic Clinical Goverance Meeting, North Devon

District Hospital

20. Pelvic Fractures

Jul 2011

Surgical and Anaesthetic Clinical Goverance Meeting, North Devon District Hospital

21. Bilateral Inguinal Hernia: Laparoscopic or open approach Dec 2010 Journal club, South West registrar training day, North Devon District Hospital.

22. To die with dignity.

Nov 2010

Surgical teaching session at North Devon District Hospital.

23. Massive blood transfusion protocol audit.

Apr 2010 Surgical and Anaesthetic Clinical Governance Meeting, North Devon District Hospital.

24. Fibrinolysis in Acute Myocardial Infarction. Jan 2009 Emergency Department Registrar teaching, Lismore Base Hospital 


\section{$\underline{\text { Research }}$}

MicroRNA-21has Anti-Inflammatory Effects in the Macrophage Response to Peritonitis

$\mathrm{PhD}$ Thesis

Aug 2012 - Aug 2014

Using mouse models of peritonitis we have been investigating the effects of over and underexpression of microRNA-21 in the macrophage response.

\section{Small Bowel Obstruction}

Jan 2012 - Aug 2014

Using our database of patients admitted to University Hospital with small bowel obstruction we have looked at predictors of mortality and the accuracy of computerised tomography.

\section{MicroRNA Dysregulation and Outcome in Bacterial Peritonitis}

$$
\text { Feb-Aug } 2012
$$

Using a novel model of chronic peritonitis we looked at microRNA expression in the peritoneum in predicted survivors compared to predicted deaths.

\section{MicroRNA Expression in Microbial Tolerance Oct 2011 - Feb 2012}

Using a novel model of chronic peritonitis we looked at microRNA expression in the peritoneum of mice following the induction of microbial tolerance.

\section{Analysis of Centrosomal Proteins in Chronic Lymphocytic Leukaemia}

BSc project

March - May 2004 
Expression of TACC3 centrosomal protein in patients with chronic lymphocytic leukaemia compared to other white cell diseases.

\section{Skills in Molecular Biology}

Cell Culture

Magnetic Bead Isolation

RNA Isolation

Polymerase Chain Reaction for messenger and microRNA.

Protein quantification

Enzyme-linked Immunosorbent Assay (ELISA)

Western Blot

Immunofluorescence

Transfection of microRNA into peritoneal macrophages

Animal Handling and Injections

Caecal Ligation and Puncture

Harvest of Peritoneal Cells, Blood and Tissues (Lung, Liver, Cardiac)

Bacterial plating and quantification 


\section{Audits:}

Supracondylar Fractures of the Humerus in Children

Jul 2011

Role: Audit design, data analysis and write up.

Loop closed: No.

Standards: Guidelines from O'Hara et al J Bone Joint Surg [Br] 2000.

Performed: North Devon District Hospital, Barnstaple, Devon.

Results: Presented at Orthopaedic teaching.

\section{Massive Blood Transfusion Protocol}

Role: Audit design, data analysis and write up.

Loop closed: Yes.

Standards: Local Guidelines

Performed: North Devon District Hospital, Barnstaple, Devon.

Results: Presented at Anaesthetic \& Surgical and Medical Clinical Governance meetings.

Fibrinolysis in acute myocardial infarction

Dec 2008

Role: Audit design, data analysis and write up.

Loop closed: Yes, July 2009, following my departure.

Standards: Local Network Guidelines

Performed: Lismore Base Hospital, Lismore, New South Wales, Australia.

Results: Presented at Emergency Department and Registrar teaching. 
Role: Data collection, analysis and write up.

Loop closed: Yes, Dec 2008, following my departure.

Standards: Department of Health Guidelines

Performed: Poole General Hospital, Poole, Dorset.

Results: Presented at local clinical governance meeting.

\section{Clinical Experience:}

I am happy running general surgical on-calls including vascular surgery. I have experience looking after patients in outpatient clinics, and on the wards. I have experience preparing the patient for surgery, directing peri-operative care in theatre, and managing them on the ward, including recognising and treating common post-operative complications.

I am happy diagnosing and managing simple cutaneous abscesses, appendicitis, peritonitis, gallstone disease, including deciding for surgical intervention, and can perform incision and drainage of abscess and appendicectomies, laparoscopic and open with supervision. I can also perform laparoscopic cholecystectomies with direction.

I have experience running trauma calls in a level 2 trauma centre.

My 6 months spent working as medical registrar in Australia has given me experience running medical on-calls, and performing medical reviews on surgical 
and orthopaedic patients, recognising and managing medical problems in surgical patients.

Continuing Medical Education (CME):

Attendance at Grand Rounds and Price Institute of Surgical Research Seminars Jan 2012-present

Principles of Clinical and Translational Research

Aug 2012

Teach the Teachers

Jul 2011

CCrISP

Jun 2011

Introduction to Medical Education

Feb 2011

ATLS

Jun 2010

Basic Surgical Skills

Mar 2008

M27 Course (Coloproctology)

Nov 2007

Introduction to ENT

Sept 2007

Advanced Life Support

Nov 2006

ALERT

Jul 2006 


\section{Teaching:}

I have experience of teaching medical students and more junior doctors in a clinical environment, making use of available patients to teach about history taking, presentation and examination techniques. I have also taught medical and work experience students in a theatre environment, educating about the surgical experience and surgical technique.

I have planned formal teaching sessions for Foundation Doctors, using both lecture based, and more interactive methods.

I have used laparoscopic training devices with colleagues to show and encourage work experience students about careers in medicine and surgery as part of a wider curriculum.

I have aided colleagues and nursing staff with skills such as ECG and arterial blood gas interpretation, intravenous cannulation, catheterisation and suturing by demonstrating and then supervising the procedures.

As part of the BBC 999 Roadshows I have taught basic resuscitation skills to members of the general public.

I undertook modules on teaching and learning as part of my regional F2 study days at Bournemouth University. I have also undertaken courses on medical education and teaching specific to medicine in order to improve my teaching skills. This has given me specific tips and practice planning teaching session as well as dealing with different and difficult situations. 
I also enjoy educating patients about their diseases and prognosis in language that they can understand, taking time to answer their questions and drawing diagrams to aid comprehension.

In my 2 years as Research Fellow in the Price Institute of Surgical Research I have taught many undergraduate and medical students research techniques, analysis of data and how to construct and present research data.

Management:

Research Fellow

Oct 2011

As the research fellow within the Veterans Affairs Surgical Research Laboratory, I organise and plan experiments. I order needed reagents and animals, ensure the laboratory meets all federal and national safety requirements and train and supervise my undergraduate and medical student laboratory assistants.

I have collaborated with multiple principle investigators across research specialities and co-ordinated research plans for projects using knockout mice.

VTE Committee Member

Nov 2009

Junior Doctor Representative on North Devon District Hospital Venous Thromboembolism Committee, introducing new VTE risk assessment forms throughout the trust, and their integration into new drug charts. 
Involved in developing new surgical rota with change of staffing levels. Managed Surgical Junior rota and annual leave.

Organised ALS courses for all F1s at Poole.

Nov 2007

\section{Regatta Director for Bournemouth Lifeguard Corps}

Jul 2007

Organised the Bournemouth Lifeguards Regatta, a two day National Beach Lifeguarding Competition, with 13 teams of six people from around the country competing in a variety of events. The events use many lifeguard skills including incidents (in the sea and on land), first aid, reel \& line, rope throwing, knots, iron man, canoeing, torpedo relay and other unique events. The competition is organised in such a way that every member of the team is involved throughout the weekend and every member of the team should be proficient in the wide variety of skills. 


\section{Meetings}

Surgical Infection Society - North America, Baltimore, MD Apr 2014

Southeastern Surgical Congress, Savannah, GA $\quad$ Feb 2014

American College of Surgeons, Washington DC Oct 2013

Surgical Infection Society - Europe, Prague, Czech Republic May 2013

Association of Veterans Affairs Surgeons, Milwaukee, WI Apr 2013

Surgical Infection Society - North America, Las Vegas, NV Apr 2013

Southeastern Surgical Congress, Jacksonville, FL Feb 2013

Academic Surgical Congress, New Orleans, LA Feb 2013

Association of Veterans Affairs Surgeons, Miami Beach, FL Apr 2012

Southeastern Surgical Congress, Birmingham, AL $\quad$ Feb 2012

Going Overseas Network, Bristol Sept 2011

\section{Societies}

Surgical Infection Society - North America Jun 2013

Women In Surgery (WinS) Aug 2010

Association of Surgeons in Training (ASIT) Jan 2010 
$\underline{\mathrm{IT}}$ :

I am comfortable using Microsoft Office, and have a GSCE (short Course) in Information Technology. I am familiar with several variations on PACS and pathology results systems. I regularly use the internet to access electronic journals and online information. I have experience using Sigma plot to statistically analyse data and create graphs to aid comprehension.

\section{Extra-Curricular:}

I enjoy Salsa and Swing dancing, climbing both indoors and outdoor, especially Winspit, on the Isle of Purbeck, Dorset. I learnt to surf when living in Byron Bay, Australia, a pastime I was able to continue whilst living in North Devon. I also enjoy scuba diving, first dipping my feet off the coast of Kenya, and going on to become a qualified PADI open water in Thailand. I have since dived in the UK, South Africa, and Australia and achieved my advanced open water diver award in Grenada.

\section{Career Plan:}

I am working towards becoming a Consultant General Surgeon with an interest in both bench and clinical research in the field of peritonitis. I have an interest in upper gastrointestinal surgery, with laparoscopic surgery and hernias. My elective in Ghana has also given me the wish to work in Africa in the future, when I have an appropriate surgical skill base. 